Please do not remove this page

RMIT

UNIVERSITY

\title{
Size, shape and surface chemistry of nano-gold dictate its cellular interactions, uptake and toxicity
}

Carnovale, Catherine; Bryant, Gary; Shukla, Ravi; Bansal, Vipul

https://researchrepository.rmit.edu.au/esploro/outputs/9921860173401341/filesAndLinks?institution=61RMIT_INST\&index=null

Carnovale, C., Bryant, G., Shukla, R., \& Bansal, V. (2016). Size, shape and surface chemistry of nano-gold dictate its cellular interactions, uptake and toxicity. Progress in Materials Science, 83, 152-190.

https://doi.org/10.1016/j.pmatsci.2016.04.003

Document Version: Accepted Manuscript

Published Version: https://doi.org/10.1016/j.pmatsci.2016.04.003

Repository homepage: https://researchrepository.rmit.edu.au

(c) 2016 Elsevier Ltd. All rights reserved.

Downloaded On 2023/04/26 22:37:44 +1000

Please do not remove this page 
Thank you for downloading this document from the RMIT Research Repository.

The RMIT Research Repository is an open access database showcasing the research outputs of RMIT University researchers.

RMIT Research Repository: http://researchbank.rmit.edu.aul

\section{Citation:}

Carnovale, C, Bryant, G, Shukla, R and Bansal, V 2016, 'Size, shape and surface chemistry of nano-gold dictate its cellular interactions, uptake and toxicity', Progress in Materials Science, vol. 83, pp. 152-190.

See this record in the RMIT Research Repository at:

https://researchbank.rmit.edu.au/view/rmit:37176

Version: Accepted Manuscript

\section{Copyright Statement:}

(c) 2016 Elsevier Ltd. All rights reserved. (c) 2016 This manuscript version is made available under the CC-BY-NC-ND 4.0 license

http://creativecommons.org/licenses/by-nc-nd/4.0/

Link to Published Version:

http://dx.doi.org/10.1016/j.pmatsci.2016.04.003 
Please cite as:

Carnovale, C., Bryant, G., Shukla, R., Bansal, V.

"The effect of shape, size and chemical composition on gold nanoparticle uptake and toxicity," Progress in Materials Science 83, 152-190 (2016). 


\section{Size, shape and surface chemistry of nano-gold dictate its cellular interactions, uptake and toxicity}

\section{Catherine Carnovale, ${ }^{\mathrm{a}, \mathrm{b}, \mathrm{c}}$ Gary Bryant, ${ }^{\mathrm{c}}$ Ravi Shukla, ${ }^{\mathrm{a}, \mathrm{b}}$ Vipul Bansal $^{\mathrm{a}, \mathrm{b}, *}$}

a Ian Potter NanoBioSensing Facility, ${ }^{\mathrm{b}}$ NanoBiotechnology Research Laboratory, ${ }^{\circ}$ Centre for Molecular and Nanoscale Physics, School of Applied Science, RMIT University, GPO Box 2476, Melbourne VIC 3001, Australia.

*E-mail: vipul.bansal@rmit.edu.au; Tel: +61 3 99252121; Fax: +61 399253747

Abstract. Colloidal gold is undoubtedly one of the most extensively studied nanomaterials, with 1000 s of different protocols currently available to synthesise gold nanoparticles (AuNPs). While developments in the synthesis of AuNPs have progressed rapidly in recent years, our understanding of their biological impact, with particular respect to the effect of shape, size, surface characteristics and aggregation states, has struggled to keep pace. It is generally agreed that when AuNPs are exposed to biological systems, these parameters directly influence their pharmacokinetic and pharmacodynamic properties by influencing AuNPs distribution, circulation time, metabolism and excretion in biological systems. However, the rules governing these properties, and the science behind them, are poorly understood. Therefore, a systematic understanding of the implications of these variables at the nano-bio interface has recently become a topic of major interest. This Review Article attempts to ignite a discussion around the influence of different physico-chemical parameters on biological activity of AuNPs, while focussing on critical aspects of cellular interactions, uptake and cytotoxicity. The review also discusses emerging trends in AuNPs uptake and toxicity that are leading to technological advances through AuNPs-based therapy, diagnostics and imaging. 
Keywords. Gold nanoparticles; uptake; toxicity; size; shape; corona.

\section{Contents}

1. Introduction

2. Synthesis of gold nanoparticles

2.1. Size controlled synthesis of gold nanoparticles

2.2. Shape controlled synthesis of gold nanoparticles

2.3. Effect of reducing agents and stabilisers on the synthesis of gold nanoparticles

3. Toxicity of nanoparticles

3.1. How to assess the toxicity of nanoparticles?

3.2. Uptake and toxicity of gold nanoparticles

3.2.1. Effect of gold nanoparticle size on uptake and toxicity

3.2.2. Effect of gold nanoparticle shape on uptake and toxicity

3.2.3. Effect of gold nanoparticle surface characteristics on uptake and toxicity

4. Influence of biological protein corona formation on nanoparticle uptake and toxicity

4.1. Effect of nanoparticle size on protein corona formation

4.2. Effect of nanoparticle shape on protein corona formation

4.3. Effect of nanoparticle surface characteristics on protein corona formation

5. Technological advances in the use of gold nanoparticles

5.1. Gold nanoparticles as diagnostic agents

5.2. Gold nanoparticles as therapeutic agents

5.3. Gold nanoparticles as bioimaging agents

6. Summary and outlook

7. Conclusions

Acknowledgements

References 


\section{Introduction}

The use of gold to promote good health has been extensively documented in literature dating back to the $1^{\text {st }}$ century [1-5], however it was not until 1856 that Faraday's pioneering work set the foundation of modern colloidal chemistry, or rather, nanotechnology [6]. It is now well known that as a particle decreases in size towards the nanoscale (Fig. 1), its inherent properties do not necessarily reflect the properties of the bulk material it is derived from, nor that of its individual atoms - this is indeed the case with gold nanoparticles (AuNPs) [7-12]. Generally speaking, as particle size decreases, the proportion of atoms which are localised on the particle surface grows, compared to those confined to the inside of the particle [13]. This effect gives rise thermal, optical, electrical, magnetic, electronic and catalytic properties [13$31]$.

In the case of metal nanoparticles, particularly, gold, silver and copper, when particle size becomes significantly small relative to the wavelength of light, the large number of surface electrons lead to interesting phenomena such as surface plasmon resonance (SPR) [32-35]. In the case of spherical AuNPs with sizes less than $60 \mathrm{~nm}$, the SPR peak absorbance appears at around $520 \mathrm{~nm}$, accounting for the ruby red colour commonly attributed to AuNPs [36]. Modifications to the size, shape and chemical environment of the particles alter the position of the plasmon band, and hence the apparent colour of the particles in solution [37-40]. It is this phenomenon which explains the use of AuNP suspensions throughout history to create the spectrum of colours possible in stained glass [9, 32, 36, 41, 42]. While size and chemical environment influence the position of plasmon bands of AuNPs, the nanoparticle shape offers better opportunities to controllably fine-tune the optical properties of these materials [43, 44]. For instance, spherical AuNPs possess limited potential for SPR tuning as the intensity and position of the absorption bands are relatively fixed with only a small red shift and 
broadening seen with increasing particle size [37]. Conversely, altering the distance along which the oscillations are permitted to occur [45], which is achieved through altering the shape of AuNPs, gives rise to interesting optical properties that span the broader visible to near-infrared spectrum, making them more suitable for biological sensing, imaging and even therapy [46-54].

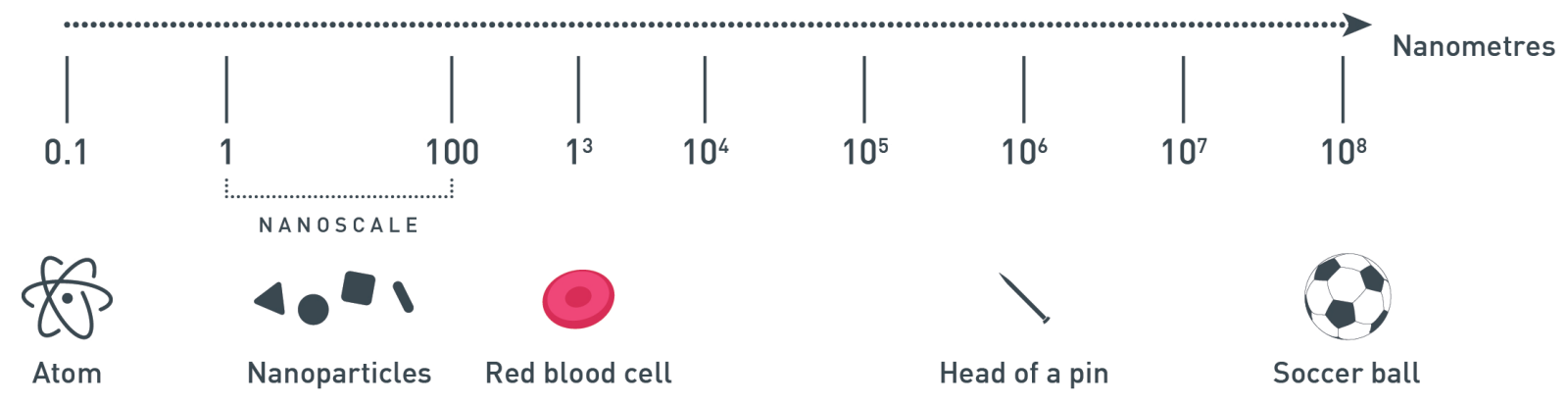

Fig. 1. Depicting the nanoscale relative to other objects.

Considering the interesting optical properties of AuNPs and their perceived biocompatibility $[55,56]$, there has been significant interest in elucidating the interactions of AuNPs with biological systems, however much of this work pertains to spherical AuNPs. Further, it is commonly thought that changes in particle shape and size could influence the way that particles are recognised, processed and excreted by the body, however this conjecture remains largely untested [48, 49, 57-62]. Notably, when AuNPs are exposed to biological systems, their surface features such as the presence of capping agents, unreduced metal ions and surface charge, can directly dictate the pharmacokinetic and pharmacodynamic properties of the nanoparticle [63-65], making it difficult to draw valid conclusions by simply comparing the biological activities of AuNPs originating from different laboratories. Therefore, a systematic understanding of the implications of these variables at the nano-bio interface has recently become a topic of major interest [65]. This Review article is an attempt to ignite a critical discussion around the influence of different physico-chemical parameters on the biological activity of AuNPs (Fig. 2). 

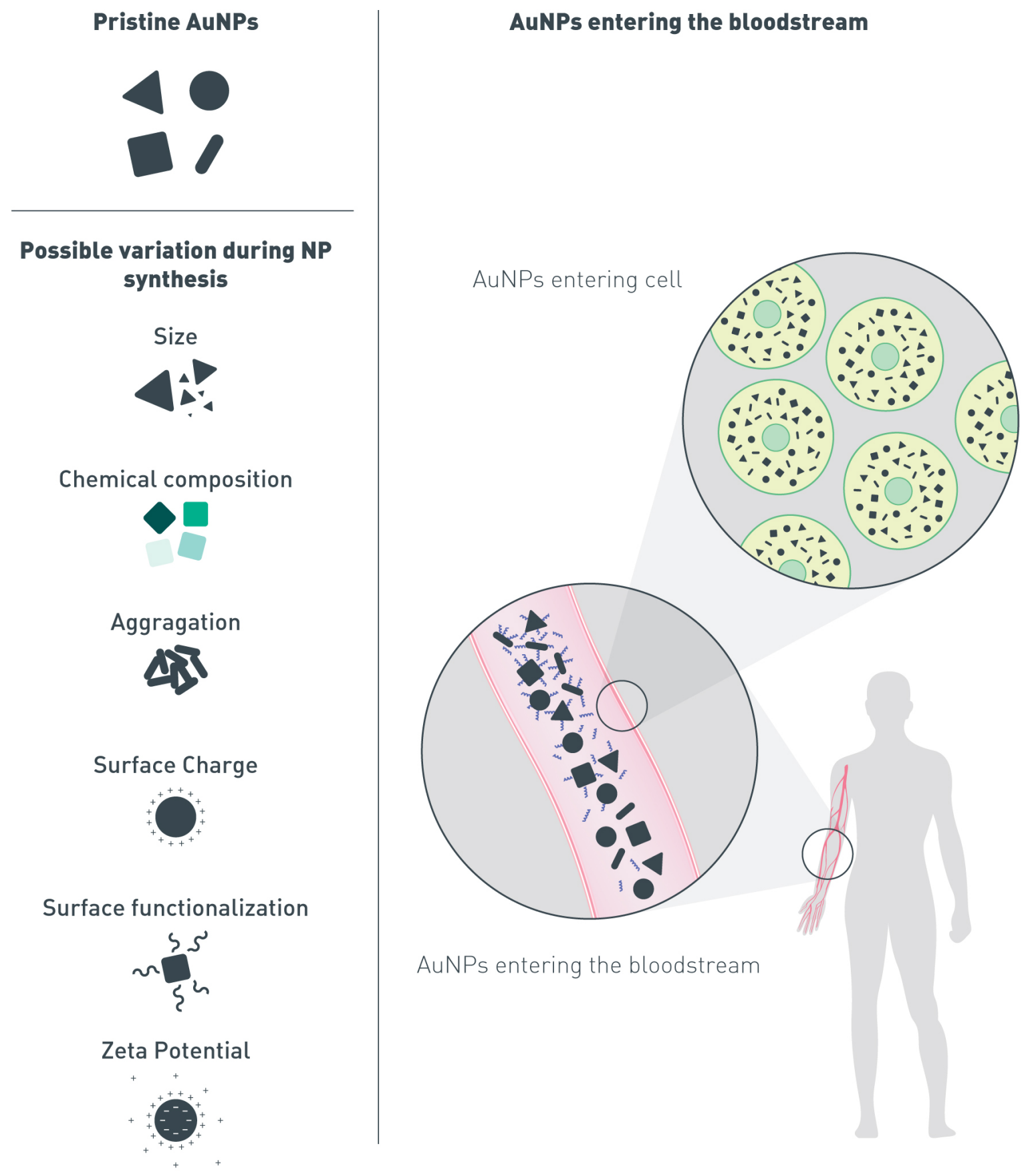

Fig. 2. Different physico-chemical properties of AuNPs that may influence their interaction with the biological systems.

While concerns exist regarding the practicality of utilising AuNPs in vivo due to potential metal accumulation in the body, such concerns have not been thoroughly tested through longterm in vivo studies [66]. It is only recently that the importance of such studies has been recognised, and the research community has more seriously started to investigate the 
influence of in vivo factors, such as spontaneous protein corona formation on nanoparticle surfaces in response to exposure to the biological fluids [67, 68]. New knowledge gained from nanoparticle-protein dynamic interactions will determine the way forward for tailoring AuNP-based systems for in vivo applications, and it will also offer equally valuable opportunities to take in vitro applications of AuNPs, such as diagnostics, to a commercialisation stage. This Review Article will therefore critically review various AuNP synthesis methods, assess relevant biological studies to highlight emerging trends in AuNPs uptake and toxicity, and highlight future directions for the application of AuNPs for biomedical investigations.

\section{Synthesis of gold nanoparticles}

While Faraday first described the reduction of tetrachloroauric(III) acid $\left(\mathrm{HAuCl}_{4}\right)$ to form colloidal gold suspensions in 1857 [6], the most popular method still used today was devised by Turkevich et. al., in 1951 [69]. During the reaction, which yields $\sim 20 \mathrm{~nm}$ gold spheres, $\mathrm{HAuCl}_{4}$ is brought to a boil at which point a solution of trisodium citrate dehydrate is added. During the procedure described by Turkevich, as well as most other in situ methods of spherical AuNP synthesis, the reaction has two main stages, viz. nucleation and growth that seem to occur concurrently [70]. The first step in the Turkevich reaction involves citrate being oxidised to form dicarboxyacetone, while in parallel $\mathrm{Au}^{3+}$ ions are reduced to $\mathrm{Au}^{1+}$ ions and subsequently to $\mathrm{Au}^{0}$ atoms. Following this step, gold atoms are generated from the disproportionation of aurous chloride molecules which can accommodate the adsorption of gold ions on their surface to form aggregates. During this process dicarboxy acetone acts as an "organiser" molecule to facilitate many of the steps of this reaction [71]. This synthesis has been subsequently adapted by many researchers to allow for size control [72], and varied chemical methods have been developed by later groups [73-76]. While all chemical methods 
must have a component which reduces gold as well as a component to provide stabilisation of the newly formed particles, these chemicals can vary greatly leading to the creation of vastly different particles with chemically different surface species [70].

The use of stabilisers is of great importance in shape-controlled synthesis of AuNPs, and a range of stabilisers have been employed to achieve the many shapes researchers seek for various applications. Generally, shape controlled synthesis is performed through a seedmediated growth process, wherein the nucleation and growth steps do not occur in parallel. Separating the two steps allows for tighter control over morphology and is generally favoured for larger spherical particles and AuNPs of different shapes [70]. The process begins by preparing small $(<10 \mathrm{~nm})$ spherical gold seed particles [77-79]. These seed particles are then added to a growth solution, typically containing a weak reducing agent, a stabilising agent and additional gold ions. While the seed particles added to the growth solution act as a catalyst for the reduction of the unreacted gold ions, the weak reducing agent in the presence of an appropriate stabiliser allows $\mathrm{Au}^{0}$ nanocrystals to be further grown in specific morphologies [70].

While chemical methods of nanoparticle synthesis are commonly employed due to their relative convenience, non-chemical or pseudo-chemical means of creating nanomaterials also exist. Reducing gold ions without the use of a chemical reductant eliminates the presence of 'contaminants' or chemicals precursors which alter the nature of the particle surface. For instance, photochemical synthesis methods harness the energy of ultra-violet radiation to induce reduction of gold ions producing uniform spherical particles. This is possible as the rate of reduction can be controlled by the level of radiation [80].

Conversely, laser ablation is described as a "top-down" technique as the starting materials for synthesis are bulk materials, typically foils, pellets, or even liquids (Fig. 3). Top-down 
methods involve the removal of nanoscale material from a bulk surface, in this case, with the use of laser light. As with all synthesis routes, there are inherent disadvantages and limitations associated with laser ablation, including relatively low yield when compared with other methods as well as difficulties associated with shape and size control [81]. This is in part due to the absence of a stabilising agent, thus if the AuNP concentration exceeds a certain limit, the particles tend to agglomerate and collapse in the solution.

\section{TOP DOWN}

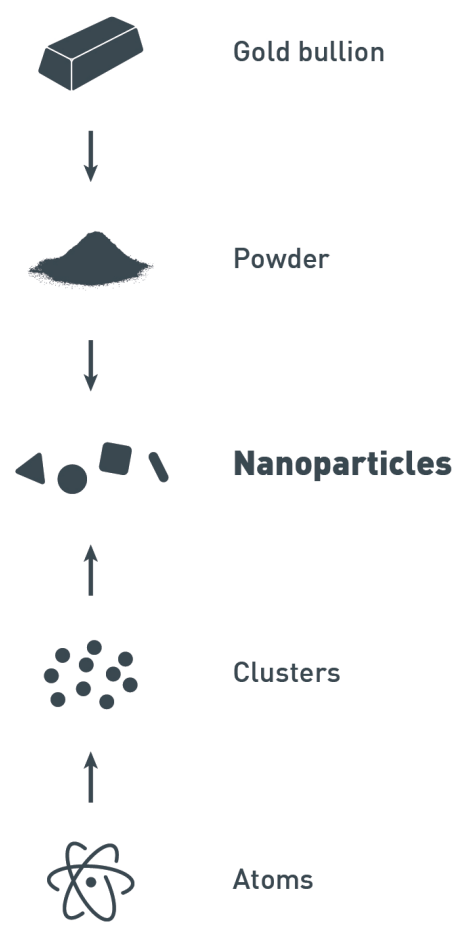

BOTTOM UP

Fig. 3. Schematic depicting the two main approaches to nanoparticle synthesis.

Additionally, a number of biological methods have been reported for the synthesis of nanoparticles of gold and other inorganic materials [53, 82-98]. These methodologies rely on the unique ability of certain microorganisms, plant extracts and biomolecules to produce nanoparticles. The biological approach of nanoparticle synthesis takes advantage of certain classes of biochemicals such as enzymes, oxidisable species, amino acids, etc. to allow these organisms to produce nanomaterials on exposure to appropriate chemical precursors [99- 
101]. Since these biochemical species involved in nanoparticle synthesis are produced in situ by the organisms, the biological synthesis of nanoparticles may be considered as a pseudochemical approach. Further understanding about biological synthesis of nanoparticles can be obtained from some of the reviews recently published in this area [102-107].

\subsection{Size controlled synthesis of gold nanoparticles}

Many years after Turkevich published his method of AuNP synthesis, Frens identified the ratio of gold salt to trisodium citrate as the defining factor governing AuNP size. The method, which allowed synthesis of particles up to $150 \mathrm{~nm}$ in size, was achieved by simply modifying the amount of trisodium citrate in the reaction; reducing levels to create larger particles [72]. This is possible because while there is sufficient sodium citrate to reduce the gold ions slowly, there is less available oxidised sodium citrate to act as a stabiliser to cap the particles and prevent further growth. The disadvantage to this process is that as the particles get bigger, they also become more polydisperse due to the parallel formation of new Au nuclei while pre-existing $\mathrm{Au}$ nuclei grow in size. In contrast, stronger reducing agents such as sodium borohydride provide a seemingly instant reduction of gold ions under ambient conditions, yielding smaller and less polydisperse particles compared to those achieved by sodium citrate [70]. While Frens pioneered the size control synthesis of AuNPs, the polydispersity of particles over $30 \mathrm{~nm}$ was significant and thus other methods for size control were developed. Another chemical method for increasing the size of spherical AuNPs involves seed mediated growth (originally called "germ-growth"), as described by Schmid et al. [108]. Using this approach, small AuNPs (such as those obtained using the Turkevich method) are used as nucleation sites for the growth of larger particles. The size of the final particles could be tuned by varying 3 factors; the diameter of the initial seed particles, the amount of seed added to the growth solution, and the amount of ionic gold present in the 
growth solution. However the size of the seed particles is of great importance, as this factor dictates the attainable size range of the final particles. While it is theoretically possible to employ this method to produce AuNPs ranging in size from 14-900 nm, the difficulty in synthesising seeds of low polydispersity in very small and very large size domains meant that the extreme ends of the size spectrum became difficult to control.

An advancement to this type of seed mediated approach was developed by Sau et al., who combined the traditional chemical method with a photoirradiation technique first shown by Esumi et al. [109] and Itakura et al. [110] in 1995, and later by Zhou in 1999 [111]. Though the method was utilised by the initial research groups for shape control, it was hitherto not exploited as a means for controlling the size of spherical AuNPs. The new method eliminated the difficulty of synthesising monodisperse seed particles via chemical methods, replacing it with a method of seed production which proceeds via photoirradiation of chloroauric acid and Triton X-100 (poly(oxyethylene)iso-octylphenyl ether)) with UV light [112]. By varying the ratios of gold ions to Triton X-100 (the stabiliser/reductant) in the system the seed particles could be tuned between 5-20 nm with low polydispersity. While only capable of attaining sizes between $5-110 \mathrm{~nm}$, these seed particles could then be used in a manner similar to Schmid et al., but with increased control over AuNPs at the smaller end of the size scale.

In 2001, the same year as the previously described Sau et al. method was published; Jana and co-workers published a method for synthesising AuNPs ranging in size from 5-40 nm [113]. In contrast to other methods, one seed particle, i.e., $3.5 \mathrm{~nm}$ citrate-capped, $\mathrm{NaBH}_{4}$-reduced AuNPs was utilised initially, however the reaction was an iterative growth process with the particles obtained from one growth reaction being used to seed another and so on, creating larger particles with each growth step (Fig. 4). The range of sizes was also affected by varying the ratio of gold seeds to metal salt in the growth solutions. 


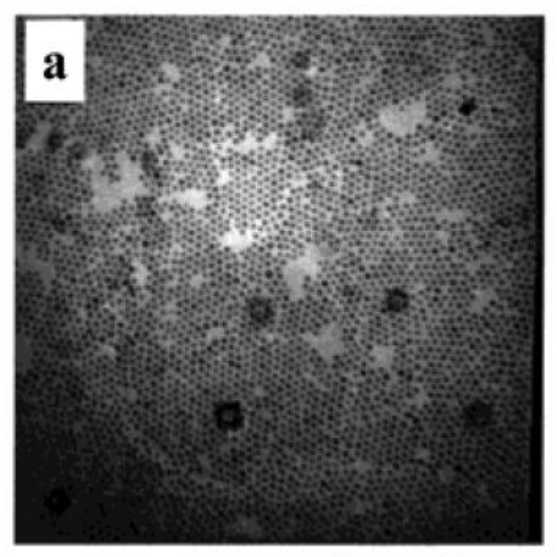

$100 \mathrm{~nm}$

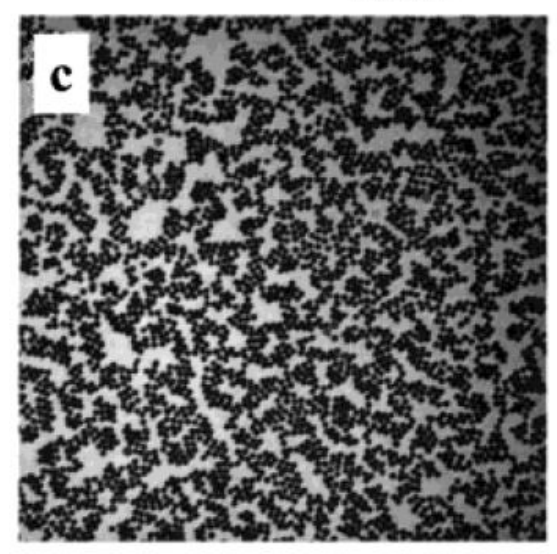

$\overline{100} \mathrm{~nm}$

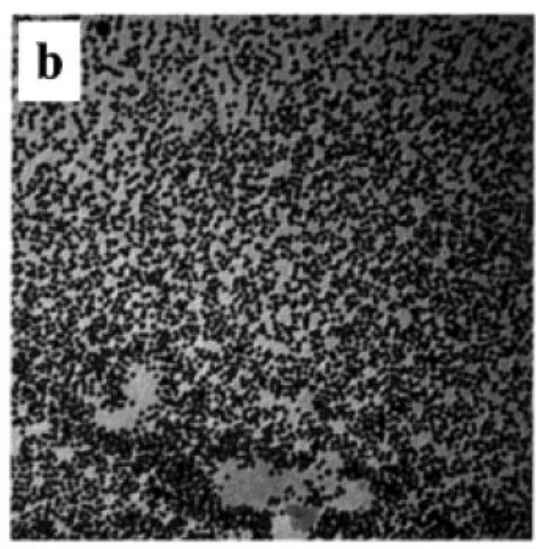

$\overline{100 \mathrm{~nm}}$

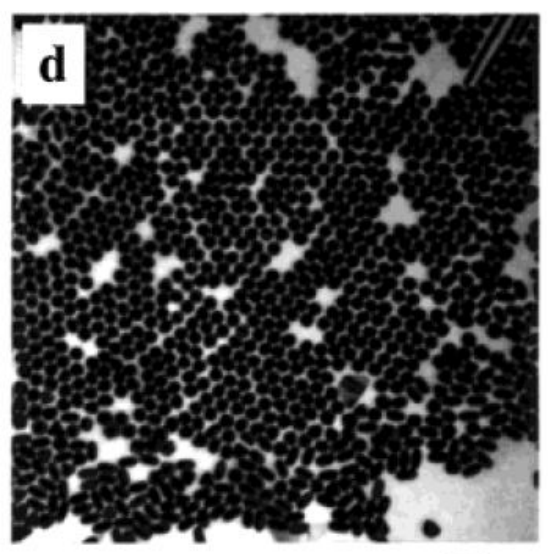

$\overline{100} \mathrm{~nm}$

Fig. 4. TEM images of AuNPs prepared by using an iterative seed mediated approach. Particle size ranges from (a) $5.5 \mathrm{~nm}$, (b) $8.0 \mathrm{~nm}$, and (c) $17 \mathrm{~nm}$ to (d) $37 \mathrm{~nm}$. Reprinted with permission from [113]. Copyright 2001 American Chemical Society.

While seed mediated processes (both iterative and non-iterative) have been used by many groups [114-117], there are additional methods for producing different sized spherical AuNPs which do not involve seed mediated growth.

Biological methods for producing various sized AuNPs have also been exploited, such as the use of plant extracts by Song et al. Using aqueous broths obtained by boiling the leaves of Magnolia (M. kobus) and Persimmon (D. kaki) plants in water as reducing agents, the group experimented with temperature and leaf broth concentrations to study the effect of these variables on AuNPs size. They noted that smaller particles were obtained (as well as a faster reaction time) with increasing temperature. For instance, $40 \mathrm{~nm}$ particles formed at $95{ }^{\circ} \mathrm{C}$ 
compared to $110 \mathrm{~nm}$ particles at room temperature, while leaf broth concentration had greater effect on the morphology of the particles rather than their size [118].

Organoamine-protected AuNP synthesis methods were introduced by Jana et al. in 2003 [5] and later refined by Hiramatsu et al. in the following year [119]. The simplified reaction involves refluxing a solution of $\mathrm{HAuCl}_{4}$ and oleylamine (9-octadecenylamine) in toluene for 2 hours. These nanoparticles differ from those produced by chemical methods as they are isolated via precipitation to yield a stable powdered sample which can easily tolerate surface modification allowing solubility in water or organic solvents. While the size range achievable is admittedly narrow, confined to $6-21 \mathrm{~nm}$, the AuNPs were very stable, and the process by which they were synthesised is simple and can be readily scaled up. In this reaction the particle size is mainly dependant on the concentration of the gold salt with greater gold concentrations producing smaller particles. Conversely, the concentration of amine within the reaction primarily controls the polydispersity of the particles, with polydispersity decreasing with increased amine concentration.

In general, it may be noted that size control of spherical AuNPs is a balancing act, with the amount of available gold ions within the system being a key factor in influencing particle size, however as with all AuNP synthesis methods, factors such as $\mathrm{pH}$, temperature, seed concentration and size, stabiliser strength and concentration, and the choice of the solvent contribute to the overall size and morphology of the resultant AuNPs [112].

Although size control of spherical AuNPs dominates the literature, size control of shapes other than spheres has been explored, though to a lesser extent. The size modification of rods or more specifically the tuning of their aspect ratio is reasonably well researched. When Yu et al. published the electrochemical method for synthesising nanorods (AuNRs) in 1997 [120], it not only uncovered the link between aspect ratio and the distinct dual band SPR peaks 
observed for AuNRs (a concept explored in more detail in section 2.1.2), but went further to demonstrate that the second peak (the longitudinal band) could be tuned by modifying the aspect ratio of the rods. The exact method by which the group accomplished this was not detailed, except to say that it was achieved by "carefully manipulating the experimental parameters". However, in 2009, Wang and co-workers utilised the same method and provided details on how rods with differing aspect ratios could be obtained [121]. They noted that rod length was controlled by altering the ratio between the surfactant (CTAB) and co-surfactant (TOAB or tetradecylammonium bromide). While they achieved some degree of size control, and were able to produce short rods with aspect ratios of $3-7$, long rods which had aspect ratios of 20-35 occurred less frequently. The original work by $\mathrm{Yu}$ was also built upon by Mohamed et al. in 1998, who additionally noted that increasing the temperature of the reaction reduced the aspect ratio of the rods [122].

Much like spherical AuNPs, rod shaped AuNPs can also be produced using a seed mediated approach, with multiple publications on the subject by Murphy Group [123, 124]. The group found that the size of shorter rods with aspect ratios under 7 could be controlled by changing the ratio of gold seeds to gold salt in the growth solution, with increased aspect ratio rods forming with decreasing amount of gold seeds. There was a limit to this effect however, with the aspect ratio failing to increase above $\sim 7-10$. They did however note lengthening of the rods with the addition of a small amount of silver nitrate into the solution [124]. They expanded on this work in their next publication; producing higher aspect ratio rods in an alternate fashion, by varying the experimental conditions of the seed mediated process. They noted that altering the timing of the reaction could increase the aspect ratio from $\sim 13$ to $\sim 18$. The same seed and three identical growth solutions were utilised in both reactions, beginning with the addition of the seed to the first growth solution, from which an aliquot was sequentially added to the next growth solution in turn. For the $\sim 13$ aspect ratio rods the 
reactions were allowed to run to completion in each growth solution, with aliquots taken after 4-5 hours. In contrast, the $\sim 18$ aspect ratio rods were formed by transferring the growth solutions while the particles were still growing, after just 15-30 seconds in each solution [125]. Similar to spherical particles, the factors influencing the aspect ratio of AuNRs are varied and include: the length of surfactant chain [126]; the size, surface charge and capping agent of the seed [127, 128]; and the amount of silver nitrate [79] .

While there are relatively large bodies of work relating to the size tuning of rod and spherical AuNPs, other shapes such as prisms and cubes are less explored. There exists a small body of work on controlling the edge length of gold nanoprisms, however unlike silver nanoprisms which show a great ability to be tuned [129-131], the dimensions of gold nanoprisms are more difficult to control. Ha and co-workers demonstrated some ability to tune the edge length of gold nanoprisms by adjusting the $\mathrm{pH}$ within the narrow range of 2 2-2-3.5. They observed increasing edge length with increased $\mathrm{pH}$, however $\mathrm{pH}$ levels above 4 failed to induce prism formation entirely [132].

The majority of size control methods for gold nanoprisms use biological agents such as Aloe vera and lemongrass leaf extracts which were utilised by Chandran et al. [133] and Shankar et al. [82, 134], respectively in Sastry's Group. Both these studies observed that increasing the amount of leaf extract decreased the edge lengths in the prisms formed. Sastry Group further expanded on this research by demonstrating that increased temperatures also led to the formation of prisms with shorter edge lengths [135].

Millstone and co-workers have conducted a large body of work on the synthesis of both gold and silver nanoprisms [7, 130, 136-138]. The group achieved shape control by using a seed mediated approach, effectively using freshly synthesised nanoprisms as seeds for further growth of larger prisms (Fig. 5). By adding the prisms to a growth solution containing 
additional gold ions in the presence of excess ascorbic acid they produced nanoprisms with edge lengths varying from 100-300 $\mathrm{nm}$ [136].

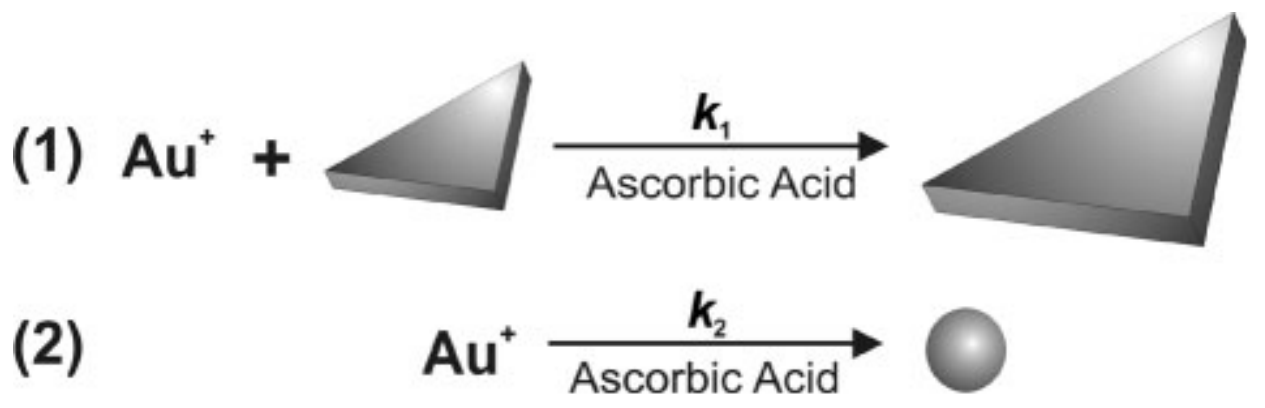

Fig. 5. Schematic representation of the two growth mechanisms likely to occur in seed mediated prismatic particle synthesis. Reprinted with permission from [136]. Copyright 2006 John Wiley \& Sons.

While significant gains have been made in the area of size control of AuNPs, the resounding message in this field is that the process is influenced by many external factors. Due to the effect of size on the location and strength of corresponding SPR bands, the desire for shape control is sought by many researchers for applications of AuNPs which depend on their optical properties. Thus research in this area is expected to expand, with the goals of more precise tunability of common shapes and the possibility of controlling additional shapes.

\subsection{Shape controlled synthesis of gold nanoparticles}

In general terms, being able to control and finely adjust parameters for the synthesis of AuNPs can benefit many potential applications. While there is limited ability to tune the optical properties of AuNPs by altering their size, there is enormous scope for the improvement in the range of possible SPR band positions by altering nanoparticle shape. Rod shaped AuNPs are arguably one of the most interesting in terms of their SPR potential as they exhibit two plasmon resonance bands, one of which can be easy tuned depending on the 
aspect ratio of the rod $[120,139,140]$. Similar to spherical AuNPs, rod shaped AuNPs display an absorption band at around $520 \mathrm{~nm}$ due to transverse oscillations or surface plasmons oscillating along the short edge of the rod; however a strong longitudinal plasmon band, whose position is dependent on the length of the rod, is also present due to surface plasmons oscillating along the long edge of the rod. The position of the longitudinal band is generally seen at wavelengths at and above $750 \mathrm{~nm}$ in the near infrared region of the spectrum (Fig. 6), which coincides with the optical transparency window of many biological tissues $[139,141]$. The optical window describes the wavelength range over which light is minimally scattered and absorbed by biological tissue. This means that light can penetrate deeper into the skin, without disturbing the tissue and hence allows for imaging of live subjects [142].

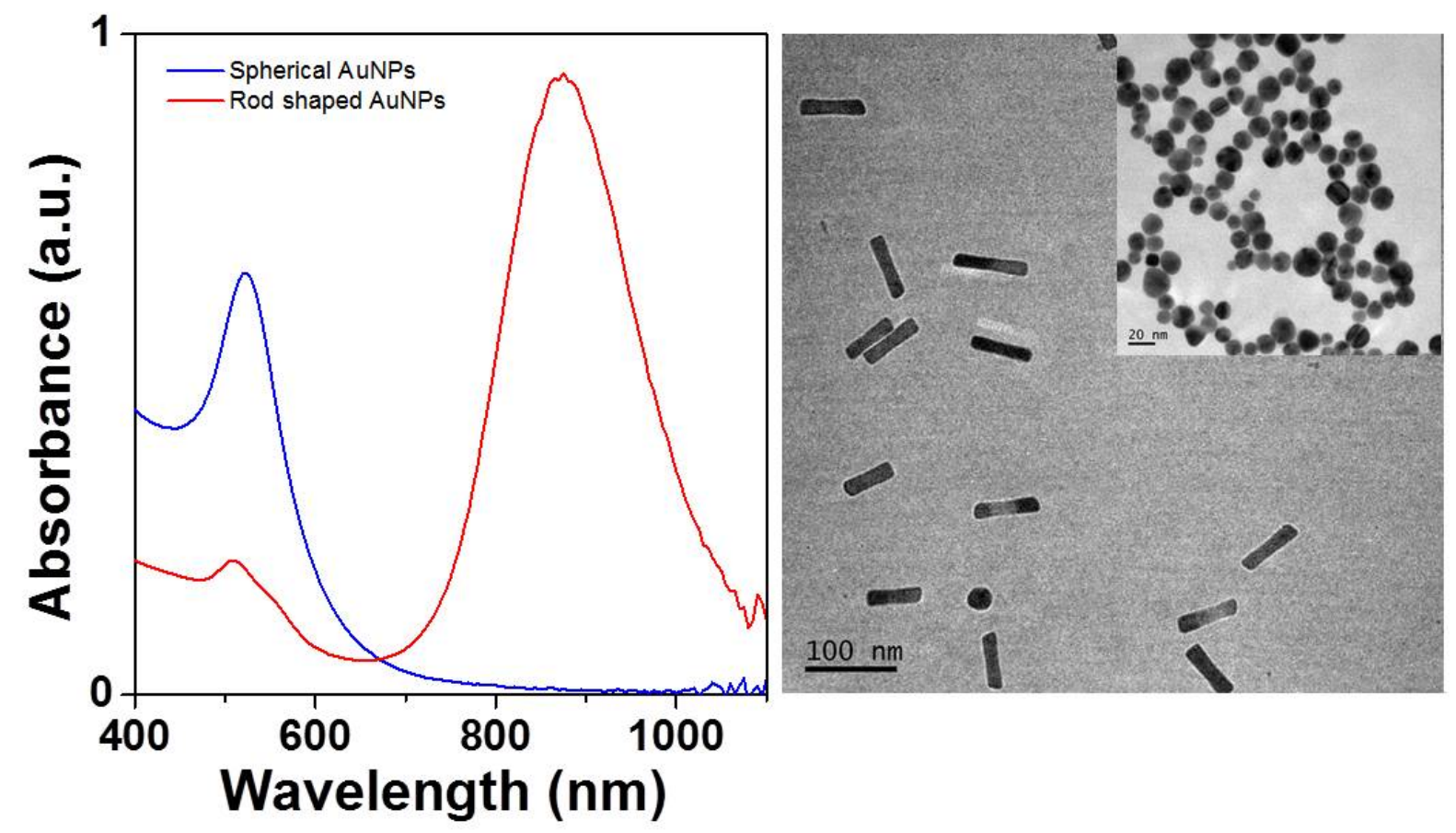

Fig. 6. UV-visible absorbance spectra (left) and TEM images of spherical (right, inset) and rod shaped AuNPs (right, main panel). Spherical AuNPs show a single absorbance peak at $\sim 520 \mathrm{~nm}$ while rod-shaped AuNPs show a small transverse peak in this region and significant longitudinal band at $900 \mathrm{~nm}$. Unpublished results from the authors' own work. 
By including a capping agent in the nanoparticle synthesis process, greater control over size and shape can be attained. While the capping agents used to date include polymers, dendrimers, additive ionic species [143] and even microbial proteins and metabolites [70], the use of a surfactant is the most common way to achieve shape control for metal nanoparticles [144]. This is achieved by preferential binding of shape-directing chemical species to different facets of a growing gold crystal based on the energy state of the facets, as well as steric interactions which relate to atomic density. [126]

While there are many surfactants which share similar traits, the most commonly used in AuNPs shape control is cetyltrimethylammonium bromide (CTAB) [145], which contains both a polar hydrophilic head group, and a non-polar hydrophobic tail (Fig. 7). This amphiphilic nature predisposes $\mathrm{CTAB}$ to form micellar arrangements in solution above a certain concentration (called the critical micelle concentration (CMC)), conferring softtemplate like nature. A frequent constituent in topical antiseptics, its cationic head group is an effective antibacterial and antifungal agent which targets the outermost membrane of Gram negative bacteria [146]. This property, in combination with its surfactant nature justifies its inclusion in some cosmetics and personal care products $[147,148]$.

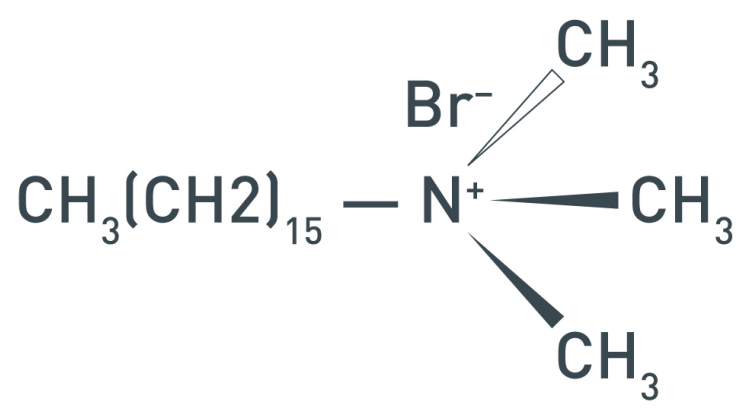

Fig. 7. Structure of CTAB.

While Murphy and co-workers [123] are credited with publishing the wet chemical method for gold nanorod synthesis using $\mathrm{CTAB}, \mathrm{Yu}$ et. al. had previously suggested that the 
formation of nanorods via electrochemical synthesis was due to the cylindrical-shaped cosurfactant CTAB [120]. While its mechanism of action is still not definitively known, it was clear to early groups that CTAB acted as a soft template $[78,79,149]$, which directed growth of nanorods by binding preferentially to certain facets of the growing gold crystal. CTAB is known to form a bilayer on AuNPs in solution as the surfactant molecules interdigitate, arranging their polar head groups both inward to the nanoparticle surface and outward to the interface with solution, assisting in stabilisation by preventing agglomeration [128, 150, 151]. The exploration of CTAB's mechanism of action has led to several attempts to explain its behaviour during nanorod synthesis $[77-79,145,152,153]$. In the years following Murphy's publication in 2001, many groups stated that the yield of nanorods obtained by following this method was strikingly low ( 4\%) [154]. This led to several groups adapting the method or formulating new methods for synthesising gold nanorods in high yield [78, 79, 139, 155]. While groups including Murphy and co-workers $[154,155]$ published an improvised method in which they identified $\mathrm{pH}$ as a critical factor for rod formation within their system, methods also emerged using micromolar concentrations of silver nitrate $\left(\mathrm{AgNO}_{3}\right)$ to induce gold nanorod formation $[78,156]$. Despite the similarity between methods, the addition of $\mathrm{AgNO}_{3}$ causes the reaction to proceed via a different proposed mechanism, and results in a slightly different shaped rod (Fig. 8) as compared with a silver free system [78, 149, 157]. The advantage of using silver is a markedly higher yield ( $~ 90-100 \%$ yield of nanorods is possible in a silver containing system compared with $\sim 20-40 \%$ in a silver free system [128]), however the aspect ratio of rods produced with silver was limited to $\sim 6$ (compared with up to $\sim 25$ for a silver free system) [128, 149]. 


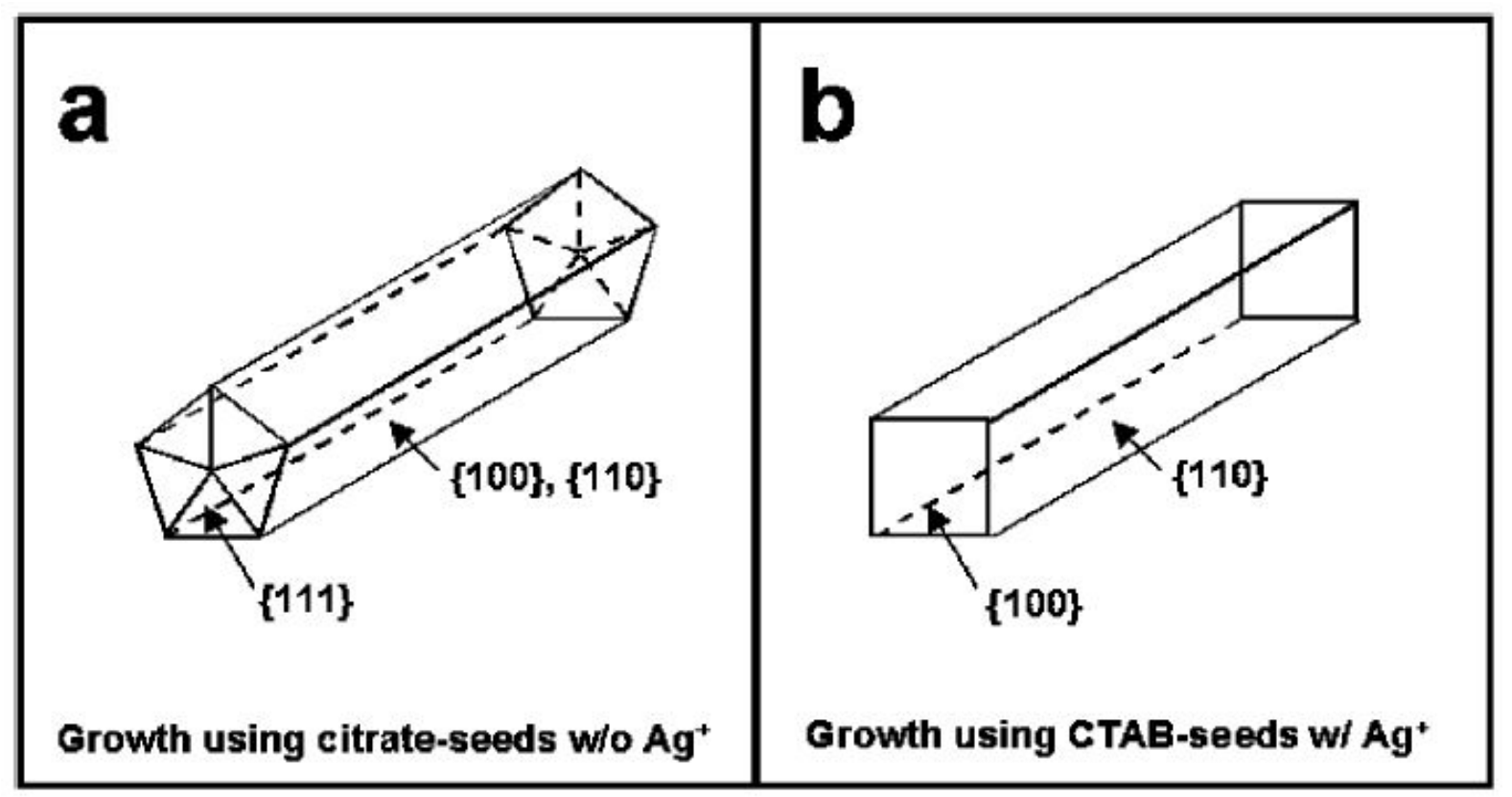

Fig. 8: Images modelling the crystallographic differences that arise if gold nanorods are synthesised using (a) citrate-capped seeds without silver or (b) CTAB-capped seeds in the presence of silver. Reprinted with permission from [156]. Copyright 2006 American Chemical Society.

The initial method for rod synthesis devised by Murphy et al., utilises citrate capped $3.5 \mathrm{~nm}$ gold seed particles, which act in dual capacities as both the initial site of growth and as a catalyst to induce reduction [123]. The citrate seed particles develop facets as they grow, resulting in the formation of penta-twinned AuNPs [149]. The penta-twinned seed particles are structured such that five $\{111\}$ crystallographic faces are cyclically arranged on each end, separated by five side faces which can either be $\{100\}$ or $\{110\}$ [77]. Sterically, CTAB is accommodated with greater ease on the $\{100\}$ or $\{110\}$ faces, when compared with the closely packed $\{111\}$ face, and hence, a bilayer of CTAB forms along these faces, blocking growth, while leaving the end face exposed for further growth [149]. CTAB helps to control the rate of the reaction by limiting the interaction of gold ions, and adding the weak reducing agent ascorbic acid to the rods allows growth to occur more quickly at the tips of the rods, which results in elongation [156]. 
In contrast, $\mathrm{CTAB}$ capped seeds were also employed to synthesise gold nanorods in the presence of silver [78]. These $1.5 \mathrm{~nm}$ seed particles are single crystalline and appear to have four $\{100\}$ side faces, and two $\{100\}$ faces on the ends. The exact mechanism of action of silver is not known, however it is thought to significantly slow the reaction process, and also act as a template via silver underpotential deposition (UPD) [78, 152, 158]. Silver UPD occurs when silver becomes reduced at a metal surface which holds a surface potential that is lower than the expected reduction potential of silver. This is energetically favoured on the $\{110\}$ surface [159], which leads to faster reduction of $\mathrm{Ag}^{+}$to $\mathrm{Ag}^{0}$ compared to the $\{100\}$ face. It is thought that the presence of silver allows CTAB to bind more effectively to the $\{110\}$ surface, and this synergistic effect promotes lengthening of the rods [156].

While CTAB is most commonly associated with gold nanorod formation, it can also be used to encourage cubic AuNP formation [157, 160-162]. Gold seed particles which are intended for cubic shaped particle growth such as those used by Kim et al., are typically stable, with $\{111\}$ faces accessible [163]. When in the presence of CTAB, which preferentially binds to the $\{100\}$ face over the $\{111\}$ face, the $\{100\}$ faces are effectively "blocked", and growth is encouraged on the $\{111\}$ face, forming cubes [161]. For this to occur, the synthesis requires elevated levels of a weak reducing agent such as ascorbic acid to be included in the system. Although incapable of facilitating a complete reduction of $\mathrm{Au}^{3+}$ ions, it ensures partial reduction to $\mathrm{Au}^{+}$ions. The final step, a careful addition of sodium hydroxide into the reaction vessel, is done with no mixing, as immediately mixing the solution causes an influx in fully reduced $\mathrm{Au}^{0}$ atoms, hastening uncontrolled growth in various directions leading to octahedral growth. Delaying mixing for more than 6 hours allows a very slow formation of $\mathrm{Au}^{0}$ atoms, allowing CTAB to prevent undirected growth, forming cubes [157]. 
While there are many published methods for producing gold nanorods using CTAB, it has emerged more recently that a number of research groups found this work difficult to reproduce. The most common issue found was that despite closely following the published synthesis protocols, the result yielded only spheres, with no or negligible rods formed within the growth solution. The first report of this was in 2007 when Durr and co-workers found that the use of high-purity ( $>99 \%$ ) CTAB did not result in rod formation, however a less pure (96\%) CTAB produced rods in high yield [47]. Though the group's focus was to utilise gold nanorods for medical imaging, they pursued this oddity further, testing five CTAB products from different suppliers, with purities ranging from 96-100\%. When the products of lower purity returned favourable results, the group concluded that an unknown impurity was most probably responsible for this effect [47]. Members of the same group, Smith and Korgel pursued this further the following year, testing ten $\mathrm{CTAB}$ products under identical conditions for rod formation [153]. Of these samples, three failed to yield rods, sustaining their earlier reports that the impurity in the $\mathrm{CTAB}$ was critical for nanorod formation $[47,153]$. While it was not definitive whether the impurity induced or prevented nanorod formation, it was hypothesised that the impurity disrupted nanorod formation during the growth phase. That same year, Millstone and co-workers detected levels of iodide $\left(\mathrm{I}^{-}\right)$on the surface of gold nanoprisms via inductively coupled plasma mass spectroscopy (ICP-MS) and confirmed with XPS (Fig. 9), which was surprising as it was not intentionally added during the synthesis and had no obvious origin. By performing ICP-MS on the starting constituents of the synthesis, it was determined that iodide was present in the CTAB which possibly accounted for the published inability to synthesis rods. This agreed with later reports by Smith's group and Rayavarapu and co-workers, and furthermore most of the researchers active in AuNP synthesis agreed that it was possible to have batch to batch variation of iodide content despite using products from the same supplier with a common product number $[153,164]$. The 
mechanism responsible for the iodide interference was attributed to its strong affinity for the $\{111\}$ crystal surface [165]. In ideal conditions for rod formation, the $\{111\}$ surface must be left unblocked (or at the very least partially unblocked) to allow for lengthening of the rods to occur. However when a growth system includes sufficient levels of both iodide and CTAB, binding to the $\{111\}$ and $\{100\}$ or $\{110\}$ surfaces respectively, rods formation becomes improbable, with spheres being the most likely outcome.
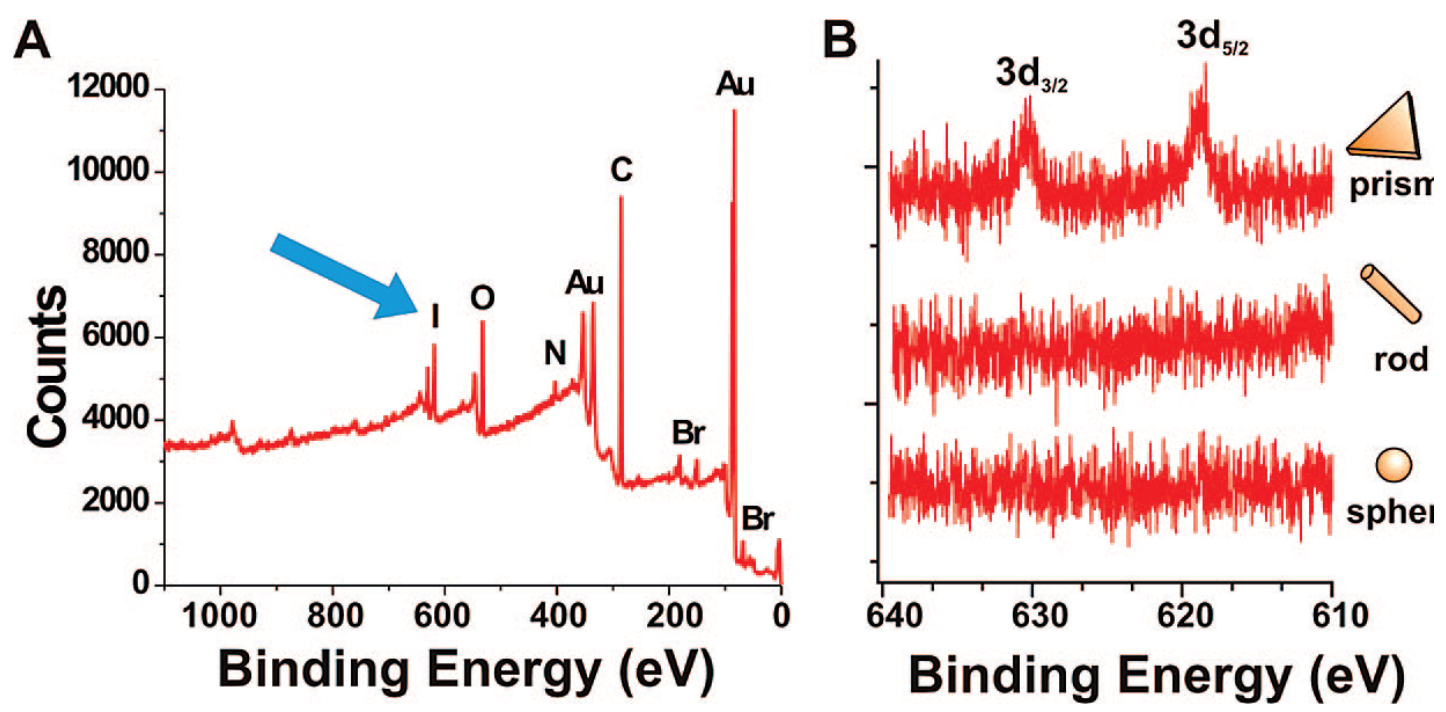

Fig. 9. (A) XPS spectra of gold nanoprisms synthesised by Millstone et al. Presence of $I$ is evident, and (B) not detected in spherical and rod shaped particles synthesised. Reprinted with permission from [138]. Copyright 2008 American Chemical Society.

While this property makes iodide ions highly undesirable for inclusion in gold nanorod synthesis, it is the key to forming triangular gold nanoprisms $[135,138,166]$. As with all crystals, each plane possesses a distinct energy level which is dictated by the reactivity of its surface electrons. For gold, a face centered cubic (fcc) metal, the order of its crystallographic planar energy is $\sigma(111)<\sigma(110)<\sigma(100)$ [165]. While it is known that iodide preferentially adsorbs to the lowest energy facet of a growing nanoparticle crystal, if concentrated sufficiently, it binds to all surfaces of the crystal [7]. When this occurs, growth is thought to 
favour the higher energy facets, (110) and (100), which results in lengthening of the prism edges, rather than increasing the prism thickness [130]. It is postulated that this growth effect may also have stoichiometric justification, as it requires fewer gold atoms to lengthen an edge, as compared to increasing the overall thickness of the particle [130]. Some examples of the various shaped CTAB synthesised AuNPs discussed are shown in Fig. 10.

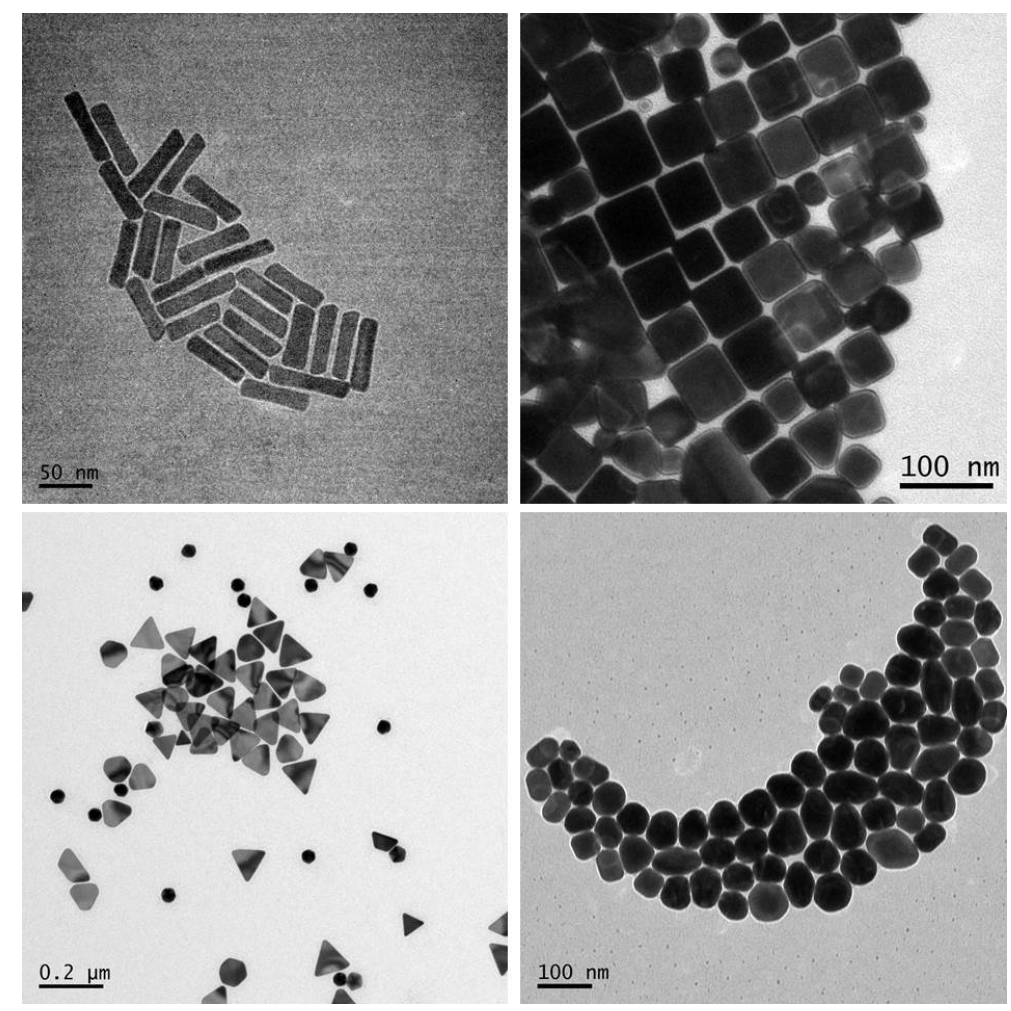

Fig. 10. TEM images (clockwise from top left) of rod shaped, cubic, quasi-spherical and prismatic AuNPs synthesised using CTAB as a shape directing surfactant. Unpublished results from the authors' own work.

\subsection{Effect of reducing agents and stabilisers on the synthesis of gold nanoparticles}

With the Turkevich method of spherical AuNP synthesis so widely used, the effect of citrate present on the resulting AuNP surface has been noted by many groups. The negative charge of the citrate coating influences the interactions of the particles with other species and can limit researchers in terms of further surface functionalisation. Notably, the negative charge inherent to DNA hampers its electrostatic binding to citrate stabilised particles, although does 
not preclude it fully [167]. Similarly, bovine serum albumin (BSA) binding to citrate stabilised AuNPs is approximately two times less than that of bare gold [168], thus emphasising the idea that individual components chosen during nanoparticle synthesis can influence the surface chemistry of the final particles. For this reason surface modifications and the development of new methods of AuNP synthesis became necessary for biological applications, to create particles with controllable surface chemistry, surface charge and stability. There are many comprehensive reviews that cover the synthesis of AuNPs in great detail $[70,103,105,128,169-171]$. In the current article, we highlight some of the key chemical agents used in nanoparticle synthesis which relate to the uptake and toxicity discussions covered in Sections 3 and 4 of this review.

Various chemicals can be used as reducing agents during AuNP synthesis, the most common being sodium borohydride, sodium citrate, ascorbic acid, and amino acids [14, 124, 149, 172]. The strength of the reducing agent (or the ease with which it is oxidised) plays an important role in controlling the rate of the reaction, thereby influencing the morphology of obtained AuNPs [135]. For instance, sodium citrate is a relatively weak reducing agent, and thus the reduction reaction does not occur instantaneously, but over approximately 10 minutes [70]. It is of no surprise that when citrate salts are employed as reducing agents, the AuNP synthesis is performed under boiling conditions to enhance the reaction rate, thus the modified Turkevich method devised by Frens reduces the amount of sodium citrate in order to achieve larger particles [72], a concept discussed in further details in Section 2.1.1. Further, while reducing agents tend to stabilize AuNPs during synthesis, sometimes stabilisers are also used to achieve additional control over AuNPs, such as, halting further growth and preventing aggregation of the particles over time. As with reducing agents, a number of stabilisers can be used during AuNP synthesis such as sodium citrate, polyethylene glycol (PEG), tetraoctylammonium bromide (TOAB) and cetyltrimethylammonium bromide 
(CTAB) [70], as well as greener alternatives such as leaf [97, 173], seed [95, 96] and fruit extracts [174]. Typically, strong reducing agents such as TOAB and sodium borohydride only bind weakly to the surface of AuNPs during synthesis, such that over time, stored AuNP solutions stabilised with these agents tend to agglomerate. In such cases, the use of additional stabilisers provide an opportunity to prepare monodisperse yet stable AuNPs [175]. Stabilisers can also play an important role in controlling the morphology of AuNPs (explored in greater detail in Section 2.1.2) through binding preferentially to specific planes of a growing Au nanocrystal, and thereby blocking the further growth of that specific plane [176, 177].

In summary, methods for synthesizing AuNPs have grown exponentially since their discovery by Faraday over 150 years ago. We are now capable of synthesising different shaped AuNPs to suit a plethora of applications which differ from imaging $[11,47,55,139$, 178-184], to therapeutics $[12,53,98,142,179,184-193]$ and sensing [194-197]. These AuNPs can be tuned with varying degrees of size control, despite researchers not necessarily understanding the full mechanisms which underpin the process. It is only through continued work and documentation in this field that we will understand the intricacies through which these synthesis reactions proceed.

\section{Toxicity of nanoparticles}

As a global multi-billion dollar industry, the area of engineered nanomaterials (ENMs) is rapidly growing, with an expanding list of applications [198-205]. While these applications are diverse in terms of their end use, they form the basis for growing environmental, health and safety concerns. Despite many applications of nanotechnology not being intended for medical or biological applications, there remains a necessity to investigate all new nanomaterials in terms of risks related to the manufacturing and use of the materials as well 
as the environmental ramifications of their use and disposal $[57,206]$. The innate size of a nanoparticle means that cellular interactions are highly likely (Fig. 11). Nanoparticles comparable to the size of a virion or bacterium are small enough to penetrate the cellular membrane and accumulate within the cell [207, 208].

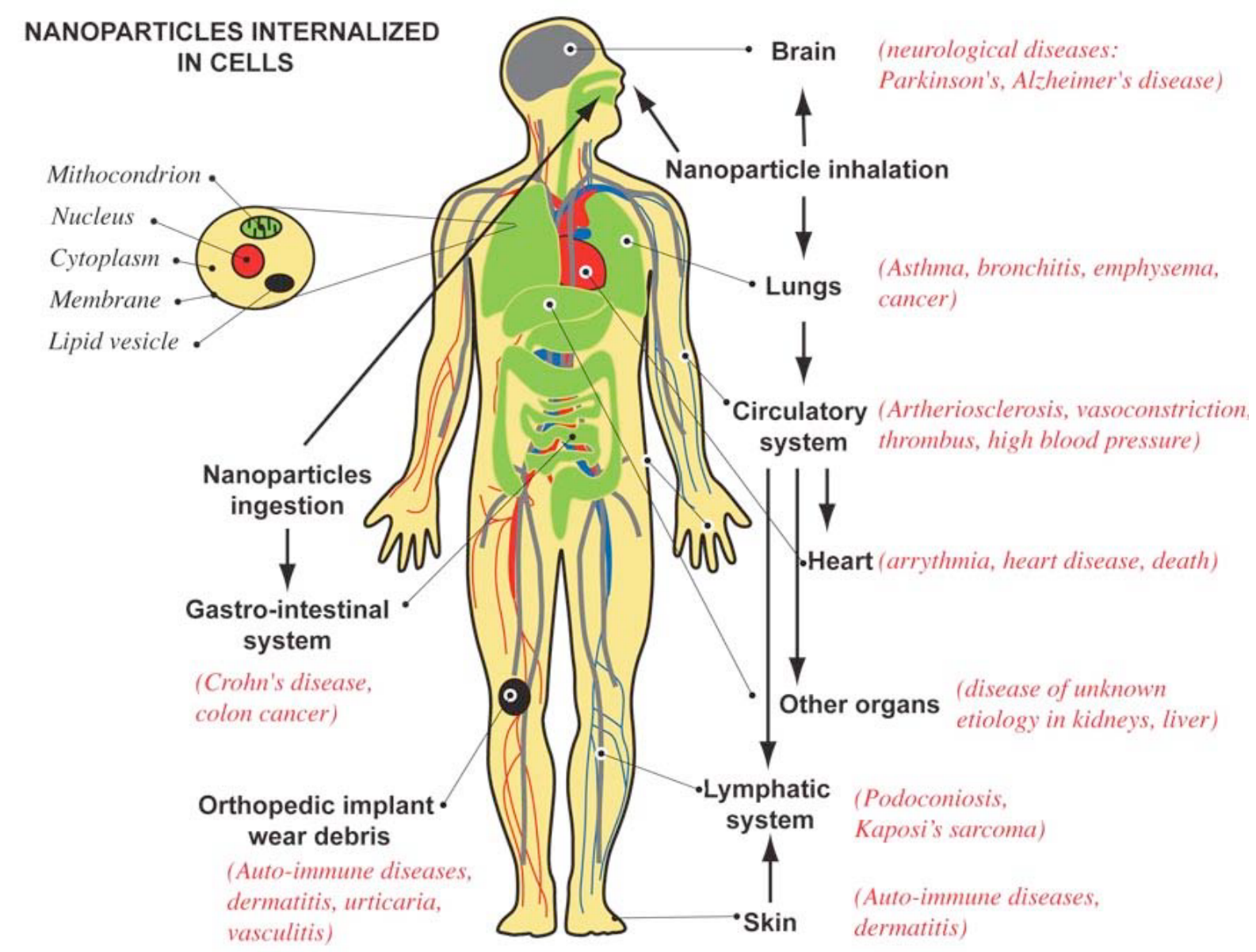

Fig 11: Schematic of the human body depicting likely routes of nanoparticle internalisation, and likely health effects from nanoparticle interaction. Reprinted with permission from [207]. Copyright 2007, American Vacuum Society.

In reality, humans have been exposed to nano- and micron-sized materials for thousands of years. Early exposure did not originate from the laboratory, but from nature, dictated by such events as dust storms, eruptions of volcanic ash, and the evaporation of oceans which generates nanoparticulate salt aerosols [207]. Since the nineteenth century, human exposure 
to nanoparticles has increased markedly, with the proliferation of combustion engines and an increase in cigarette sales among other causes [207, 209, 210]. The likelihood of exposure to intentionally designed nanomaterials is relatively small for most of the population in comparison to exposure from other anthropogenic and naturally occurring sources; however due to their common size, the investigation of their health effects unites under the umbrella of nanotoxicology [57, 211].

Although nanoparticles can theoretically be created from any element, the vast majority of research is performed on nanomaterials derived from carbon, silicon, polymers, metals and metal oxides [199]. Each of these materials in their bulk form possesses vastly different characteristics which may or may not be inherited by their nanoparticle counterparts [13]. While we know that size is an important factor for defining a nanomaterial, when examining the interaction between a biological interface and an ENM, there are over 30 variable factors which are known to have an impact on the way that nanoparticles are recognised, up-taken and processed intracellularly [211]. These variables include, but are not limited to size, shape, surface charge, surface area, surface functionality, suspending media, tendency for aggregation, chemical nature and the nature of its protein corona in biological fluids [212]. Hence the merits and dangers of individual ENMs must be assessed on a case by case basis, until enough is understood about ENMs to predict the properties and behaviours of new samples [213].

\subsection{How to assess the toxicity of nanoparticles?}

While it may be possible to predict biocompatible or bio-adverse results based on surface chemistry in silico, measuring the toxicity of nanoparticles in cellular systems in vitro is a necessary prerequisite for medical or consumer use of ENMs [57]. There are myriad of established assays for assessing the toxicity of materials in cellular systems which can be 
grouped into general categories depending on the endpoint measured [214]. The question posed by many research groups [206, 211, 215-218] is whether assays which have been optimised for general chemical compounds can be used to measure the effects of ENMs or whether the assays require modification to assess nanoscale materials.

Permeability assays, which assess viability based on the integrity of the cellular membrane most commonly include dye inclusion/exclusion assays (e.g., trypan blue which selectively stains dead cells but cannot permeate the membrane of living cells) and cytolysis detection assays which measure specific intracellular substances (e.g. lactate dehydrogenase (LDH) which is released from lysed cells when they die) [57]. A general disadvantage to the use of permeability assays is related to the endpoint itself [214]. By measuring toxicity only at the point where the cell membrane ruptures, it would be incorrect to assume that the cells deemed viable are in fact fully functioning, healthy cells. In reality, permeability assays cannot detect early or more subtle forms of cellular stress or damage. While this fact remains true for trypan blue, there are no noted specific disadvantages related to the use of ENMs in this assay [218]. It should be noted however that it can become time consuming and cumbersome to perform the trypan blue assay on a large number of samples when compared with other techniques. On the other hand, interference was noted by Han and co-workers between LDH assays and copper, silver and titanium dioxide nanoparticles [215]. This interference is due to adsorption of the LDH molecule onto the nanoparticles, which causes a decrease of free LDH within the system, which manifests as falsely reduced toxicity measurements.

Functional assays are often utilised as they relate to a specific metabolic pathway or function performed by the cell to a quantifiable level of cell viability. Common examples of this form of assay include tetrazolium-based assays such as MTS [3-(4,5-dimethylthiazol-2-yl)-5-(3carboxymethoxyphenyl)-2-(4-sulfophenyl)-2H-tetrazolium] and MTT [3-(4,5- 
dimethylthiazol-2-yl)-2,5-diphenyltetrazolium bromide] [219], as well as alternatives such as the Presto Blue metabolic assay [181], and Neutral Red assays [220]. Tetrazolium salts are able to selectively identify metabolically active cells because only these cells possess the mitochondrial activity required to cleave a tetrazolium ring thus creating formazan. Formazan formation results in a visible purple colour (Fig. 12), which appears only in viable cells, giving rise to the ability to detect the amount of viable cells colorimetrically [219]. While this type of assay is very commonly used, they may not always be suitable for assessing ENMs. Carbon nanotubes (CNTs) cannot be reliably tested using this assay because they adsorb formazan which falsely appears as decreased colour formation and can be interpreted as decreased cell viability $[217,219]$. This may be avoided by the addition of a step to remove the nanoparticles from the cell containing plate before adding the tetrazolium compound; however this is not traditionally commonplace [206]. As a precautionary measure, particles can be tested in a cell free system to check if they have any formazan reduction activity prior to performing the full assay. Such a test was carried out by Sayes et al. on zinc oxide nanoparticles to establish that they had no effect on formazan reduction [221]. Considering that a number of ENMs which utilize AuNPs possess wide ranging catalytic [222] and nanozyme properties $[194,195]$, it is likely that many ENMs may not be suitable for testing in all cytotoxicity assays. Unfortunately, most published reports on cytotoxicity of AuNPs and other ENMs fail to undertake such precautionary tests, resulting in a vast amount of literature citing outcomes which may not be fully trusted without revalidation.

Another common problem encountered with assays which are read spectrophotometrically such as MTS and MTT is that each nanoparticle absorbs light over a particular wavelength band, which may coincide with the wavelength that the assay is read at. This has been reported to be the case for sodium titanate nanoparticles [223] as well as citrate stabilised AuNPs [218]; however this problem may be potentially alleviated by adding a centrifugation 
step to the MTT protocol or by removing the nanoparticles prior to the addition of the tetrazolium compound [218]. Despite this fact, it is not common practice in such assays to remove the analyte before continuing the assay. Moreover, the innately "sticky" nature of ENMs, (adhering to the reaction vessel, cellular surface, etc.) makes it difficult for the EMS to be removed without disturbing the surrounding cells before performing assays. Alternate strategies, such as those involving control experiments, wherein pre-fixed (dead) cells are exposed to ENMs to assess non-specific cellular binding of ENMs, may address the issue or ENM's stickiness to the cellular surfaces.

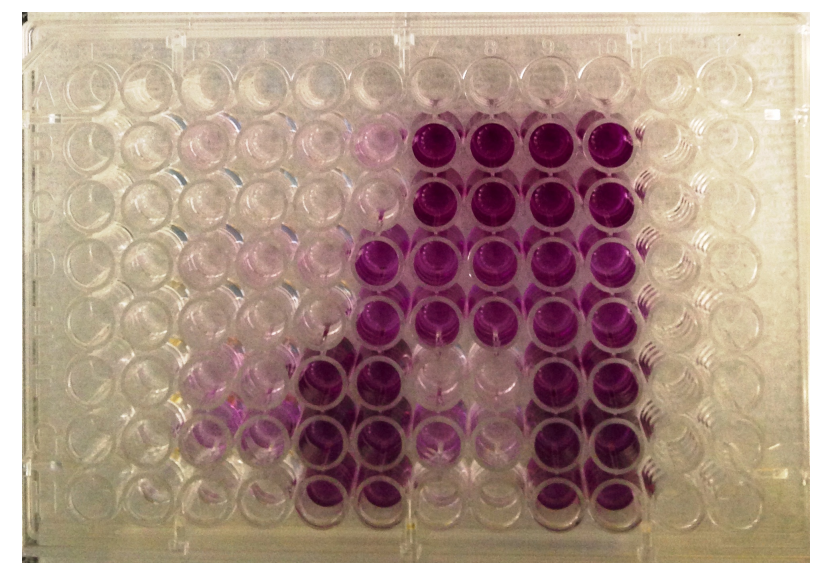

Fig. 12. A 96 well plate after development of purple formazan crystals, denoting cell viability.

Genomic or proteomic assays such the enzyme-linked immunosorbent assay (ELISA) are not impervious to similar forms of interference [206]. ELISA can be used to determine if proinflammatory markers or cytokines, such as TNF $\alpha$ [56], interleukin 1- $\beta$ [56], interleukin-6 or interleukin-8 are being released from cells following treatment with nanoparticles. For instance, CNTs were found to adsorb interleukin- 8 as reported by Montiero-Riviere and Inman [224], while Veranth and co-workers [225] reported other nanoparticles including $\mathrm{SiO}_{2}$ and $\mathrm{TiO}_{2}$ behaving similarly in the case of interleukin-6, leading to the detection of lower than expected levels of cytokines. 
The resounding message emerging from the literature regarding the toxicity of nanomaterials highlights the importance of choosing an appropriate assay for each individual ENM with consideration for the endpoint being examined, and to perform appropriate control experiments before critically analysing the results obtained. It is obvious that each assay must be optimised for new nanomaterials, adding additional steps to minimise interference when necessary. Where possible it is also advised to cross check results by using more than one assay to expose false readings [217]. From the authors' experience, some of the foremost considerations that must be followed in choosing the correct assays for toxicity assessment of ENMs including gold, are: (i) appropriate assessment of the potential for nanoparticle aggregation in cell culture medium, (ii) careful assessment of potential adsorption of the assayed component onto the nanoparticle surface, and (iii) consideration of the nanoparticle's inherent chemical activity in producing the reaction product. For instance, it is now wellestablished that gold and many other metal nanoparticles show strong reducing capabilities. Since MTS/MTT assays rely on reduction of these tetrazolium compounds into formazan crystals, one must be very cautious when choosing such assays for assessing biocompatibility of metal nanoparticles. Similarly, recent reports have demonstrated that some of the nanoparticles such as gold and iron oxide behave as nanozymes by demonstrating biological enzyme-like activity (peroxidase, catalase, etc.) [194, 195]. These new findings may further influence the way ENMs should be assessed for in vitro cytotoxicity.

Of equal importance in choosing the correct assay to assess the toxicity of ENMs is identifying an appropriate line of cells on which to perform the assay. It is commonly thought that incidental exposure to nanoparticles is via respiration, ingestion or through the skin [211, $213,216]$. For this reason, nanoparticle toxicity assays are commonly performed on skin cells or cells from the respiratory or gastrointestinal systems [60, 62, 224-226]. However researchers interested in assessing the therapeutic potential of ENMs in applications such as 
biological imaging [54, 183, 227, 228] and drug delivery [227, 229-234] perform tests on common tumour cell lines of the breast $[144,178]$, prostate $[178,185,235]$ and cervix [59, 236]. While it appears appropriate to choose cell lines depending on the end application, to assess the overall cytotoxicity of a particular ENM, it is critical to test a number of different cell lines in a single comprehensive study.

\begin{tabular}{|c|c|c|c|}
\hline Assay & Principle & Common Issues & Reference \\
\hline $\begin{array}{l}\text { Trypan blue } \\
\text { assay }\end{array}$ & $\begin{array}{l}\text { Exclusion test - } \\
\text { selectively stains dead } \\
\text { cells. }\end{array}$ & $\begin{array}{l}\text { Time consuming for } \\
\text { multiple samples. }\end{array}$ & {$[237]$} \\
\hline LDH assay & $\begin{array}{l}\text { Cytolysis detection } \\
\text { assay. } \\
\text { Measures release of } \\
\text { LDH colorimetrically. }\end{array}$ & $\begin{array}{l}\text { Time consuming for } \\
\text { multiple samples. } \\
\mathrm{LDH} \text { adsorption by } \\
\text { ENMs (including } \mathrm{Ag}, \mathrm{Cu} \\
\text { and } \mathrm{TiO}_{2} \text { ). } \\
\text { Inhibition of } \mathrm{LDH} \\
\text { activity. }\end{array}$ & $\begin{array}{l}\mathrm{ZnO}[238,239] \\
\mathrm{Cu} \text { and } \mathrm{TiO}_{2}[215] \\
\mathrm{Ag}[215,240]\end{array}$ \\
\hline $\begin{array}{l}\text { Neutral Red } \\
\text { Assay }\end{array}$ & $\begin{array}{l}\text { Functional Assay. } \\
\text { Measurement of viable } \\
\text { cells after lysosomal } \\
\text { uptake of dye. }\end{array}$ & $\begin{array}{l}\text { Dye adsorption by ENMs } \\
\text { (e.g. Carbon). } \\
\text { Optical interference. }\end{array}$ & $\begin{array}{l}\text { Carbon ENMs [219, } \\
224,241] \\
\mathrm{Fe}_{3} \mathrm{O}_{4} \text { or } \mathrm{TiO}_{2}[242]\end{array}$ \\
\hline $\begin{array}{l}\text { Tetrazolium- } \\
\text { based assays } \\
\text { (MTS and } \\
\text { MTT) }\end{array}$ & $\begin{array}{l}\text { Functional Assay. } \\
\text { Tetrazolium conversion } \\
\text { to formazan, allows } \\
\text { measurement of } \\
\text { metabolically active } \\
\text { cells colorimetrically. }\end{array}$ & $\begin{array}{l}\text { Formazan adsorption by } \\
\text { ENMs (including CNTs). } \\
\text { Susceptible to reduction } \\
\text { by other species (i.e. } \\
\text { superoxide). } \\
\text { Optical interference. }\end{array}$ & $\begin{array}{l}\text { CNT [241, 243, } \\
244] \\
\text { Carbon ENMs [224, } \\
238] \\
\mathrm{TiO}_{2}[238,245] \\
\mathrm{Si}[246] \\
\mathrm{Ag}[247] \\
\mathrm{Metal} \text { oxides [248] } \\
\mathrm{Au}[218]\end{array}$ \\
\hline $\begin{array}{l}\text { Enzyme-linked } \\
\text { immunosorbent } \\
\text { assay (ELISA) }\end{array}$ & $\begin{array}{l}\text { Analytic assay for the } \\
\text { detection of immune } \\
\text { response. } \\
\text { Measurement of the } \\
\text { release of cytokines } \\
\text { colorimetrically. }\end{array}$ & $\begin{array}{l}\text { Adsorption of cytokines } \\
\text { by ENMs (e.g. CNTs and } \\
\text { interleukin-8). }\end{array}$ & 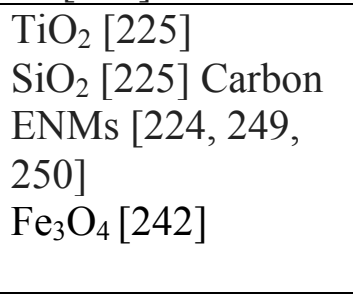 \\
\hline Comet assay & $\begin{array}{l}\text { Single-cell gel } \\
\text { electrophoresis. } \\
\text { Detects DNA damage } \\
\text { by measuring single- } \\
\text { and double-strand } \\
\text { breaks in DNA. }\end{array}$ & $\begin{array}{l}\text { Interference with } \\
\text { formamidopyrimidine } \\
\text { DNA glycosylase. } \\
\text { Direct DNA-ENM } \\
\text { interaction } \\
\text { Photocatalytic ENMs, } \\
\text { can generate increased } \\
\text { DNA damage after } \\
\text { exposure to UV light }\end{array}$ & $\begin{array}{l}\mathrm{Ag}, \mathrm{CeO}_{2}, \\
\mathrm{Co}_{3} \mathrm{O}_{4} \text { and } \mathrm{SiO}_{2} \\
{[251]} \\
\mathrm{TiO}_{2}[252] \\
\mathrm{CeO}_{2}, \mathrm{TiO}_{2}, \mathrm{SiO}_{2} \\
{[253]}\end{array}$ \\
\hline
\end{tabular}




\begin{tabular}{|c|c|c|c|}
\hline & & (e.g. $\mathrm{TiO}_{2}$ ) & \\
\hline $\begin{array}{l}\text { Micronuclei } \\
\text { test }\end{array}$ & $\begin{array}{l}\text { Identification of } \\
\text { cytogenetic material by } \\
\text { measuring changes in } \\
\text { the frequency of } \\
\text { micronucleus } \\
\text { formation. }\end{array}$ & $\begin{array}{l}\text { Decreased NP } \\
\text { endocytosis after } \\
\text { treatment with } \\
\text { cytochalasin B. }\end{array}$ & $\mathrm{Fe}_{3} \mathrm{O}_{4}[254]$ \\
\hline
\end{tabular}

Table 1. Summary of commonly used assays for the cytotoxicity assessment of nanomaterials and the likely points of interference associated with each assay.

\subsection{Uptake and toxicity of gold nanoparticles}

To date, the techniques used to measure of the toxicity of AuNPs of varying shapes and sizes are consistent with the techniques used for nanomaterials in general (as outlined in Section 3.1). For AuNPs, a range of techniques have been employed including LDH [255] and trypan blue [256], however the "gold standard" assay [64, 65] for cytotoxicity is the MTT assay which is by far the most commonly used [56, 257-262]. While there are a small number of reports of inference to the MTT assay by AuNPs [218, 263], there are multiple ways in which the MTT assay can be modified to overcome specific issues [206].

While gold in its bulk form, and particles of micron size range or larger, are generally thought of as non-catalytic, stable, inert and biocompatible, the uptake and toxicity of AuNPs is a far more complex issue [65]. With key variables such as the synthesis, size and shape of the nanoparticle as well as the cell type and endpoint examined [264], researchers have begun to form a matrix of results based on these findings. While some studies draw valid comparisons based on their own results [59], other reviews collate and compare the toxicity of particles synthesised by different groups over many years, using varied synthesis methods $[64,65$, 265].

Shukla et al., published one of the pioneering reports on biocompatibility assessment of AuNPs [56]. This study examined the cytotoxicity and intracellular uptake dynamics of 
AuNPs in macrophage cells. Atomic force microscopy (AFM) studies shed light on endocytosis processes involved in AuNPs uptake, while revealing that AuNPs taken-up by the cells could not be expelled out of the cells for extended time periods. One of the notable findings of this study was that these AuNPs were not only found to be highly biocompatible, they showed antioxidant properties at higher dosages and longer treatment points. This was concluded based on their ability to reduce the level of reactive oxygen species (ROS) and reactive nitrogen species (RNS) produced by the cells. This study also demonstrated for the first time that spherical AuNPs didn't induce the formation of proinflammatory cytokines such as TNF $\alpha$ and interleukin1 $\beta$ by macrophage cells.

This study was followed by a comprehensive study by Chithrani and co-workers with regards to nanoparticle shape, size and toxicity [59]. The study examined five citrate stabilised spheres of different diameters and two CTAB stabilised rod-shaped AuNPs of different aspect ratio. To be able to compare the particles in terms of toxicity and uptake, the positively charged $\mathrm{CTAB}$ present on the surface of the gold nanorods was exchanged with negatively charged citric acid ligands so that it was common across all seven nanoparticles. The study concluded that nanoparticles synthesised in this way did not cause toxicity to HeLa (immortal cervical cancer) cells in the doses examined. This finding of negligible toxicity has been validated by ours and many other groups who tested spherical [56, 236, 257, 262, 266] and rod shaped [260] AuNPs in a number of different cells.

In contrast to these reports, some other groups such as Patra and co-workers synthesised one particular type of nanoparticle, e.g. citrate-reduced $33 \mathrm{~nm}$ spheres and tested its toxicity in three different cell lines [267]. Their results showed that the same nanoparticle was toxic in human carcinoma lung cells (A549), while remaining nontoxic over the same dose range in both baby hamster kidney cells (BHK21) and human hepatocellular liver carcinoma cells 
(HepG2). When better understood, this cell-selective effect could be harnessed as a possible treatment for certain forms of cancer.

In 2010, Alkilany and Murphy compiled a comprehensive review of other group's results regarding the toxicity and cellular uptake of AuNPs [64]. Over 20 studies were examined, most commonly, groups studied spherical and rod shaped particles, however a range of chemical stabilisers were employed including citrate (most common), CTAB, various amino acids, and PEG both in vitro and in vivo. The authors found that there was no clear conclusion to draw on the toxicity of AuNPs, with such conflicting results between groups. The analysis of existing research outcomes led them to hypothesize that particle uptake, distribution and toxicity depended greatly on the interaction between the particle surface and the surrounding biological media [64, 265].

\subsubsection{Effect of gold nanoparticle size on uptake and toxicity}

Using methods such as ICP-MS and related techniques, it is possible to quantify the uptake of nanoparticles by relating the gold concentration of a known population of AuNP treated cells to the number of particles per cell. These results can be confirmed visually using electron microscopy. Chithrani and co-workers performed such a study on 14, 30, 50, 74 and $100 \mathrm{~nm}$

gold spheres [59]. The study estimated the number of nanoparticles per cell (calculated from the number of gold atoms obtained using inductively coupled plasma atomic emission spectroscopy), and found that maximum uptake (by number) occurred for the $50 \mathrm{~nm}$ particles; however despite the difference in uptake quantity, none of the spherical particles tested induced any significant cytotoxic event. These findings correlate well with other groups who found similar size dependent trends for uptake maxima [268-270] as well as uptake speed maxima [271] for $\sim 50 \mathrm{~nm}$ AuNPs. The studies that performed additional electron microscopy 
found that $50 \mathrm{~nm}$ AuNPs could not enter inside the nucleus, a possible reason for their lack of toxicity $[59,271]$.

In one of our earliest investigations, using a combination of imaging tools such as TEM, AFM and confocal microscopy, we demonstrated that when $\sim 10 \mathrm{~nm}$ AuNPs were exposed to RAW264.7 macrophage cells, these particles were sequestered in the endosomes, and these endosomes migrated from the cellular membrane towards the nucleus in a time-dependant fashion [56]. Even after longer exposure times, while endosomes carrying these AuNPs were found to beautifully arrange themselves just outside the endoplasmic reticulum network emerging from the nuclear pore, none of the AuNPs were observed to penetrate the nucleus (Fig. 13).

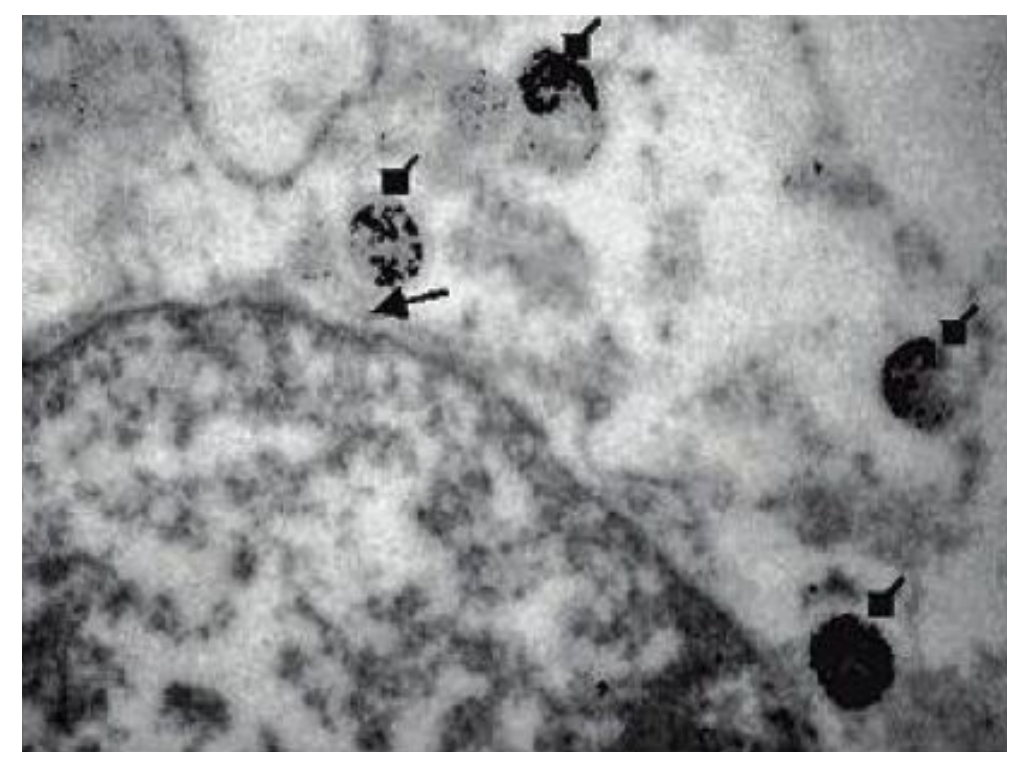

Fig. 13. TEM image of a RAW264.7 macrophage cell dosed with $\sim 10 \mathrm{~nm}$ AuNPs. Triangulartipped arrows show the reticuloendothelial network emerging from a nuclear pore. The square-tipped arrows show AuNPs present inside lysosomal/ endosomal bodies. Reprinted with permission from [56]. Copyright 2005 American Chemical Society.

One proposed mechanism for seemingly enhanced uptake of AuNPs is that their size is within the range of viruses and lipid-carrying proteins which would typically be engulfed or 
endocytosed by the cell [268]. However, the broader literature is less clear, with reports varying depending on surface modifications and the cell line chosen. There are many reports which indicate that AuNPs of varying sizes demonstrate negligible toxicity [56, 236, 257, $262,266]$; however there are also significant number of papers which dispute this [272-274].

A notable in vivo example of size dependent toxicity was obtained by Chen and co-workers who tested eight AuNPs of sizes ranging from 3 to $100 \mathrm{~nm}$, injecting the doses intraperitoneally into mice [274]. While nanoparticles of sizes 3, 5, 50 and $100 \mathrm{~nm}$ did not induce any apparent cytotoxic effects, AuNPs ranging from 8-37 $\mathrm{nm}$ initially caused changes in appetite and fur colour, progressing to bruising and bleeding under the skin, the development of a crooked spine and eventual death. Physiological changes were detected in lung, liver and spleen tissue samples taken from the mice treated with 8-37 nm AuNPs that were not seen in mice dosed with smaller or larger nanoparticles. These changes include the presence of emphysema like structures within the lungs, depletion of immunologically active lymphoid tissue within the spleen and an increase in Kupffer cells inside the liver, which would suggest that it was the site of a large scale immune response [274].

While typical cell culture experiments are most often based on the methodology of single exposure and subsequent reading, the long term effects of exposure to AuNPs hold equal importance. By exposing human dermal fibroblasts (CF-31) to citrate-capped 13 and $45 \mathrm{~nm}$ spherical AuNPs for up to six days, Mironava et. al., determined that despite an initial increase in doubling time observed as a function of concentration for both particle sizes, the effect on the cells was not permanent [275]. Using electron microscopy, the cells were observed to transfer internalised AuNPs to their daughter cells during division, effectively decreasing the number of internalised particles in each cell over time. As the number of internalised particles decreased over generation, the cell doubling time returned to that 
similar of the control cells over a 5 day recovery period. These findings are in agreement with Liaw and co-workers who tested citrate-capped $10 \mathrm{~nm}$ spherical AuNPs on human osteogenic sarcoma cells (MG63) [276]. By exposing cells to the nanoparticles for a period of 20 hours (at concentrations of 1 and $10 \mathrm{ppm}$ ) and monitoring them for a further 21 days they concluded that there was no difference in viability, doubling time or morphology compared with the control group at the final time point. These observations highlight the significance of exposure levels, such that if the organism is able to tolerate the chosen dose initially, it may be able to overcome cytotoxicity through in vivo metabolic mechanisms.

\subsubsection{Effect of gold nanoparticle shape on uptake and toxicity}

While there are studies that discuss the synthesis of triangular/prismatic $[7,78,135,144,149$, 277, 278] and cubic $[41,144,149,157,161,162]$ AuNPs and their potential for biological use, such particles have been the focus of relatively few biological studies in comparison to spherical nanoparticles. Following spherical AuNPs, the shape that has captured the highest interest of researchers is the gold nanorod, with the relationship between toxicity and nanorod length, or more specifically their aspect ratios, explored by many groups [64, 142, 260, 279282].

As previously discussed, gold nanorods are popularly synthesised using CTAB, a cationic surfactant used to influence shape; however pristine CTAB above $1 \mu \mathrm{M}$ concentration has been shown to be toxic to certain mammalian cells [62]. For this reason, some groups choose to modify gold nanorods originally synthesised using CTAB, by chemical exchange or surface functionalisation to give the particles a new, less toxic coating. Cellular uptake of these rods, when compared to spheres, has been shown to be slower, in lower quantities, and to induce a higher cytotoxic response $[59,60,280,281]$. Surface modifications often involve the use of polymers such as PEG to dispel the toxicity associated with CTAB; however it is 
reported that this high molecular weight non-fouling molecule discourages cellular uptake $[212,283]$, and drastically slows the process of endocytosis [60]. When comparing the effect of changing the aspect ratio of rods it was found that lower aspect ratio rods are taken up in higher quantities than those with higher aspect ratios (Fig. 14) [59]. This is somewhat expected as spherical AuNPs, which have the lowest possible aspect ratio (1:1) are generally uptaken by cells in much higher quantities.

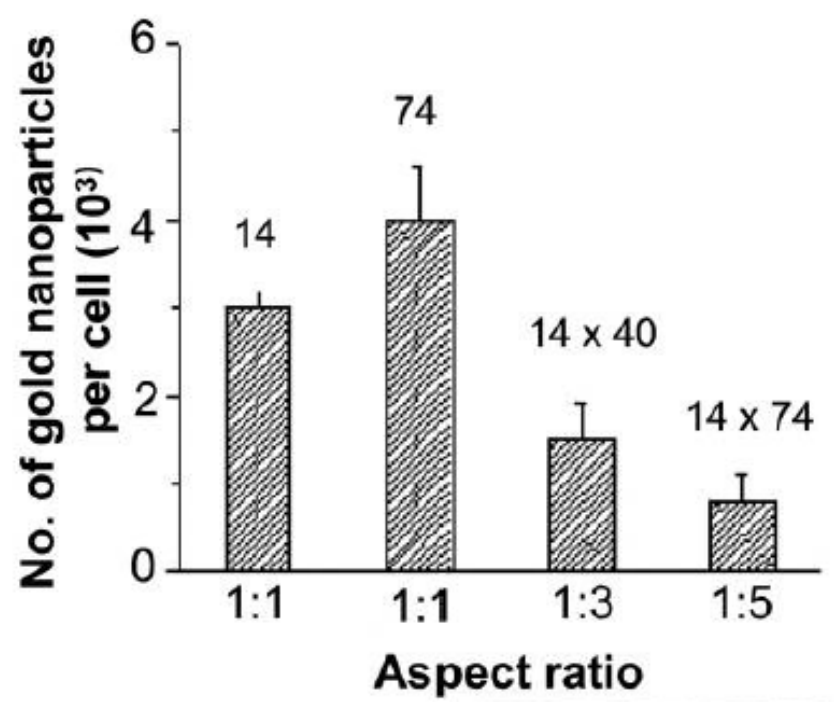

Fig. 14. Uptake of spherical versus rod AuNPs, showing preferential uptake of spheres (or particles of aspect ratio 1:1) Reprinted with permission from [59]. Copyright (2006) American Chemical Society.

Other groups elected to test their gold nanorods as-synthesised, without any modification of the surface. Wang and co-workers examined the uptake and toxicity of various sized gold nanospheres (synthesised without CTAB) and gold nanorods (synthesised with CTAB) [62]. While they found no toxic effect from all tested nanospheres, they found a drastic increase in toxicity from all gold nanorods. The group related the increased toxicity to levels of free CTAB within the sample, i.e. CTAB left unreacted after synthesis which is not bound to the surface of the particles, and performed a more thorough series of wash steps using 
centrifugation. After washing the particles three times, they observed a $60 \%$ improvement in cell viability compared with the same particles unwashed. Highlighting the degree of improvement that can be gained from washing gold nanorods thoroughly, Connor and coworkers eliminated toxic effects completely from CTAB AuNPs by centrifugation and washing, contrasting with high levels of toxicity for unwashed particles [257].

While less explored, preliminary studies have also been performed on the effect of prismatic AuNPs on various cells - both human and animal. Singh et al. [284] synthesised gold nanoprisms using fresh lemon grass extract, an example of one of the many biogenic synthesis methods developed to provide shape control. The difficulties related to making high yield nanoprisms (or purifying solutions to retain a high yield of nanoprisms) is well documented in the literature $[82,285,286]$, and as such, TEM images of the particles used by the group depict many persistent small spherical particles, as well as prisms with "edges cut" - effectively hexagons. Negating potential issues with sample purity, the nanotriangles were found to be well tolerated by cancerous and non-cancerous cell lines, with $80 \%$ cell viability at doses of up to $800 \mu \mathrm{M}$. Further imaging studies confirmed that the cells do take up the prismatic particles; however these particles did not enter the nucleus, but rather remained within the cytoplasmic space.

While the effect of shape can be quite drastic when comparing forms such as spheres and rods, Wani and Ahmad performed a shape and size dependant study on the antifungal activity of two AuNP samples, viz. gold nanodisks and mixed polyhedral shapes [49]. While they drew a conclusion that the enhanced antifungal activity observed from the gold nanodisks was due to their size, in reality, the two sets of shapes were not clearly defined, with mixed populations and high polydispersity apparent. The two shapes were synthesised using 
different methods, utilising different reducing agents, which also has the potential to influence the difference in activity.

Overall the findings suggest that while there may indeed be shape specific effects on cellular uptake and toxicity of AuNPs, the importance of eliminating surface and size effects to draw clear conclusions on the effect of gold shape on biological activity remains paramount.

\subsubsection{Effect of gold nanoparticle surface characteristics on uptake and toxicity}

Use of the term "gold nanoparticle" typically refers to a nanoparticle synthesised with a hard inorganic gold core and almost always with a soft organic corona. However, depending on the method of synthesis, and any modifications applied post-synthesis, the surface may vary greatly between different AuNPs [211]. It is widely thought that the chemical composition of a nanoparticle is one of many factors which contribute to the level of cytotoxicity it exhibits; however there are relatively few studies which explicitly establish this precedent.

Connor and co-workers demonstrated that starting materials such as gold salt $\left(\mathrm{AuCl}_{4}^{-}\right)$and CTAB were cytotoxic when tested alone, however when they were utilised along with other chemicals during synthesis, the resulting nanoparticle did not necessarily show cytotoxic effects [257]. The group tested spherical particles surface modified with cysteine, citrate, glucose, biotin and CTAB, finding negligible cytotoxicity in human leukemic cells [257].

In a similar system, Das et al. looked at three spherical AuNPs with different surface modifications - aspartic acid, trisodium citrate dihydrate and BSA finding negligible cytotoxicity from all particles through in vitro testing [187]. The group also tested the nanoparticles on mice to monitor toxicity after ingestion. In this experiment, the particles stabilised with BSA were found to be the most biocompatible, while the particles stabilised with aspartic acid and trisodium citrate dehydrate exhibited damage to the liver and kidneys. 
The group identified stability of nanoparticles in biological media and surface charge as key factors in influencing biocompatibility of nanoparticles [187].

The effect of surface charge has been investigated by many groups $[258,260,287]$ to determine its role in cytotoxicity. Goodman and co-workers found that identically synthesised cationic and anionic spherical AuNPs exhibited different cytotoxicity levels, with cationic particles observed as moderately toxic while anionic particles were deemed nontoxic [258]. This disagrees with the findings of Schaeublin and co-workers who tested three spherical AuNPs; positively charged, negatively charged and neutral [287]. In this study, both the positively and negatively charged particles were found toxic, with the negatively charged particles eliciting a stronger cytotoxic effect. The authors concede that this may be related to the outer chemistry of the cationic particles not being similar, due to different methods of charging the particles surface.

More recently, to understand how nanoparticle surface charge influences their uptake and toxicity, our group utilised tyrosine amino acid-reduced/capped AuNPs as a model system (Fig. 15) [172]. These negatively charged AuNPs showed no toxicity to Gram negative Escherichia coli bacteria and A549 human lung carcinoma. When the negative charge on the AuNPs surface was reduced through coating with a cationic amino acid lysine, it was noted that although nanoparticle uptake increased for both the bacteria and mammalian cells, it did not influence their toxicity. These observations were further validated by functionalising tyrosine-capped AuNPs independently either, with a cytotoxic polyoxometalate molecule or with polyoxometalate in combination with lysine. This investigation showed that the cytotoxicity of these polyoxometalate-functionalised AuNPs is dependent on the overall surface charge of the AuNP carrier system such that with an overall reduction in negative charge, the uptake and therefore cytotoxicity is enhanced. In contrast, when we utilised 
polyoxometalate-functionalised tyrosine-capped silver nanoparticles for a similar study, they showed toxicity against both Gram negative bacteria E. coli and Gram positive bacteria Staphylococcus albus, while showing no cytotoxicity against PC3 human epithelial cells [288]. It remains unclear at this stage whether the difference in Ag and Au toxicity profiles of nanoparticles with similar surface characteristics was due to differences in nanomaterial composition or to the difference in the mammalian cell line. Our current efforts remain focussed on attaining a better understanding of these fundamentally important questions [289].

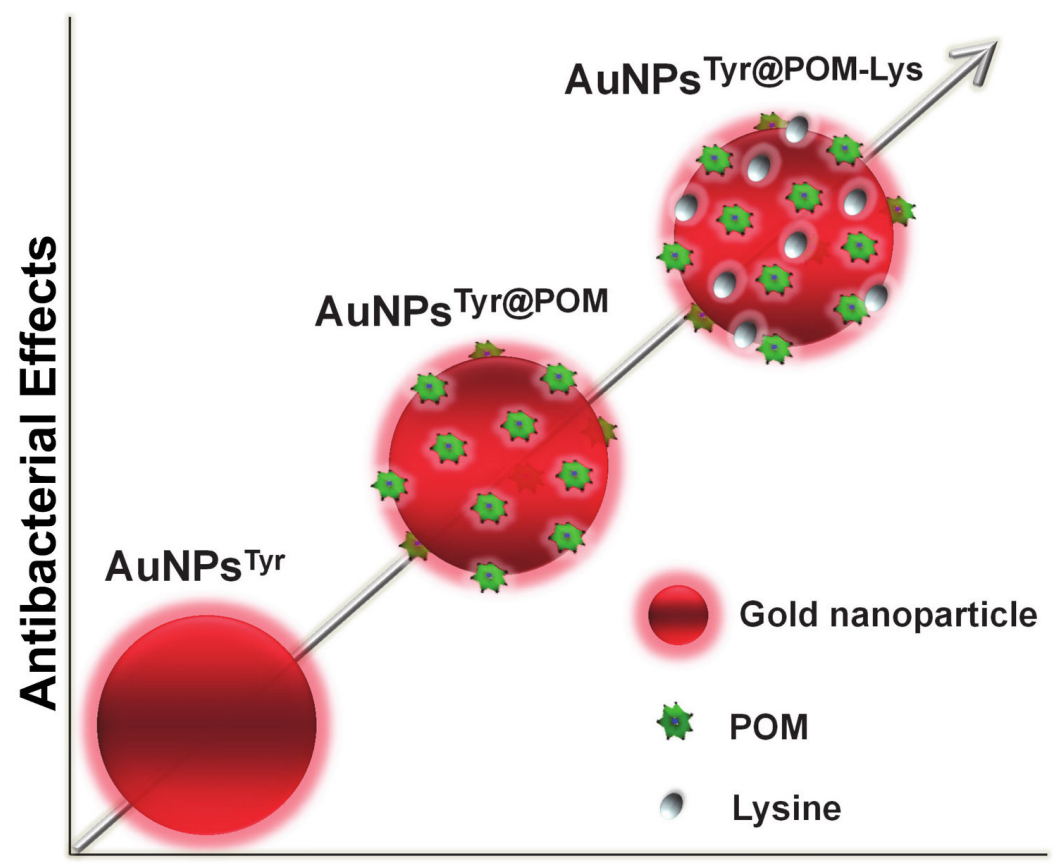

\section{Surface Functionalization}

Fig. 15. Schematic showing the relationship between antibacterial activity and surface functionalisation with the AuNPs synthesised by Daima et al. Reprinted with permission from [172]. Licensed under CC BY 2013.

Biological media are buffered solutions containing a mixture of electrolytes and proteins which can interact with the nanoparticle surface [260]. While nanoparticles may be stable in situ for extended periods of time, this alone does not confer stability in cell culture media 
$[290,291]$. Alkilany and co-workers found that gold nanorods change surface charge when exposed to a cell culture medium due to proteins adsorbing to the surface. The group tested positively charged rods synthesised using CTAB, against rods which were identical before being coated with polyacrylic acid (PAA) to switch the surface charge [260]. The initial charge of the rod was shown to be irrelevant as all rods had high levels of BSA adsorbed on their surface, which at physiological $\mathrm{pH}$ has a negative charge [292]. With surface charge constant, the toxic effect observed from the positively charged gold nanorods was attributed to free CTAB remaining in the nanoparticle samples. To make this point, and demonstrate the relatively low importance of initial charge, the group coated the negatively charged, nontoxic PAA-coated gold nanorods with positively charged polyallylamine hydrochloride (PAH). Unlike the positively charged CTAB rods, the PAH rods displayed negligible toxicity [260]. The group stressed the importance of studying the behaviour of nanoparticles after exposure to biological media as the nanoparticle-protein interaction is an important factor in uptake and toxicity.

This suggests that the surface characteristics of AuNPs play a rather complex role in determining their mode of biological action. It remains almost certain that the surface characteristics of as-synthesised AuNPs are instantaneously modified on their contact with biological fluids or cell growth media. It is these modified surface characteristics that are responsible for AuNPs final mode of action. However, it should be possible to fine-tune the surface features of as-synthesised AuNPs such that their interaction with the biological fluids (before interacting with cells) can be finely controlled. The authors believe that this aspect has significant scope for future developments in the field, and have therefore elaborated on biological corona on the nanoparticle surface in Section 4. 


\begin{tabular}{|c|c|c|c|c|c|}
\hline $\begin{array}{l}\text { AuNP } \\
\text { shape }\end{array}$ & AuNP size (nm) & $\begin{array}{ll}\text { AuNP } & \text { surface } \\
\text { properties }\end{array}$ & Experimental conditions & Conclusions & Reference \\
\hline Spheres & 4,12 , and 18 & $\begin{array}{l}4 \mathrm{~nm} \text { : cysteine and } \\
\text { citrate. } \\
12 \mathrm{~nm} \text { : glucose. } \\
18 \mathrm{~nm} \text { : citrate, biotin, } \\
\text { and CTAB. }\end{array}$ & $\begin{array}{l}\text { K562 leukaemia cell line. } \\
\text { Toxicity measured using MTT. } \\
\text { Uptake confirmed using TEM. }\end{array}$ & $\begin{array}{l}\text { Despite observing toxicity of } \\
\text { precursors CTAB and } \mathrm{AuCl}_{4} \text {, when } \\
\text { washed all particles were well } \\
\text { tolerated. }\end{array}$ & $\begin{array}{l}\text { Connor et } \\
\text { al. }[257] \\
2005\end{array}$ \\
\hline $\begin{array}{l}\text { Spheres } \\
\text { and rods }\end{array}$ & $\begin{array}{l}\text { Spheres }-14,30 \text {, } \\
50,74 \text { and } 100 \text {. } \\
\text { Rods }-40 \times 14 \\
\text { and } 74 \times 14 \text {. }\end{array}$ & $\begin{array}{l}\text { Spheres: citrate. } \\
\text { Rods: CTAB replaced } \\
\text { by citrate. }\end{array}$ & $\begin{array}{l}\text { HeLa cells. } \\
\text { Uptake measured with ICPMS } \\
\text { following } 6 \text { hour incubation. } \\
\text { Toxicity measured using Trypan Blue }\end{array}$ & $\begin{array}{l}\text { Maximum uptake of 50nm spherical } \\
\text { AuNPs. } \\
\text { Rod-shaped AuNPs with lower aspect } \\
\text { ratio showed greater uptake. } \\
\text { No toxicity observed. }\end{array}$ & $\begin{array}{l}\text { Chithrani } \\
\text { et al. [59] } \\
2006\end{array}$ \\
\hline $\begin{array}{l}\text { Spheres } \\
\text { and rods }\end{array}$ & $\begin{array}{l}\text { Spheres: } 5,12 \text {, } \\
20,30,50 \text { and } \\
70 . \\
\text { Rod aspect } \\
\text { ratios }: 2.1,2.5 \text {, } \\
3.0,3.3 \text { and } 3.5 \text {. }\end{array}$ & $\begin{array}{l}\text { Spheres: citrate } \\
\text { Rods: CTAB and PSS }\end{array}$ & $\begin{array}{l}\text { HaCaT cells. } \\
\text { Toxicity measured using MTT. }\end{array}$ & $\begin{array}{l}\text { All spherical AuNPs were well } \\
\text { tolerated. }\end{array}$ & $\begin{array}{l}\text { Wang et } \\
\text { al. } 2008 \\
{[62]}\end{array}$ \\
\hline Rods & $18 \times 40$ & $\begin{array}{l}\text { CTAB replaced with } \\
\text { PSS, PDADMAC and } \\
\text { PAH }\end{array}$ & $\begin{array}{l}\text { HeLa cells. } \\
\text { Toxicity measured using Trypan Blue. } \\
\text { Uptake measured using ICP-MS } \\
\text { following } 6 \text { hour incubation. }\end{array}$ & $\begin{array}{l}\text { Low toxicity }(\$ 20 \%) \text { in all conditions. } \\
\text { Negatively charged PSS coated AuNR } \\
\text { showed lowest uptake. } \\
\text { AuNRs coated in PSS followed by a } \\
\text { layer of positively charged } \\
\text { PDADMAC showed highest uptake. }\end{array}$ & $\begin{array}{l}\text { Hauck et } \\
\text { al. }[293] \\
2008\end{array}$ \\
\hline Spheres & 13 and 45 & Citrate & $\begin{array}{l}\text { Human dermal fibroblasts (CF-31) } \\
\text { Uptake assessed using SEM following } \\
\text { exposure for up to six days. }\end{array}$ & $\begin{array}{l}45 \mathrm{~nm} \text { AuNPs penetrate cells via } \\
\text { clathrin-mediated endocytosis, while } \\
13 \mathrm{~nm} \text { AuNPs enter via phagocytosis. }\end{array}$ & $\begin{array}{l}\text { Mironova } \\
\text { et al. } \\
\text { [275] } \\
2010\end{array}$ \\
\hline Sphere & $15-20$ & $\begin{array}{l}\text { Aspartic acid, citrate } \\
\text { and BSA }\end{array}$ & $\begin{array}{l}\text { Human fibroblast cell line (MRC-5) } \\
\text { Cytotoxicity was measured using water } \\
\text { Soluble Tetrazolium-1 assay. } \\
\text { Oral toxicity was performed using a }\end{array}$ & $\begin{array}{l}\text { AuNPs were non-toxic to MRC-5 } \\
\text { cells. } \\
\text { Citrate AuNPs caused a hepatotoxic } \\
\text { and nephrotoxic response. }\end{array}$ & $\begin{array}{l}\text { Das et al. } \\
{[187]} \\
2012 \text {. }\end{array}$ \\
\hline
\end{tabular}




\begin{tabular}{|c|c|c|c|c|c|}
\hline & & & murine model system. & $\begin{array}{l}\text { Aspartic acid AuNPs caused } \\
\text { hepatotoxicity. }\end{array}$ & \\
\hline Spheres & 11.7 and 13.5 & $\begin{array}{l}\text { Collagen (13.5) and } \\
\text { PMA (11.7) }\end{array}$ & $\begin{array}{l}\text { Cervical carcinoma and lung } \\
\text { adenocarcinoma cells. } \\
\text { Toxicity measured using MTT. } \\
\text { Uptake measured using ICP-MS } \\
\text { following } 4 \text { hour incubation }\end{array}$ & $\begin{array}{l}\text { Collagen-coated gold NPs exhibit } \\
\text { lower cytotoxicity, but higher uptake } \\
\text { levels than PMA-coated gold NPs }\end{array}$ & $\begin{array}{l}\text { Marisca et } \\
\text { al. }[294] \\
2015\end{array}$ \\
\hline Spheres & 2,4 , and 6 & $\begin{array}{l}\text { Cationic - thioalkyl } \\
\text { tetra(ethylene } \\
\text { glycol)ated } \\
\text { trimethylammonium } \\
\text { (TTMA), anionic - } \\
\text { carboxylate ligands } \\
\text { (COOH) and } \\
\text { zwitterionic AuNPs }\end{array}$ & $\begin{array}{l}\text { HeLa cells. } \\
\text { Uptake measured using ICP-MS } \\
\text { following } 3 \text { hour incubation }\end{array}$ & $\begin{array}{l}\text { For zwitterionic and anionic particles, } \\
\text { uptake decreased with increasing } \\
\text { AuNP size. For cationic particles, } \\
\text { uptake increased with increasing } \\
\text { particle size. } \\
\text { Preliminary studies showed low } \\
\text { cytotoxicity of all AuNPs tested. }\end{array}$ & $\begin{array}{l}\text { Jiang et al. } \\
{[295]} \\
2015 \text {. }\end{array}$ \\
\hline Spheres & 15,50 and 100 & $\begin{array}{l}\text { "Bare gold" } \\
\text { Negatively charged, } \\
\text { used as purchased. }\end{array}$ & $\begin{array}{l}\text { Caco-2 cells. } \\
\text { Uptake measured using ICP-MS } \\
\text { following incubation periods of } 1-24 \\
\text { hours. }\end{array}$ & $\begin{array}{l}\text { As AuNP size decreased, the rate of } \\
\text { cellular absorption increased, however } \\
\text { cellular accumulation decreased. } \\
\text { Furthermore, accumulation of AuNPs } \\
\text { was found to be the cause of } \\
\text { cytotoxicity observed. }\end{array}$ & $\begin{array}{l}\text { Yao et al. } \\
{[296]} \\
2015\end{array}$ \\
\hline $\begin{array}{l}\text { Stars and } \\
\text { spheres }\end{array}$ & $\begin{array}{l}30 \text { (stars) } \\
60 \text { (spheres) }\end{array}$ & HEPES buffered & $\begin{array}{l}\text { Human skin fibroblasts and rat fat pad } \\
\text { endothelial cells. } \\
\text { Toxicity measured using MTS. }\end{array}$ & $\begin{array}{l}\text { Spheres showed greater toxicity than } \\
\text { stars in both cell lines. } \\
\text { Spheres were more toxic to endothelial } \\
\text { cells as compared to fibroblasts. }\end{array}$ & $\begin{array}{l}\text { Favi et al. } \\
{[297]} \\
2015\end{array}$ \\
\hline
\end{tabular}

Table 2. Summary of uptake and toxicity studies of AuNPs of different shapes, sizes and surface coatings. PDADMAC poly(diallyldimethylammonium chloride), PSS - poly(4-styrenesulfonic acid), PAH - poly(allylamine hydrochloride), PMA - poly(isobutylenealt-maleic anhydride), PSS - poly(styrenesulfonate) 


\section{Influence of biological protein corona formation on nanoparticle uptake and toxicity}

With intravenous injection the optimal route of administration for many AuNP based therapies, it is fair to assume that the blood will be the initial biological environment encountered by many of these nanoparticles. In the same way that other materials including medical implants become coated with proteins almost immediately after introduction to the blood [298], the competitive dynamic process of forming a protein corona commences at the nanoparticle surface almost instantaneously (Fig. 16). All inorganic nanoparticles, including gold, invoke the formation of a protein corona when introduced to protein containing solutions such as biological media or blood $[68,265,291,299]$. The time dependant process begins in as little as seconds to minutes with proteins of high mobility localising on the surface of the particle forming what is termed a soft corona due to its transient existence. Over the following hours, proteins which are less mobile but carry higher affinity for the surface of the particle may replace the initial proteins to form a more permanent hard corona in what is known as Vroman's effect [300].

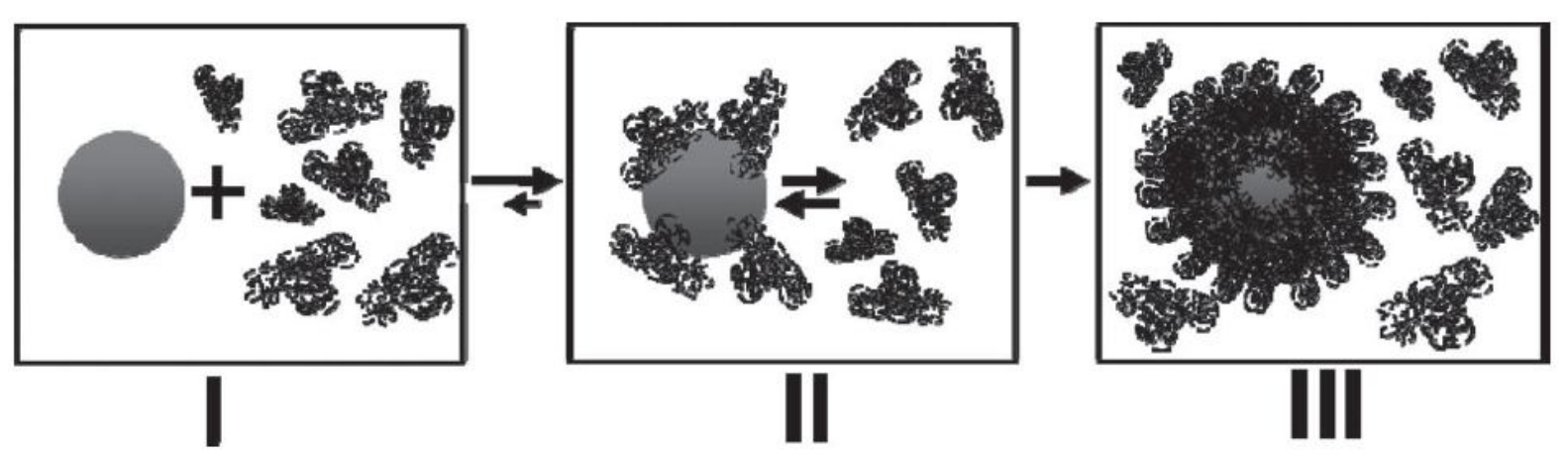

Fig. 16. The evolution of a protein corona begins almost immediately after introduction of a nanoparticle to protein rich conditions (I). Initially, the nanoparticle is covered with proteins which are abundant and highly mobile (II), the proteins species are exchanged over time resulting in hard corona of strongly bound proteins (III). Reprinted with permission from [301]. Copyright 2011 John Wiley \& Sons. 
To understand this effect, model proteins such as BSA or human serum albumin (HSA) are often used, as they represent albumin, the most abundant protein found in human blood. Despite the model used, the composition of the protein corona is unique, and influenced by many external variables relating not only to the nanoparticle itself, but also the nature of the biological system being probed. The composition of the protein corona is generally thought to consist of 10-50 proteins [265] and while highly abundant proteins in the blood such as albumin, immunoglobulin $\mathrm{G}$ ( $\mathrm{IgG}$ ), fibrinogen and apolipoproteins are most common constituents of the protein coronas studied to date, their relative abundance on the nanoparticle surface does not necessarily correlate with their natural abundance in the blood [302].

While many mechanisms exist to explain the process of protein binding to the nanoparticle surface, the most widely accepted is the entropy-driven binding model [302, 303]. This exchange occurs because the release of water molecules from the area close to the nanoparticle surface is energetically favoured (due to high entropy increase) compared to the relatively small decrease in entropy caused by the binding of a protein in its place.

It is thought that cellular-nanoparticle interactions are greatly dependant on the composition of the protein corona; and that the nanoparticle core, hydrophobicity, size, shape, charge and surface functionalisation elicit some effect on the types of proteins that are attracted to form the corona $[301,302]$. It is widely accepted that the protein corona confers the nanoparticle its biological identity, and thus it can be suggested that the uptake of AuNPs by cells is dictated by the species of proteins, their orientation and arrangement on the surface of the nanoparticle [260, 304]. Understanding the relationship between causal factors and the final composition of the protein corona may therefore prove insightful to the unpredictable and often contradictory results obtained by researchers probing the toxicity of AuNPs. 


\subsection{Effect of nanoparticle size on protein corona formation}

The general paradigm linking nanoparticle size and protein corona formation is typically thought to hinge on the degree of curvature on the nanoparticle surface $[68,280,298,305$, 306]. This is most commonly probed by examining spherical particles of different diameters, and comparing to binding observed on macroscopic flat surfaces of similar surface chemistry [299, 307-310]. Geometrically, it can be understood that differences in the degree of curvature may favour or inhibit proteins depending on their three dimensional structure, allowing for certain proteins to make contact with a greater area of the particle offering greater stability, or sterically inhibiting or possibly disrupting others upon making contact $[305,308,311]$. The knowledge that curvature is influential on protein-nanoparticle interactions is seemingly universal for all nanoparticles; however with respect to the protein perspective the results are less predictable. Having a large degree of variation in size, structure and composition between various proteins, the interactions must be probed or modelled for each protein and nanoparticle in question taking into account such variables as the preferred structure of each protein as well as the position and number of binding sites available on the nanoparticle surface. It must be noted that even with this knowledge, assessing the binding of each protein alone does not necessarily provide transferable information related to binding affinity of the proteins in a highly dynamic environment as would be expected within the blood.

Size dependant effects have been seen in many nanoparticles despite their elemental composition. For instance, Shang and co-workers examined the behaviours of cytochrome c proteins on the surface of different sized silica nanoparticles. Their finding showed that the cytochrome c structure became increasingly distorted upon binding to larger silica nanoparticles, while also becoming increasingly unstable in its new conformation [312]. 
Conversely, Roach and co-workers found that the structure of albumin becomes increasing disordered after binding to larger silica nanoparticles while fibrinogen becomes increasingly compromised upon binding to smaller particles with higher surface curvature [308] (Fig. 17). Such size dependant effects were also recorded by Dobrovolskaia and co-workers in the case of 30 and $50 \mathrm{~nm}$ AuNPs with $30 \mathrm{~nm}$ particles binding to a greater range of protein species when compared with the $50 \mathrm{~nm}$ particles of similar surface chemistry [313].

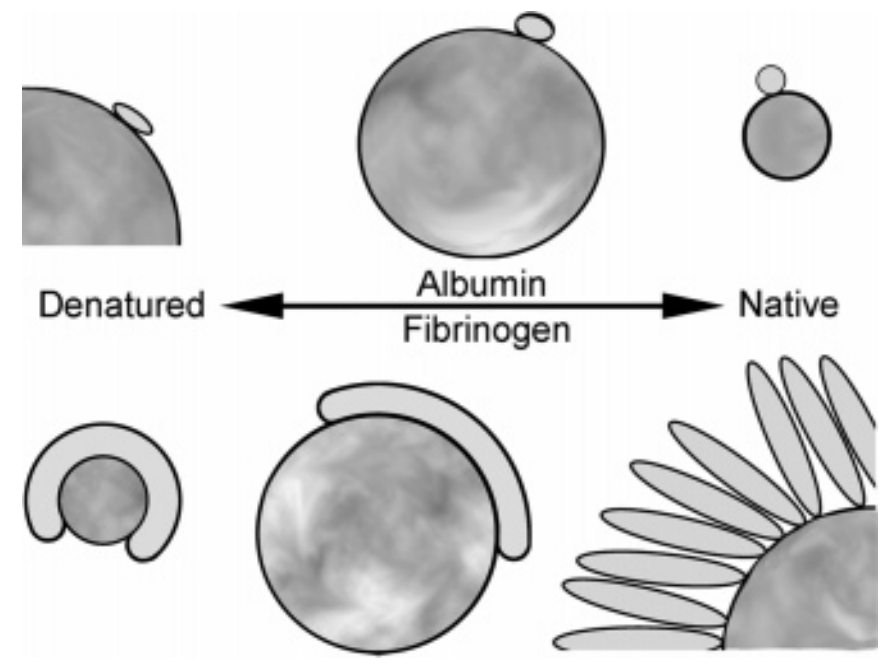

Fig. 17. Schematic showing how the size of a spherical particle (and thus the degree of its surface curvature) can affect the structure of bound proteins. While the structure of albumin becomes increasing disordered after binding to larger silica nanoparticles, fibrinogen becomes increasingly compromised upon binding to smaller particles which possess higher surface curvature. Reprinted with permission from [308]. Copyright 2006 American Chemical Society.

While it is clear that the composition of the corona is influenced by nanoparticle size, the question remains how to maximally manipulate this effect for therapeutical gain. For therapies that rely on long circulation times, avoiding nonspecific uptake of nanoparticles by the immune system, more specifically, the reticuloendothelial system (RES) and the mononuclear phagocyte system (MPS), is critical [283, 314, 315]. It is known that certain proteins within the blood act as flags for the RES and MPS systems; such proteins are termed 
opsonins (and their binding to the nanoparticle surface, opsonisation) and they provide the link between a nanoparticle and its capture by the MPS system [315-318]. Known opsonins include certain immunoglobulins (IgG and $\operatorname{IgM}$ ), specific complement proteins (most notably C3), von Willebrand factor, thrombospondin, fibronectin, and mannose-binding protein. Conversely, other classes of proteins coexist that are deemed dysopsonic due to their opposing effect, suppressing the recognition and elimination of opsonised entities by the RES and MPS. PEGylation or the process of coating an object with linear chains of covalently attached PEG macromolecules is commonly employed for in vivo application of AuNPs to minimise such unwanted effects. As well as improving biocompatibility, PEGylation also decreases the extent of protein adsorption thus decreasing the risk of opsonisation $[182,315$, 319]. The process of PEGylation and its subsequent effect on nanomaterials has already been discussed in a number of outstanding reviews [182, 320-323].

An extensive study in this field performed by Casals and co-workers utilised citrate stabilised AuNPs in sizes ranging from $4-40 \mathrm{~nm}$ to probe the size effect on protein corona formation, with particular emphasis on the density and persistence of both hard and soft coronal states. The group found that $4 \mathrm{~nm}$ AuNPs were not able to form a stable protein corona despite prolonged incubation times, consistent with the hypothesis that particles of this size do not notably activate RES or MPS $[68,306]$. The $10 \mathrm{~nm}$ AuNPs behaved as expected for particles of this size, forming an initial transient soft corona followed by a persistent hard corona at longer incubation times. The largest $40 \mathrm{~nm}$ particles examined in this study initially behaved like $10 \mathrm{~nm}$ particles, forming a soft corona transitioning into a hard corona over time; however the hard corona which formed on the $40 \mathrm{~nm}$ particles was both less dense and less strongly bound compared to the $10 \mathrm{~nm}$ particles. The group concluded that a particle of 10 $\mathrm{nm}$ is ideally sized for optimal protein coverage, being of a comparable size to the most 
abundant serum proteins (albumins) while the $40 \mathrm{~nm}$ particles exceed the ideal size for serum protein binding, and were more prone to opsonisation [68].

In contrast to these trends, Lacerda and co-workers probed the kinetics of specific serum proteins such as albumin, fibrinogen, $\gamma$-globulin, histone and insulin, monitoring their binding on citrate stabilised AuNPs of sizes from 5-100 nm. Their findings highlighted a trend of increasing nanoparticle-protein binding strength with increasing nanoparticle size, until the size reached $60 \mathrm{~nm}$, after which the trend dissipated. The cooperativity of the binding, i.e. the affinity of a particular protein for a nanoparticle after binding by successive proteins, decreased with nanoparticle size in all cases except insulin. These discrepancies draw attention to difficulties encountered by researchers in this area, whereby information gained by examining proteins individually does not necessarily correlate to results obtained in a competitive binding environment [324].

Walkey and co-workers examined citrate stabilised AuNPs ranging in size from 15-90 nm after grafting with $5 \mathrm{kDa}$ PEG on the AuNP surface with varying density. By altering the PEG-AuNP ratio during grafting, PEG densities ranging from $0-1.25 \mathrm{PEG} / \mathrm{nm}^{2}$ were achieved. The study revealed two relationships, viz. a correlation between decreasing AuNP size and increased adsorption of serum proteins, as well as decreased adsorption of serum protein with increasing PEG grafting density. They reasoned that a decrease in nanoparticle size is synonymous with an increase in curvature on the surface of the nanoparticle, allowing better accommodation of PEG molecules with increased space, as opposed to the larger particles that forced a more crowded layer of PEG molecules. The fanned out arrangement of PEG molecules was claimed to lower the thermodynamic barrier for protein adsorption, leading to increased protein binding [309]. 


\begin{tabular}{|c|c|c|c|}
\hline $\begin{array}{ll}\text { AuNP } & \text { size } \\
(\mathbf{n m}) & \end{array}$ & $\begin{array}{l}\text { AuNP } \\
\text { characteristics }\end{array}$ & Conclusion & Reference \\
\hline $\begin{array}{l}5,10,20,30, \\
60,80 \text { and } 100\end{array}$ & $\begin{array}{l}\text { Citrate stabilised } \\
\text { spherical AuNPs }\end{array}$ & $\begin{array}{l}\text { Increased nanoparticle-protein } \\
\text { binding strength observed with } \\
\text { increasing AuNP size (up to } 60 \\
\mathrm{~nm} \text { ). } \\
\text { Cooperativity of binding } \\
\text { decreased with AuNP size in all } \\
\text { cases except insulin. }\end{array}$ & $\begin{array}{l}\text { Lacerda et al. } \\
2009\end{array}$ \\
\hline 30 and 50 & $\begin{array}{l}\text { Citrate stabilised } \\
\text { spherical AuNPs }\end{array}$ & $\begin{array}{l}30 \mathrm{~nm} \text { particles bound to a } \\
\text { greater range of protein species } \\
\text { as compared to the } 50 \mathrm{~nm} \\
\text { particles of similar surface } \\
\text { chemistry. }\end{array}$ & $\begin{array}{l}\text { Dobrovolskaia et } \\
\text { al. [326] } 2009\end{array}$ \\
\hline $\begin{array}{l}4,10,13,16, \\
24, \text { and } 40\end{array}$ & $\begin{array}{l}\text { Citrate stabilised } \\
\text { spherical AuNPs }\end{array}$ & $\begin{array}{l}10 \mathrm{~nm} \text { AuNP is ideally sized for } \\
\text { optimal protein coverage. } \\
40 \mathrm{~nm} \text { AuNP exceeds the ideal } \\
\text { size for serum protein binding. }\end{array}$ & $\begin{array}{l}\text { Casals et al. [68] } \\
2010\end{array}$ \\
\hline $\begin{array}{l}15,30,60 \text {, and } \\
90\end{array}$ & $\begin{array}{l}\text { Citrate stabilised } \\
\text { PEGylated } \\
\text { spherical AuNPs }\end{array}$ & $\begin{array}{l}\text { Decreased AuNP size lead to } \\
\text { increased adsorption of serum } \\
\text { proteins. } \\
\text { Increased PEG grafting density } \\
\text { decreased adsorption of serum } \\
\text { protein. }\end{array}$ & $\begin{array}{l}\text { Walkley et al. } \\
\text { [309] } 2012\end{array}$ \\
\hline $\begin{array}{l}\text { Spheres: } 20 \\
\text { and } 30 \\
\text { Rods: Aspect } \\
\text { ratio } 4 \text { and } 20\end{array}$ & $\begin{array}{l}\text { CTAB capped } \\
\text { spherical and rod } \\
\text { shaped AuNPs }\end{array}$ & $\begin{array}{l}\text { Protein corona formation was } \\
\text { detected on the surface of } \\
\text { AuNPs, regardless of size and } \\
\text { shape. }\end{array}$ & $\begin{array}{l}\text { Mirsadeghi et al. } \\
\text { [327] } 2015\end{array}$ \\
\hline
\end{tabular}

Table 3. Summary of studies examining the effect of AuNP size on protein corona formation.

\subsection{Effect of nanoparticle shape on protein corona formation}

In a similar way that the size of a nanoparticle affects protein corona formation, shape plays an important, albeit less understood role. Much of the shape related effects on protein corona formation are indirectly gained though uptake studies, monitoring cell-nanoparticle interactions and inferring the state of the protein corona from these results $[59,185,280]$. Despite the small number of studies in this area, it is generally agreed that shape affects the manner in which a protein can bind to the surface of a nanoparticle, with the introduction of such features as curvature, flat planes, sharp edges, corners, and pores on various shapes. 
Such features may favour or hinder binding of individual proteins depending on their conformation, or cause them to undergo structural changes [265].

Ramezani and co-workers performed a molecular dynamic simulation to compare the binding of HSA protein to cubic and spherical AuNPs with similar surface areas. The data showed that binding to cubic AuNPs causes the albumin to unfold more significantly than it does with spherical particles. Interestingly, the simulation showed that the distance between HSA molecules on the cubic AuNPs was larger than on the spherical AuNPs, highlighting that the unfolding effect is much stronger for cubic AuNPs than spherical AuNPs. The group also noted changes in the secondary structure of HSA upon binding to cubic particles, an effect not observed with spherical AuNPs. The authors reasoned that the curvature of spherical particles allows proteins to preserve their original structure by permitting greater gyration of the protein after binding, whereas a flat surface (consistent with the facets of a cubic particle) would not allow such movements [328].

Gagner and co-workers synthesised both spherical and rod shaped AuNPs using two enzymes, lysozyme and $\alpha$-chymotrypsin, to monitor the structure and function of proteins after adsorption. They showed that higher density adsorption occurs on the surface of gold nanorods, as compared with spherical AuNPs, which they attributed to the long cylindrical surface of gold nanorods. When examining lysozyme, the group noted a higher degree of secondary structure disruption on rods, as compared with spheres $(15 \%$ and $10 \%$, respectively). Conversely, $\alpha$-chymotrypsin was capable of retaining its secondary structure at low levels of coverage on both shapes, however as coverage became denser; a $40 \%$ loss of secondary structure was detected. Of particular interest is the fact that the change in $\alpha$ chymotrypsin's secondary structure led to an $86 \%$ reduction in activity [329]. 
Focussed on the link between nanoparticle shape and the stability of a bound protein, Asuri and co-workers compared the binding of enzyme soybean peroxidise with the surface of C-60 fullerenes and with flat graphite flakes. The group noted that upon binding to the highly curved surface of the fullerene, the enzyme possessed much greater stability with an enhanced (2.5 times) half-life, leading to enhanced enzymatic activity as compared to the flat supports. The authors hypothesised that the effect of enhanced stability on highly curved surfaces may not be limited to carbon and could apply to other materials including gold [310].

Investigating rod shaped particles, Gagner performed ligand exchange to remove CTAB from the nanoparticle surface, and reasoned that the increased binding they observed on gold nanorods was due to their long cylindrical surface [329]. Conversely, Caswell [330] and Chang [331] (Fig. 18) probed protein binding on as-synthesised rods obtained using CTAB. Both groups found that protein adsorbed preferentially to the ends of the rod shaped particles, and suggested that this may be due to the CTAB being tightly packed on the less highly curved long dimension, which may inhibit protein binding. With this knowledge, Chithrani and Chan examined rods coated with transferrin, a blood plasma protein vital in iron transportation [280]. They found that rods with lower aspect ratios displayed a higher degree of binding compared to rods with high aspect ratios. They reasoned that this finding, in agreement with Casswell and Chang, was due to increased curvature on the ends of the lower aspect ratio rods, and could also lead to more strongly bound proteins in these areas [280].

The effects reported for other materials are consistent with the findings for gold, suggesting that they are true shape effects, and not necessarily related to the core material. Deng and coworkers examined $\mathrm{TiO}_{2}$ nanorods, nanotubes and nanospheres [332]. Consistent with many gold related reports, their results showed that nanospheres bound to higher amounts of protein 
compared to both rods and tubes. The most interesting result was the comparison of protein species found on the $\mathrm{TiO}_{2}$ rods and tubes, with $\mathrm{IgM}$ and $\mathrm{IgG}$ the major constituents of the rod corona, while fibrinogen was the major constituent of the nanotube corona. With immunoglobulins $\operatorname{IgM}$ and $\operatorname{IgG}$ being known opsonins, this study highlights shape to be an important consideration for potentially avoiding nanoparticle detection by the immune system $[265,307]$.

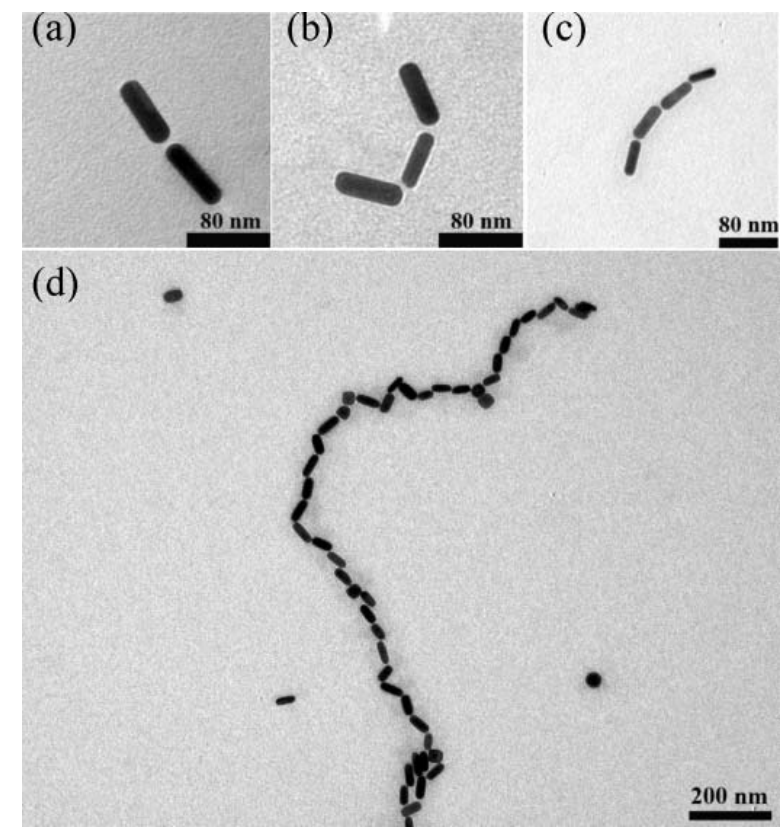

Fig. 18. TEM images of gold nanorods assembled end-to-end after exposure to mouse antibody/antigen biomolecules. By varying the concentration of biomolecules, chains of increasing length are assembled. Reproduced with permission from [331]. Copyright 2005 The Royal Society of Chemistry.

It is possible however that shape may not have such noticeable effects in all settings. One study which did not see any significant shape related effects was conducted by Boulos and co-workers who examined gold nanorods of aspect ratios 3.5 and 18, along with $20 \mathrm{~nm}$ spherical AuNPs. They studied the particles after they were coated with PEG, as well as after a polyelectrolyte coating that was used to recreate the original cationic state seen in CTAB synthesised particles. They found that PEG did not prevent binding of BSA protein to any 
particle, and all PEGylated particles showed cooperative binding regardless of nanoparticle shape. BSA was shown to have a higher affinity for polyelectrolyte coated particles which possessed a strongly positive surface charge, and this remained true of both shapes studied [333].

\begin{tabular}{|c|c|c|c|}
\hline $\begin{array}{l}\text { AuNP } \\
\text { shape }\end{array}$ & AuNP characteristics & Conclusion & Reference \\
\hline $\begin{array}{l}\text { Spheres } \\
\text { and rods }\end{array}$ & $\begin{array}{l}\text { Transferrin coated } 14 \\
\text { and } 50 \mathrm{~nm} \text { spherical } \\
\text { AuNPs. CTAB } \\
\text { stabilised, transferrin } \\
\text { coated AuNRs } 20 \times 30 \text {, } \\
14 \times 50 \text { and } 7 \times 42 \mathrm{~nm}\end{array}$ & $\begin{array}{l}\text { Proteins adsorbed only onto the ends } \\
\text { of the AuNRs due to residual CTAB. } \\
\text { AuNRs with lower aspect ratios } \\
\text { displayed a higher degree of binding } \\
\text { compared to AuNRs with high aspect } \\
\text { ratio }\end{array}$ & $\begin{array}{l}\text { Chithrani and } \\
\text { Chan [280] } \\
2007\end{array}$ \\
\hline $\begin{array}{l}\text { Spheres } \\
\text { and rods }\end{array}$ & $\begin{array}{l}\text { CTAB stabilised 10nm } \\
\text { spheres and } \\
\text { CTAB stabilised } \\
\text { AuNRs } 10 \times 36 \mathrm{~nm}\end{array}$ & $\begin{array}{l}\text { Higher density protein adsorption } \\
\text { occurs on the surface of AuNRs. } \\
\text { More significant lysozyme secondary } \\
\text { structure disruption to observed upon } \\
\text { interaction with AuNRs }\end{array}$ & $\begin{array}{l}\text { Gagner et al. } \\
\text { [329] } 2011\end{array}$ \\
\hline $\begin{array}{l}\text { Spheres } \\
\text { and rods }\end{array}$ & $\begin{array}{l}\text { PEG and } \\
\text { polyelectrolyte coated } \\
\text { 20nm spherical AuNPs } \\
\text { and AuNRs of aspect } \\
\text { ratios } 3.5 \text { and } 18 \text {. }\end{array}$ & $\begin{array}{l}\text { No significant shape related effects } \\
\text { observed }\end{array}$ & $\begin{array}{l}\text { Boulos et al. } \\
\text { [333] } 2013\end{array}$ \\
\hline $\begin{array}{l}\text { Spheres } \\
\text { and cubes }\end{array}$ & $\begin{array}{l}\text { Cubic AuNP with } 80 \\
\mathrm{~nm} \text { side length and } \\
60 \mathrm{~nm} \text { spherical AuNP }\end{array}$ & $\begin{array}{l}\text { Molecular dynamic simulation } \\
\text { showed distance between HSA and } \\
\text { cubic AuNPs was larger than with } \\
\text { spherical AuNPs. Curvature of } \\
\text { spherical particles allows proteins to } \\
\text { preserve their original structure after } \\
\text { binding. }\end{array}$ & $\begin{array}{l}\text { Ramezani et } \\
\text { al. }[328] \\
2014\end{array}$ \\
\hline $\begin{array}{l}\text { Spheres } \\
\text { and rods }\end{array}$ & $\begin{array}{l}\text { CTAB capped AuNPs. } \\
20 \text { and } 30 \mathrm{~nm} \text { spherical } \\
\text { AuNPs. AuNRs of } \\
\text { aspect ratios } 4 \text { and } 20 .\end{array}$ & $\begin{array}{l}\text { Protein corona formation was } \\
\text { observed on the surface of AuNPs, } \\
\text { regardless of size and shape. }\end{array}$ & $\begin{array}{l}\text { Mirsadeghi et } \\
\text { al. }[327] \\
2015\end{array}$ \\
\hline
\end{tabular}

Table 4. Summary of studies examining the effect of AuNP shapes on protein corona formation.

\subsection{Effect of nanoparticle surface characteristics on protein corona formation}

The effect of the surface characteristics of nanoparticles on the formation a protein corona may be examined with varying levels of subtlety. The most fundamental aspect may involve comparison of the protein corona formed around nanoparticles of different inorganic 
compositions. Deng and co-workers analysed the composition of the protein coronas which formed on two commonly used metal oxide particles of comparable size and surface charge, viz. $\mathrm{ZnO}\left(31 \mathrm{~nm}\right.$ diameter, $-24 \mathrm{mV}$ zetapotential) and $\mathrm{TiO}_{2}(30 \mathrm{~nm}$ diameter, $-26 \mathrm{mV}$ zetapotential). The group found that the elemental core of the nanoparticle influenced both the species and concentration of bound proteins with dramatically different coronas elucidated from each nanoparticle [332].

The next layer of subtlety is surface coating or functionalisation, a practice often employed to fine-tune parameters such as biodistribution, circulation, accumulation and clearance of nanoparticles in drug delivery systems [302, 317]. In addition to their study on different sized AuNPs, Casals and co-workers studied the effect that surface functionalisation of AuNPs had on the formation of a protein corona. The group examined the protein coronas that formed on citrate stabilised AuNPs of sizes 4-40 nm, comparing them with those formed after modification of the nanoparticles with a self-assembled monolayer carrying a net positive (aminoundecanethiol) or negative (mercaptoundecanoic acid) charge. The group found that the negatively charged nanoparticles were unable to form a hard corona, with the loosely bound soft corona washing off easily despite an extended incubation period in cell culture medium. Conversely, the positively charge particles formed a soft transient corona more rapidly, driven by electrostatic forces between the positively charged surface and negatively charged proteins in the media. In this case, the soft corona possessed higher stability than the hard corona (formed on the citrate stabilised AuNPs), and was persistent after purification [68].

Exploring the effects of spherical nucleic acid (SNA) nanoparticles, Chinen and co-workers used SNAs with an AuNP core, surface modified with a $3^{\prime}$ thiol-modified guanine-rich sequence to observe if the three-dimensional structure of the oligonucleotides impacted on 
the structure and composition of the proteins that bind to the surface of the particle. The study revealed that the structure of the chosen oligonucleotide can dictate the protein species that binds to the surface. The altered corona was shown to impact on the cellular uptake of the particles, showing increased macrophage uptake. These findings are particularly relevant in terms of nanotherapeutics development, where rapid blood clearance or increased cellular uptake is desired [334].

These findings are consistent with many other groups that have investigated the protein coronas which form on AuNPs after PEGylation. The process is commonly employed for in vivo application of gold nanorods, to avoid the potential toxicity derived from CTAB persistent on the surface after synthesis. While PEGylation of gold nanorods is performed as a way of ensuring biocompatibility, its presence is known to cause a reduction in uptake for the reasons described above. The complications surrounding this depend on the intended fate of the nanoparticle with a potential trade-off between longevity within the bloodstream and the likely degree of uptake. The 'hydrophilic stealth coating' that PEG molecules form around the particle $[309,319,335]$, may protect it from elimination via immune intervention, but may also reduce uptake by cells via the same mechanism $[59,185]$.

Cui and co-workers compared the protein coronas which formed on nanoparticles with various surface modifications, such as citrate, thioglycolic acid, cysteine and PEG with varying molecular weights of 2 and $5 \mathrm{kDa}$. The $5 \mathrm{kDa}$ PEGylated particles were unable to from a protein corona in any of the protein environments studied, while the $2 \mathrm{kDa}$ PEGylated particles showed protein corona formation in BSA, but not with transferrin or fibrinogen [336]. This finding is consistent with the work of Cruje and Chithrani [337] as well as Dobrovolskaia and co-workers [326] who found that the amount of protein bound in the corona may be influenced by the molecular weight (i.e. chain length) of the PEG molecules 
within the AuNP coating, with longer PEG chain lengths consistent with lower levels of protein interaction with the nanoparticle surface (Fig. 19).

Walkey and co-workers compared the protein corona composition between citrate-capped AuNPs and PEGylated citrate-capped AuNPs. Complement protein C3 was detected at levels of $30 \% \mathrm{w} / \mathrm{w}$ on the unmodified AuNPs, reducing to a level of $5 \% \mathrm{w} / \mathrm{w}$ after PEGylation, showing that modification was sufficient to significantly reduce, but not totally eliminate, opsonisation [309].

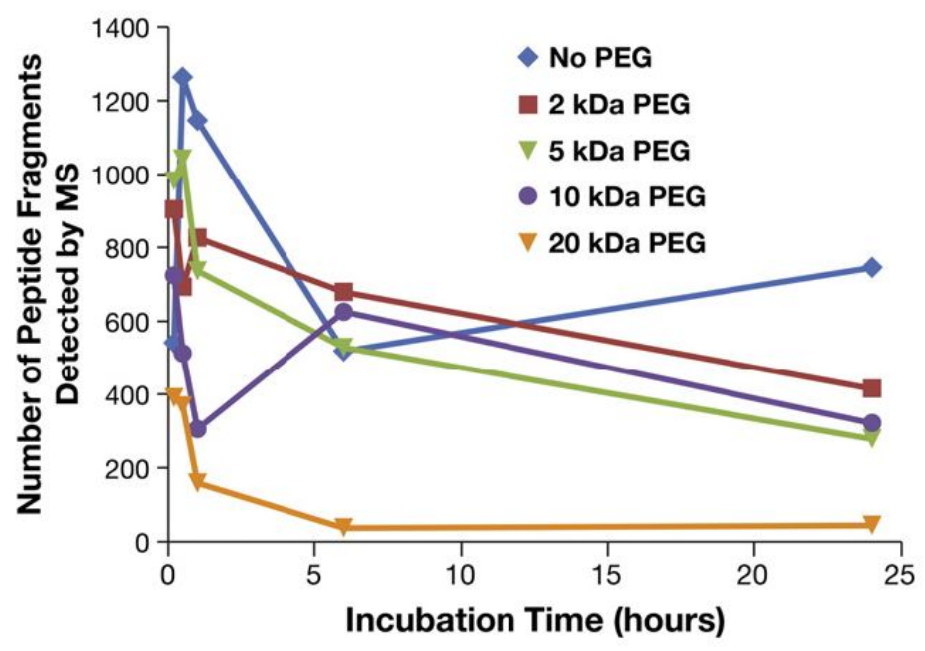

Fig. 19. Graph showing the extent of bound proteins to $30 \mathrm{~nm}$ AuNPs uncoated or coated with PEG molecules of different molecular weights over time. Coating the AuNPs with longer PEG chain lengths leads to lower levels of bound protein. Reprinted with permission from reference [326]. Copyright 2014 Elsevier Inc.

\begin{tabular}{|l|l|l|l|}
\hline $\begin{array}{l}\text { Surface } \\
\text { Functionalisation }\end{array}$ & $\begin{array}{l}\text { AuNP } \\
\text { Characteristics }\end{array}$ & Conclusions & Reference \\
\hline $\begin{array}{l}\text { Citrate AuNPs } \\
\text { modified with } \\
\text { aminoundecanethiol } \\
\text { and } \\
\text { mercaptoundecanoic } \\
\text { acid }\end{array}$ & $\begin{array}{l}\text { 4,10,13, 16, 24, } \\
\text { and 40 nm } \\
\text { spherical AuNPs }\end{array}$ & $\begin{array}{l}\text { Negatively charged AuNPs were } \\
\text { unable to form a hard corona. } \\
\text { Positively charge AuNPs formed a } \\
\text { soft transient corona more rapidly. }\end{array}$ & $\begin{array}{l}\text { Casals } \text { et } \\
\text { al. }[68] \\
2010\end{array}$ \\
\hline Citrate and PEG & $\begin{array}{l}\text { 15,30,60, and } \\
\text { 90nm spherical } \\
\text { AuNPs }\end{array}$ & $\begin{array}{l}\text { Complement protein C3 was } \\
\text { detected at higher levels on } \\
\text { unmodified AuNPs, compared with } \\
\text { PEGylated AuNPs. Modification was }\end{array}$ & $\begin{array}{l}\text { Walkey et } \\
\text { al. [309] }\end{array}$ \\
\hline
\end{tabular}




\begin{tabular}{|l|l|l|l|}
\hline & & $\begin{array}{l}\text { sufficient to significantly reduce, but } \\
\text { not totally eliminate, opsonisation. }\end{array}$ & \\
\hline $\begin{array}{l}\text { Citrate, thioglycolic } \\
\text { acid, cysteine and }\end{array}$ & $\begin{array}{l}38 \mathrm{~nm} \text { spherical } \\
\text { AuNPs }\end{array}$ & $\begin{array}{l}5 \mathrm{kDa} \text { PEGylated particles were } \\
\text { unable to from a protein corona in } \\
\text { any of the protein environments } \\
\text { studied. } \\
\text { 2 kDa PEGylated particles showed } \\
\text { protein corona formation in BSA, but } \\
\text { not with transferrin or fibrinogen }\end{array}$ & $\begin{array}{l}\text { Cui } \text { et al. } \\
\text { [336] 2014 }\end{array}$ \\
\hline $\begin{array}{l}\text { Citrate and lipoic } \\
\text { acid }\end{array}$ & $\begin{array}{l}\text { 40 nm spherical } \\
\text { AuNPs }\end{array}$ & $\begin{array}{l}\text { No significant surface chemistry } \\
\text { related effects. } \\
\text { HSA and IgG formed coronas over } \\
\text { both AuNPs, while fibrinogen caused } \\
\text { agglomeration in both. }\end{array}$ & $\begin{array}{l}\text { Sasidharan } \\
\text { et al. } \text { [338] } \\
\text { 2015 }\end{array}$ \\
\hline
\end{tabular}

Table 5. Summary of studies examining the effect of AuNP surface functionalisation on protein corona formation.

\section{Technological advances in the use of gold nanoparticles}

The use of gold to promote good health has been documented in literature dating back to at least the 1st century, when Pliny detailed its multiple functions in what is now regarded as the one of the earliest encyclopaedias ever compiled - Naturalis Historia [1]. Listed for both its medical and magico-religious properties, gold is described as being both a cure for fistulas, haemorrhoids and warts as well as an amulet to be worn for protection against harmful charms $[1,339]$.

Predating this publication, the use of gold as a purifying tonic or elixir by the Egyptians [2] and more tangibly the appliance of flat gold bands as dental prosthetics by the Etruscans [3] is believed to date back to the thirtieth century B.C. and the seventh century B.C., respectively. The Vedic age of ancient India (ca.1750-500 B.C.) saw gold utilised as a therapy for memory loss, poor eyesight and infertility and since the 8th century the use of Swarnabhasma (swarna means gold, and bhasma means ash) or gold ash (a nanoparticulate form of gold) began, a practice which is still continued by Ayurvedic followers to treat asthma, autoimmune and nervous disorders [340, 341]. During the Renaissance, physician 
and alchemist Paracelsus revived the idea of using gold as a medicine when he created Aurum Potabile, a colloidal gold suspension which he prescribed for sufferers of epilepsy [4].

Today, the use of AuNPs for biotechnological and medical advancement is progressing rapidly with biosensors, bioimaging techniques and therapeutic agents dependant on the unique properties of AuNPs beginning to pass clinical phase trials with countless more in development.

\subsection{Gold nanoparticles as diagnostic agents}

Comprising both in vitro and in vivo applications, the use of AuNPs as biosensors is widespread, owing to the interesting SPR behaviour of AuNPs in varied environments [342]. Some examples of the use of AuNPs include sensors for bacteria [343-345], early cancer markers [346], and specific biomolecular interactions [347].

It is not widely known, but AuNPs have formed the basis of home pregnancy tests such as Carter Wallace's “First Response" since the early 1990's. Utilising the aggregation tendency of AuNPs, the tests combined micrometre sized latex particles and AuNPs functionalised with different epitopes of human chorionic gonadotropin antibodies. When the gonadotropin hormone present in the urine of woman during pregnancy, contacts AuNPs within the sensor, the particles agglomerate forming visible pink aggregates [348]. Working via a similar principle, ImmunoCAP (Phadia, Inc) is a commercially available allergy test which uses whole blood samples to create an immunoglobulin E (IgE) profile [349]. The test is used to differentiate allergy like symptoms (such as bronchospasm, rhinitis, conjunctivitis, eczema, angioedema, and nausea) and helps to provide a clinical diagnosis to a specific allergen. Preloaded with 10 common allergens including pet hair, pollen and dust mites, once blood is added, if IgG antibodies are present in the blood, they bind to the specific sections of the test strip containing the relevant allergen. The developer solution containing dried gold-anti-IgE 
conjugate is then released indicating an allergy to a particular trigger by forming pink/red lines due to the formation of complexes between the AuNPs and bound IgE antibodies. Similar principle is utilised by many other tests for detection of polynucleotides [350], proteins [351], antiproteins [352] and heavy metals [353].

Working via a different principal, SoPRano (ParmaDiagnostics, Belgium) uses localised surface plasmon resonance (LSPR) to detect and quantify binding effects which occur on the surface of AuNPs [354]. Using negatively charged AuNRs, the system can be used to probe biomolecular interaction kinetics, antibody detection and blood brain barrier permeability. By first coating the rods with a biomolecule of interest and exposing them to different concentrations of analyte, the interaction causes a measurable difference in the absorbance value or an LSPR shift, which can be read using an absorbance plate reader.

As an alternative to methods which require a 'lock and key' approach to sensing (where specific recognition between analyte and receptor must takes place), the 'chemical nose' approach uses an array of AuNPs as receptors for protein analysis [355], and clinical diagnostics [356-358]). The technique uses the interaction between a fluorescent polymer and an array of AuNPs with various surface characteristics (such as surface charge and surface functional groups). While the polymer's fluorescence is quenched when attached to the AuNPs, once dissociated through competitive binding of proteins to certain AuNPs, a fluorescence pattern is generated (Fig. 20). This pattern can be analysed to detect individual proteins and differentiate between protein species, giving both quantitative and qualitative data. The Rotello research group has made significant progress in this area, detecting and differentiating between bacterial strains [359], quantifying proteins [355, 360, 361], and identifying cancerous cells [362] [363]. 
a)

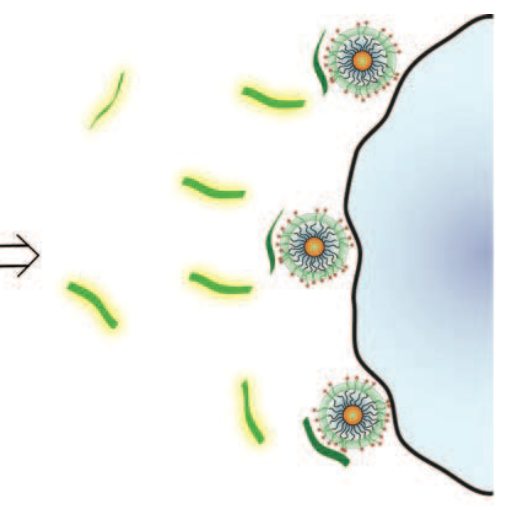

b)

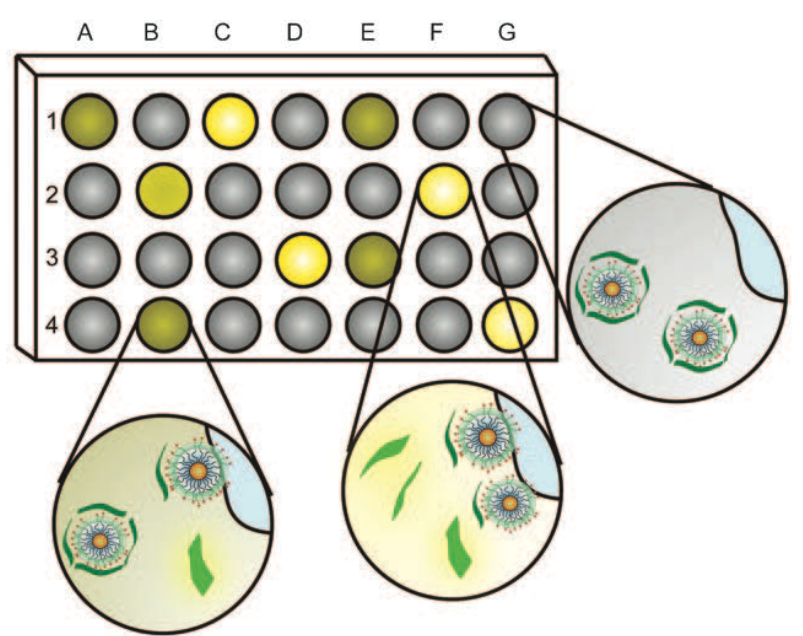

Fig. 20. Schematic depicting a nanoparticle-conjugated polymer sensor array, wherein (a) anionic conjugated polymers bound on to cationic AuNPs are displaced by negatively charged bacteria surfaces, and (b) a fluorescent pattern is generated during the polymer displacement process by the bacteria. Reprinted with permission from [359]. Copyright 2008 John Wiley \& Sons.

Another notable breakthrough in this area is the potential for diagnosis of lung cancer using the exhaled breath of subjects. While most published methods are performed with liquid samples (generally blood), the non-invasive method developed by Peng et al. requires the collection of exhaled air from patients to detect specific volatile organic compounds (VOCs) which have been linked to the presence of lung cancer at certain concentrations [357]. The group has since identified VOCs which are markers for breast, colorectal, prostate, head and neck cancers, and further developed exhaled breath analysis sensors for these VOCs with AuNP arrays [356, 358]. 
Combining the expanding field of genomic medicine with nanodiagnostics, Halo et al. developed the NanoFlare system to detect live cancer cells circulating within the blood. The system, which features a spherical gold nanoparticle conjugated with single-stranded DNA, was found capable of detecting metastatic activity at early stages by attaching to mRNA on the target gene. This binding activity facilitated the release of a fluorescently labelled "reporter flare" which could be detected using flow cytometry down to the single cell level. The significance of this technique extends beyond its diagnostic potential, as following detection assay, the cells could potentially be isolated and cultured allowing genetic analysis of the cancer, a potential breakthrough for personalised medicine. [364]

\begin{tabular}{|c|c|c|c|}
\hline $\begin{array}{l}\text { Diagnostic } \\
\text { Target }\end{array}$ & AuNP & Diagnostic mechanism & Reference \\
\hline $\begin{array}{l}\text { ImmunoCAP } \\
\text { allergy test }\end{array}$ & $\begin{array}{l}\text { AuNPs } \\
\text { functionalised with } \\
\text { anti-IgE conjugates }\end{array}$ & $\begin{array}{l}\text { IgG antibodies present in the blood, } \\
\text { bind to the specific sections of the test } \\
\text { strip containing the relevant allergen. } \\
\text { Allergies are indicated by pink/red } \\
\text { lines due to the formation of a } \\
\text { complex between AuNPs and IgE } \\
\text { antibodies. }\end{array}$ & $\begin{array}{l}\text { Ewan and } \\
\text { Coote [349] } \\
1990\end{array}$ \\
\hline $\begin{array}{l}\text { "First } \\
\text { Response" } \\
\text { pregnancy test }\end{array}$ & $\begin{array}{l}\text { AuNPs } \\
\text { functionalised with } \\
\text { epitopes of human } \\
\text { chorionic } \\
\text { gonadotropin } \\
\text { antibodies }\end{array}$ & $\begin{array}{l}\text { Gonadotropin hormone contacts } \\
\text { AuNPs causing particles } \\
\text { agglomeration forming visible pink } \\
\text { aggregates. }\end{array}$ & $\begin{array}{l}\text { Bangs } \\
{[348] 1996}\end{array}$ \\
\hline $\begin{array}{l}\text { Polynucleotide } \\
\text { detection for } \\
\text { diagnosis of } \\
\text { genetic disease }\end{array}$ & $\begin{array}{l}\text { 13nm spherical } \\
\text { AuNPs modified } \\
\text { with } \\
\text { mercaptoalkyloligo } \\
\text { nucleotide }\end{array}$ & $\begin{array}{l}\text { Multistep process to colorimetrically } \\
\text { detect specific polynucleotides which } \\
\text { form coloured complexes with } \\
\text { mercaptoalkyloligonucleotide } \\
\text { modified AuNPs. }\end{array}$ & $\begin{array}{l}\text { Elghanian } \\
\text { et al. [350] } \\
1997\end{array}$ \\
\hline $\begin{array}{l}\text { Aggregation } \\
\text { based protein } \\
\text { sensor }\end{array}$ & $\begin{array}{l}\text { AuNPs conjugated } \\
\text { with p- } \\
\text { aminophenyl-â-D- } \\
\text { lactopyranoside } \\
\text { (Lac). }\end{array}$ & $\begin{array}{l}\text { Lac-conjugated AuNPs aggregate } \\
\text { when exposed to Recinus } \\
\text { communis indicated by a colour } \\
\text { change from pinkish-red to purple. }\end{array}$ & $\begin{array}{l}\text { Otsuka et } \\
\text { al. }[351] \\
2001\end{array}$ \\
\hline $\begin{array}{l}\text { Colorimetric } \\
\text { detection of } \\
\text { heavy metal } \\
\text { ions }\end{array}$ & $\begin{array}{l}\text { 13nm AuNPs } \\
\text { capped with 11- } \\
\text { mercaptoundecanoi } \\
\text { c acid }\end{array}$ & $\begin{array}{l}\text { Aggregation of AuNPs in the presence } \\
\text { of heavy metals detected by a visible } \\
\text { colour change. }\end{array}$ & $\begin{array}{l}\text { Kim et al. } \\
\text { [353] } 2001\end{array}$ \\
\hline Aggregation & $10 \mathrm{~nm}$ AuNPs & Aggregation of AuNPs in the presence & Thanh and \\
\hline
\end{tabular}




\begin{tabular}{|c|c|c|c|}
\hline $\begin{array}{l}\text { based antibody } \\
\text { sensor. }\end{array}$ & $\begin{array}{l}\text { coated with protein } \\
\text { antigens }\end{array}$ & $\begin{array}{l}\text { of their corresponding antibodies } \\
\text { causes a shift in absorption maximum } \\
\text { from } 620 \mathrm{~nm} \text {. }\end{array}$ & $\begin{array}{l}\text { Rosenzweig } \\
\text { [352] } 2002 .\end{array}$ \\
\hline $\begin{array}{l}\text { Chemical nose } \\
\text { for protein } \\
\text { analysis and } \\
\text { clinical } \\
\text { diagnostics }\end{array}$ & $\begin{array}{l}\text { Array of AuNPs } \\
\text { with varied surface } \\
\text { characteristics } \\
\text { (such as surface } \\
\text { charge and surface } \\
\text { functional groups). }\end{array}$ & $\begin{array}{l}\text { Fluorescence pattern is generated after } \\
\text { the displacement of fluorescent } \\
\text { polymers from the AuNP surface }\end{array}$ & $\begin{array}{l}\text { You et al. } \\
\text { [355] } 2007\end{array}$ \\
\hline $\begin{array}{l}\text { Chemoresistor } \\
\text { breath test for } \\
\text { cancer } \\
\text { diagnosis }\end{array}$ & $\begin{array}{l}\text { 5-nm AuNPs } \\
\text { capped with } \\
\text { different organic } \\
\text { functionalities }\end{array}$ & $\begin{array}{l}\text { Detection of volatile organic } \\
\text { compounds which are markers for } \\
\text { certain cancers by measuring changes } \\
\text { in resistance in the presence of analyte. }\end{array}$ & $\begin{array}{l}\text { Peng et al. } \\
\text { [357] } 2009\end{array}$ \\
\hline $\begin{array}{l}\text { Biomolecular } \\
\text { interaction } \\
\text { kinetics, } \\
\text { antibody } \\
\text { detection and } \\
\text { blood brain } \\
\text { barrier } \\
\text { permeability } \\
\text { probe }\end{array}$ & $\begin{array}{l}\text { SoPRano AuNRs. } \\
\text { Negatively charged } \\
\text { AuNRs with } \\
\text { specific } \\
\text { biomolecular } \\
\text { coating }\end{array}$ & $\begin{array}{l}\text { Interaction between the AuNRs and } \\
\text { analyte causes an LSPR shift, read } \\
\text { using an absorbance plate reader. }\end{array}$ & $\begin{array}{l}\text { Dell et al. } \\
\text { [354] } 2012 .\end{array}$ \\
\hline $\begin{array}{l}\text { Detection of } \\
\text { live cancer } \\
\text { cells within the } \\
\text { blood }\end{array}$ & $\begin{array}{l}\text { NanoFlare } \\
\text { spherical AuNP } \\
\text { conjugated with } \\
\text { single-stranded } \\
\text { DNA }\end{array}$ & $\begin{array}{l}\text { AuNP attached to mRNA on the target } \\
\text { gene. The binding activity facilitates } \\
\text { the release of a fluorescently labelled } \\
\text { "reporter flare" detected using flow } \\
\text { cytometry. }\end{array}$ & $\begin{array}{l}\text { Halo et al. } \\
{[364] 2014}\end{array}$ \\
\hline
\end{tabular}

Table 6. Summary of the application of AuNPs as diagnostic agents.

\subsection{Gold nanoparticles as therapeutic agents}

The area of AuNPs as therapeutic agents is both diverse and rapidly growing. Researchers are attempting to treat HIV [365], bacterial infections [366], inflammations [367] and coronary diseases [368] with AuNP based therapies; however anticancer activities [12, 186, 190, 229, 369-379] forms the bulk of the research. While both aurous $\left.\left(\mathrm{Au}^{\mathrm{I}}\right]\right)$ and auric $\left(\mathrm{Au}^{\mathrm{III}}\right)$ gold complexes are commonplace in pharmaceuticals $[380,381][273,382]$, the prevalence of AuNP $\left(\mathrm{Au}^{0}\right)$ based therapies is far less common. Presented in this review are the AuNP based therapies that are approaching or have progressed to clinical trial phase. 
Possibly the first AuNP based therapy to reach (and pass) Phase I clinical trials, CYT-6091 is a $27 \mathrm{~nm}$ citrate stabilised AuNP surface functionalised with both tumour necrosis factor- $\alpha$ (TNF- $\alpha$ ) and thiolated PEG [377]. The antitumor effects of TNF- $\alpha$ (more specifically recombinant human TNF - rhTNF) have been known for decades; however its severe toxicity in humans has previously limited its dosage [379]. TNF- $\alpha$ acts in multiple capacities acts as a proinflammatory cytokine, to disrupt tumour vasculature and when used in combination with chemotherapy, allows the subsequent treatment to penetrate tumours more effectively eliciting greater results. The therapy first developed in 2004 by researchers as Aurimune by CytImmune Sciences Inc. (Rockville, MD, USA) [191] achieves circumvention of RES uptake, leading to increased circulation time in part due to its surface PEGylation, which was also shown to reduce the expected toxicity of rhTNF, and increased its accumulation inside the tumours rather than in the surrounding tissues. This study used thiolated AuNPs as the vehicle for the therapy due to the strong binding affinity for rhTNF, noting that the AuNP bound rhTNF had a 5 fold longer half-life in plasma than native rhTNF. It was also noted that AuNPs restricted the biodistribution of the treatment, showing greater specificity for targeted tumour sites, and their notable absence in healthy tissues. This allowed higher doses to be administered with reduced incidence of adverse side effects and systemic toxicity. After progressing through Phase I clinical trials, CYT-6091 is proposed to be next used to treat non-small lung cancer in combination with chemotherapy as part of Phase II trials [377].

Harnessing the SPR effects of AuNPs, researchers are employing plasmonic phototherapy to treat cardiovascular disease as an alternative to statin based therapy. Notably while statin therapy is successful in lowering cholesterol, its effectiveness in inducing atheroma (plaque) regression is less clear [383]. The research group led by Khalamov developed a plasmonic nanophotothermic treatment consisting of allogenic stem cells containing gold-coated silica nanoparticles [384]. The human study, which was preceded by an animal study using 
miniature swine [368] recruited 180 patients, of which 60 were given the silica-AuNP treatment to allow comparison to more conventional techniques. The nanoparticles were administered through a patch implanted into the affected artery and 7 days post-surgery, irradiation of the particles with near-infrared (NIR) irradiation took place $(821 \mathrm{~nm}, 35-44$ $\mathrm{W} / \mathrm{cm}^{2}, 7$ minutes). Due to the maximum light absorption by these particles in the NIR region, the absorbed photo-energy is converted into thermal energy, which in turn burns the surrounding tissues; in this case, the atheroma. This technique, which is referred to as nanoburning, saw success in Phase I trials with significant atheroma regression observed, though the second planned trial has been discontinued [385].

Cofounded by Naomi Halas, part of the team responsible for the invention of gold nanoshells for NIR therapy [386], Nanospectra Biosciences Inc. (Houston, TX) has focused their efforts over the past decade on the development of AuroLase therapy. The photothermal therapy which utilises AuroShell particles comprising of a $120 \mathrm{~nm}$ silica core surrounded by a $15 \mathrm{~nm}$ outer gold shell is used in combination with NIR irradiation to treat head and neck tumours. The nanoparticle treatment is delivered intravenously and shows accumulation in solid tumours due to the enhanced permeability and retention (EPR) effect of solid tumours because of their abnormally formed vasculature and poor drainage [387]. After sufficient accumulation of AuroShells (generally occurring 12-24 hours post-infusion), the area is illuminated by an $808 \mathrm{~nm}$ wavelength laser causing the nanoparticles to heat up, effectively burning the tumour. The FDA-approved pilot study was completed showing promising results with Phase II trials planned to target metastatic lung cancer [388].

Besides phototherapy, radioisotopes of gold have also been exploited for imaging and therapy of cancers. The low $\left(\mathrm{Au}^{199}: \beta_{\max }-0.46 \mathrm{MeV}\right.$; half-life - 2.7 days $)$, and moderate $\left(\mathrm{Au}^{198}: \beta_{\max }-\right.$ $0.96 \mathrm{keV}$; half-life 3.2 days) energy beta particles emitting isotopes, due to their desirable 
half-life characteristics offer ideal opportunities for radioimaging $\left(\mathrm{Au}^{199}\right)$ and therapy $\left(\mathrm{Au}^{198}\right)$. To circumvent the limitations associated with traditional metal based radiopharmaceuticals, nanoparticles of gold have been employed as radioactive probe for imaging and radiotherapy of solid tumours [389]. Several groups have demonstrated the utility of radioactive AuNPsbased nanodevices in targeted radiopharmaceutical dose delivery to the tumours [53, 98, 390]. In a pioneering study, Shukla et al recently reported a AuNPs-based targeted radiopharmaceutical approach towards radiotherapy of prostate cancer [53]. This method demonstrated rapid, room temperature synthesis of ${ }^{198}$ AuNPs using epigallocatechin gallate (EGCG), a clinically-approved phytochemical from green tea. These EGCG-reduced radioactive AuNPs were amenable to facile manipulation of radioactive dosage within the nanoparticle matrix, offering a simple tool with potential for clinical translation. Since EGCG can target a $67 \mathrm{KDa}$ receptor protein (Lam 67R) overexpressed on cancer cells, these nanoparticles exhibited selective uptake in prostate cancer cells. These nanoparticles showed remarkable stability in blood plasma and a desirable biodistribution profile in prostate tumour bearing mice, leading to $\sim 80 \%$ reduction in tumour volume. The levels of white blood cells, red blood cells, platelets and lymphocytes were found comparable to the control groups, thus supporting high therapeutic efficacy of these radioactive ${ }^{198}$ AuNPs.

\begin{tabular}{|c|c|c|c|}
\hline $\begin{array}{l}\text { Therapeutic } \\
\text { Target }\end{array}$ & AuNP & Therapeutic mechanism & Reference \\
\hline $\begin{array}{l}\text { NIR irradiation } \\
\text { to treat head and } \\
\text { neck tumours }\end{array}$ & $\begin{array}{l}\text { AuroShell }-120 \mathrm{~nm} \\
\text { silica core particle } \\
\text { surrounded by a } 15 \\
\mathrm{~nm} \text { outer gold shell }\end{array}$ & $\begin{array}{l}\text { Following intravenous nanoparticle } \\
\text { administration, particles } \\
\text { accumulate in solid tumours due to } \\
\text { the enhanced permeability and } \\
\text { retention (EPR) effect. } \\
\text { After sufficient accumulation of } \\
\text { AuroShells (generally occurring } \\
12-24 \text { hours post-infusion), the area } \\
\text { is illuminated by an } 808 \text { nm laser } \\
\text { causing the nanoparticles to heat } \\
\text { and burning the tumour tissue. }\end{array}$ & $\begin{array}{l}\text { Averitt et } \\
\text { al. }[386] \\
1997\end{array}$ \\
\hline $\begin{array}{l}\text { CYT- } 6091 \text { for } \\
\text { the treatment of }\end{array}$ & $\begin{array}{l}27 \text { nm citrate } \\
\text { stabilised AuNP, }\end{array}$ & $\begin{array}{l}\text { In this formulation, antitumor agent } \\
\text { TNF- } \alpha \text { is less toxic, has decreased }\end{array}$ & $\begin{array}{l}\text { Paciotti et } \\
\text { al. }[191]\end{array}$ \\
\hline
\end{tabular}




\begin{tabular}{|c|c|c|c|}
\hline $\begin{array}{l}\text { advanced stage } \\
\text { nonresectable } \\
\text { cancers }\end{array}$ & $\begin{array}{l}\text { surface functionalised } \\
\text { with TNF- } \alpha \text { and } \\
\text { thiolated PEG }\end{array}$ & $\begin{array}{l}\text { circulation time, and evades RES } \\
\text { uptake due to the surface } \\
\text { PEGylation of the AuNPs. }\end{array}$ & $\begin{array}{l}2004 \\
\text { Libutti et al. } \\
\text { [377] } 2010\end{array}$ \\
\hline $\begin{array}{l}\text { Plasmonic } \\
\text { phototherapy } \\
\text { for the } \\
\text { treatment of } \\
\text { cardiovascular } \\
\text { disease }\end{array}$ & $\begin{array}{l}\text { Allogenic stem cells } \\
\text { containing gold- } \\
\text { coated silica } \\
\text { nanoparticles }\end{array}$ & $\begin{array}{l}\text { AuNPs administered through a } \\
\text { patch implanted into the artery are } \\
\text { activated using NIR irradiation. } \\
\text { The absorbed energy burns the } \\
\text { surrounding tissues /atheroma. }\end{array}$ & $\begin{array}{l}\text { Kharlamov } \\
\text { et al. }[384] \\
2010\end{array}$ \\
\hline $\begin{array}{l}\text { Targeted } \\
\text { radiopharmaceu } \\
\text { tical treatment } \\
\text { of prostate } \\
\text { cancer }\end{array}$ & $\begin{array}{l}\text { EGCG-reduced } \\
\text { radioactive }{ }^{198} \text { AuNPs }\end{array}$ & $\begin{array}{l}\text { EGCG targets } 67 \text { KDa receptor } \\
\text { protein (Lam } 67 \mathrm{R} \text { ) overexpressed } \\
\text { on cancer cells, allowing selective } \\
\text { uptake in prostate cancer cells }\end{array}$ & $\begin{array}{l}\text { Shukla et } \\
\text { al. }[56] \\
2012\end{array}$ \\
\hline $\begin{array}{l}\text { Photothermally } \\
\text { active LiposAu } \\
\text { NPs for the } \\
\text { tumour ablation. }\end{array}$ & $\begin{array}{l}100-120 \mathrm{~nm} \text { gold } \\
\text { coated liposomes }\end{array}$ & $\begin{array}{l}\text { Target-non-specific LiposAu NPs } \\
\text { tuned to an absorbance range of } \\
750 \mathrm{~nm} \text { are intravenously injected. } \\
\text { Target site laser irradiated to kill } \\
\text { cancer cells. LiposAu NPs are } \\
\text { shown to degrade into smaller } \\
\text { particles to allow their excretion. }\end{array}$ & $\begin{array}{l}\text { Rengan et } \\
\text { al. [391] } \\
2015\end{array}$ \\
\hline
\end{tabular}

Table 7. Summary of the application of AuNPs as therapeutic agents.

\subsection{Gold nanoparticles as bioimaging agents}

The use of gold as an immunostaining agent was first documented in 1971 when Faulk and Taylor used antibody coated AuNPs to visualise specific antigens using TEM [392]. Relying on the 'lock and key' mechanisms of antibody-antigen interactions in combination with the high electron density properties of gold, immunolabelling methods have expanded with multiple labelling possibilities (using different sized AuNPs) [393], and adaptations have been made for visualisation using SEM [394, 395] and dark field microscopy [374].

The use of AuNPs as an alternative to iodine based contrast agents was discovered serendipitously by Wilhelm Röntgen in 1895 when taking an X-ray of a subject wearing a gold ring [396]. Gold, both in its nano and macro forms, exhibits high X-ray attenuation due to its high electron density [397, 398] (Fig. 21); however AuNPs offer additional enhanced permeability and retention effects inside tumour regions, unique SPR effects and are able to 
be surface functionalised to target specific tissues or organs, making it possible to combine imaging with therapeutic treatment. X-ray computed tomography (CT) imaging creates detailed structural scans of the body by exploiting the natural variation in X-ray absorption between different tissues [399]. The use of traditional contrast agents for CT imaging (typically iodine based) has allowed contrast to be created artificially in areas where it does not naturally exist. However, the downfalls with iodine-based CT contrast agents include low retention time, nephrotoxicity, thyroid gland abnormalities and anaphylaxis [400-402]. Further, the use of AuNPs as contrast agents is not limited to CT scanning and can extend to optical coherence tomography [403] and photoacoustic tomography [404].

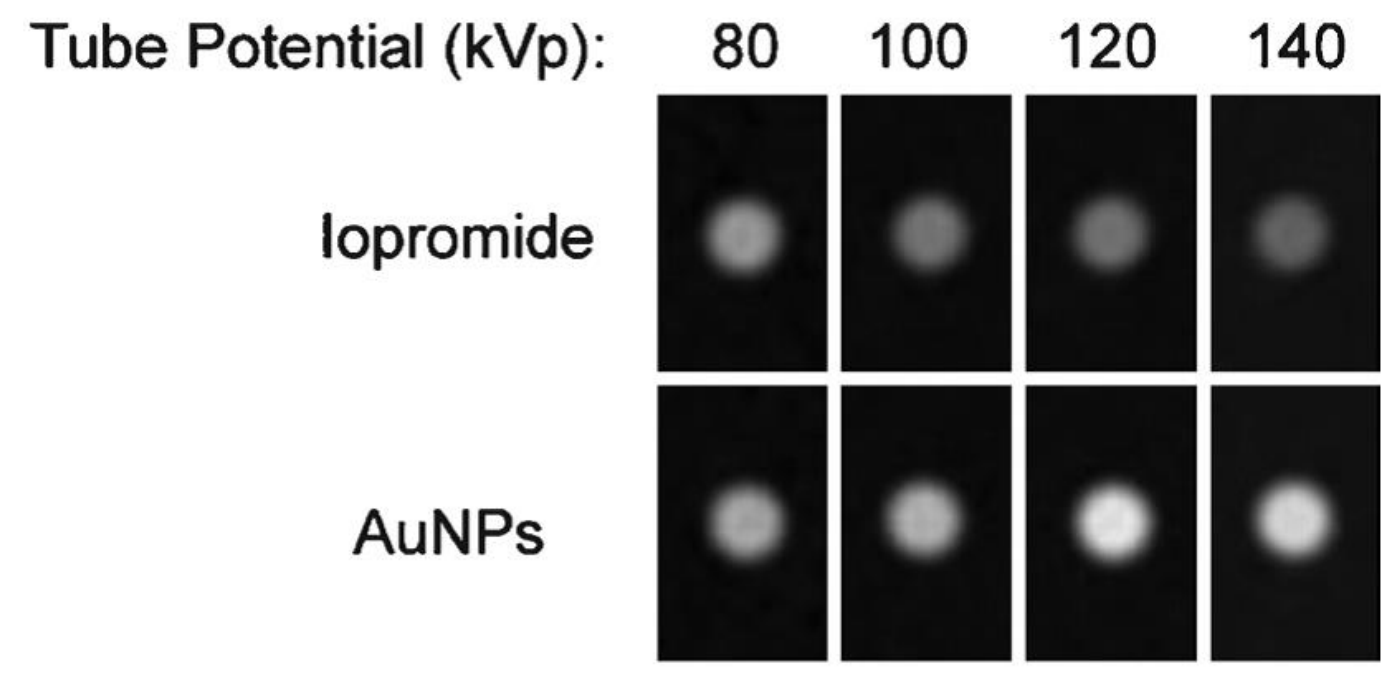

Fig. 21. CT images comparing Iopromide (commercial iodinated imaging agent) and AuNPs. Contrast agents are compared over a range of tube potentials (energy and intensity of the $X$ ray beam) with AuNPs showing superior contrast in all conditions tested. Reprinted with permission from [405]. Copyright 2010 Elsevier Inc.

With sufficient work on the efficacy of AuNPs as bioimaging agents in vitro, many groups are testing AuNP based imaging agents on animal models in vivo [66, 141, 184, 282, 401]. CT imaging of the liver is an important tool for the diagnosis, treatment and monitoring of cancer as it is a common site for secondary cancer presentation. However resolution of the livers microstructure is difficult, even with the use of conventional contrast agents [406]. 
Specifically, iodinated contrast agents exhibit low levels of liver uptake, demonstrating the demand for target (tissue or organ) specific contrast agents. Sun and co-workers created AuNPs surface modified with heparin, a naturally occurring biomolecule with anticoagulant properties, to compare their performance with a commercial iodinated contrast agent. The heparin modified AuNPs displayed liver specificity [406, 407], allowing for differentiation of liver tissues and clear visualisation of vessels less than $1 \mathrm{~mm}$ in diameter. In contrast, the iodine based agent provided markedly ( 3.2 fold) less contrast. The mice received a dosage of $200 \mathrm{~mL}$ of a $250 \mathrm{mg} \mathrm{Au} / \mathrm{kg}$ solution in this study, as these AuNPs preparation were found to be biocompatible to human hepatocellular liver carcinoma (HepG2) cells to the levels of 100 $\mathrm{mg} / \mathrm{mL}$ [406]. The authors acknowledge that while promising, extensive cytotoxicity testing is necessary for the progress of this technology.

Alternatively, researchers have used AuNPs to improve the short imaging window associated with iodinated CT contrast agents due to their low circulation times [401, 402]. By PEGcoating AuNPs to elude RES uptake, when injected into rats the PEGylated AuNPs demonstrated an X-ray absorption coefficient 5.7 times higher than a commercial iodinated CT contrast agent, as well as a blood circulation time 4 hours longer. While this study noted accumulation of AuNPs in the spleen and liver, there was no appreciable toxicity seen for up to one month, nor was toxicity observed after conducting an MTT test on human hepatocellular liver carcinoma (HepG2) cells using concentrations of the particles higher than the expected therapeutic dose levels [401].

To demonstrate this point further, Au et al. tested the circulation time of PEGylated AuNPs in vivo using mice. After injecting the mice with either PEGylated AuNPs or an iodinated contrast agent, the mice were CT imaged immediately and after 6 and 24 hours. While PEGylated particles showed clear contrast which continued to the last time point of the 
experiment at 24 hours, the iodinated contrast provided sufficient contrast immediately, failing at the subsequent 6 and 24 hour time points [408]. This study highlights the use of AuNPs for prolonged and delayed imaging of subjects which could be useful for real time imaging during procedures.

The ability to combine cancer diagnostics and therapeutics into a single process is a goal currently pursued by many research groups [371, 374, 376, 378, 409]. By harnessing the SPR capabilities of AuNPs, the idea of imaging and delivering photothermal treatment using one diagnostic tool may become a reality in the near future. The research group led by El-Sayad employs gold nanorods of a chosen aspect ratio which strongly absorb and scatter light in the NIR region after surface modifying them with anti-epidermal growth factor receptor (antiEGFR) monoclonal antibodies. Due to the high expression of EGFR on the surface of malignant cells, the rods were observed to have $>2$-fold higher uptake by malignant cells (oral epithelial cell lines HOC 313 clone 8 and HSC 3) versus non-malignant cells (human epithelial cells (HaCaT). Because of the increased uptake of AuNPs and thus strong light scattering capability, the malignant cells were clearly visible using dark field microscopy. Furthermore photothermal treatment using an $800 \mathrm{~nm}$ laser required half the dose to kill the malignant cells as compared with non-malignant cells. Similar results were obtained using folic acid functionalised AuNPs to target epithelial cancer cells by Bhattacharya et al. [229] and bombesin functionalised AuNPs to target breast and prostate cancer by Chanda et al. [178].

Inspired by such promising results, Niidome and co-workers performed an in vivo study of PEGylated and CTAB stabilised AuNRs to determine their cytotoxicity and biodistribution after intravenous delivery into mice. Using human cervical cells (HeLa) the cytotoxicity of PEGylated AuNRs was found to be very low, with $\sim 90 \%$ cell viability at doses of $0.5 \mathrm{mM}$ in 
contrast to the high cytotoxicity observed with CTAB stabilised AuNRs (which were only washed to remove free $\mathrm{CTAB}$ once). The group then injected the tail veins of mice with either PEGylated or CTAB stabilised AuNRs. After specific time points the animals were sacrificed, with their blood and organs collected and tested for gold content to determine the biodistribution of AuNRs. While CTAB stabilised rods were found primarily in the liver after 30 minutes $(\sim 30 \%$ of injected dose $),<10 \%$ of the injected dose was present in the blood. PEGylated AuNRs in contrast had prolonged circulation time with 54\% of the injected dose found in the blood after 30 minutes. This level decreased over time, until being completely removed from circulation at 72 hours. At this time $35 \%$ of the injected dose was found inside the liver while only a small amount was detected in the other organs tested (lung, spleen and kidney) [282]. This demonstrates the importance of surface functionalisation in terms of achieving controlled biodistribution of AuNPs, while supporting the efficacy of PEG for evading RES uptake of AuNPs. In combination with PEGylation, targeted surface decoration of AuNPs could create tailored imaging and photothermal systems to treat various cancers.

\begin{tabular}{|l|l|l|l|}
\hline $\begin{array}{l}\text { Bioimaging } \\
\text { application }\end{array}$ & AuNP & Bioimaging advantages & Reference \\
\hline $\begin{array}{l}\text { Molecular } \\
\text { imaging and } \\
\text { photothermal } \\
\text { cancer } \\
\text { therapy }\end{array}$ & $\begin{array}{l}\text { AuNRs of } \\
\text { aspect ratio 3.9 } \\
\text { conjugated with } \\
\text { anti-EGFR } \\
\text { monoclonal } \\
\text { antibodies. }\end{array}$ & $\begin{array}{l}\text { AuNRs show higher affinity for } \\
\text { malignant cells due to an } \\
\text { overexpression of EGFR. } \\
\text { Increased uptake and strong light } \\
\text { scattering capability, allow malignant } \\
\text { cells to be visualised using dark field } \\
\text { microscopy. }\end{array}$ & $\begin{array}{l}\text { Huang } \text { et al. } \\
{[374] 2006}\end{array}$ \\
\hline $\begin{array}{l}\text { Targeted } \\
\text { delivery of } \\
\text { anticancer } \\
\text { drugs, tumour } \\
\text { imaging, and } \\
\text { tumour ablation }\end{array}$ & $\begin{array}{l}\text { 5nm AuNPs } \\
\text { functionalised } \\
\text { with folic acid } \\
\text { and various PEG } \\
\text { backbones. }\end{array}$ & $\begin{array}{l}\text { AuNPs are preferentially taken up by } \\
\text { ovarian cancer and myeloma cell lines } \\
\text { which show over expression of folate } \\
\text { receptors (FR). }\end{array}$ & $\begin{array}{l}\text { Bhattacharya } \\
\text { et al. } \text { 229] } \\
\text { 2007 }\end{array}$ \\
\hline $\begin{array}{l}\text { CT imaging of } \\
\text { the liver }\end{array}$ & $\begin{array}{l}\text { PEG-coated } \\
\text { 30nm spherical } \\
\text { AuNPs }\end{array}$ & $\begin{array}{l}\text { PEGylated AuNPs demonstrate higher } \\
\text { X-ray absorption coefficient and longer } \\
\text { blood circulation time compared with } \\
\text { traditional CT contrast agents. }\end{array}$ & $\begin{array}{l}\text { Kim et al. } \\
\text { [401] 2007 }\end{array}$ \\
\hline $\begin{array}{l}\text { In vivo } \\
\text { molecular }\end{array}$ & $\begin{array}{l}\text { CTAB stabilised } \\
\text { AuNRs (aspect }\end{array}$ & $\begin{array}{l}\text { Bombesin AuNRs show increased } \\
\text { affinity for prostate and breast cancer }\end{array}$ & $\begin{array}{l}\text { Chanda } \text { et al. } \\
\text { [178] 2009 }\end{array}$ \\
\hline
\end{tabular}




\begin{tabular}{|c|c|c|c|}
\hline $\begin{array}{l}\text { imaging for } \\
\text { breast and } \\
\text { prostate cancers }\end{array}$ & $\begin{array}{l}\text { ratio } 3.1) \text {, } \\
\text { conjugated with } \\
\text { bombesin } \\
\text { peptides. }\end{array}$ & $\begin{array}{l}\text { cells which show overexpression of } \\
\text { gastrin releasing peptide receptors. }\end{array}$ & \\
\hline $\begin{array}{l}\text { CT imaging of } \\
\text { the liver }\end{array}$ & $\begin{array}{l}\text { Heparin } \\
\text { modified AuNPs }\end{array}$ & $\begin{array}{l}\text { Traditional iodinated contrast agents } \\
\text { exhibit low levels of liver uptake, while } \\
\text { heparin modified AuNPs display liver } \\
\text { specificity to provide clearer } \\
\text { visualisation. }\end{array}$ & $\begin{array}{l}\text { Sun et al. } \\
\text { [406] } 2009\end{array}$ \\
\hline $\begin{array}{l}\text { Long time scale } \\
\text { CT imaging }\end{array}$ & $\begin{array}{l}14,18, \text { and } 21 \\
\text { nm PEG-coated } \\
\text { AuNPs }\end{array}$ & $\begin{array}{l}\text { AuNPs provided clear contrast for } 4 \\
\text { times longer than traditional CT } \\
\text { contrast agents. Potentially important } \\
\text { factor for real time surgical imaging. }\end{array}$ & $\begin{array}{l}\text { Au et al. } \\
\text { [408] } 2013\end{array}$ \\
\hline $\begin{array}{l}\text { Single cell } \\
\text { imaging }\end{array}$ & $\begin{array}{l}\text { DNA modified } \\
42 \mathrm{~nm} \text { spherical } \\
\text { AuNPs with } \\
\text { various } \\
\text { PEGylation and } \\
\text { peptide surface } \\
\text { modifications to } \\
\text { target specific } \\
\text { cellular sites. }\end{array}$ & $\begin{array}{l}\text { SERS intensity of AuNPs allows live } \\
\text { cell visualised of dynamic cellular } \\
\text { changes which can employed for } \\
\text { applications such as drug and stimulus } \\
\text { response measurements. }\end{array}$ & $\begin{array}{l}\text { Kang et al. } \\
\text { [410] } 2015\end{array}$ \\
\hline
\end{tabular}

Table 8. Summary of the applications of AuNPs as bioimaging agents.

\section{Summary and outlook}

Overall, this Review has provided a critical analysis of different AuNPs synthesis methods, while assessing relevant biological studies to highlight emerging trends in AuNPs uptake and toxicity. Among different nanomaterials, AuNPs undoubtedly show some of the most interesting physico-chemical properties that make them useful for a number of biological applications including medical imaging $[139,141,183,184,378]$, therapy $[12,53,142,179$, $369,378,390]$, diagnostics [55, 180, 190, 194, 195, 411], biosensing [70, 412, 413] as well as gene $[188,192,414-416]$ and drug delivery $[142,186,189,191]$. Some of the major driving forces for their consistent interest in biomedical applications are that AuNPs appear to be well tolerated in biological systems causing minimal cytotoxicity, while providing opportunities for facile surface manipulations as well as exhibiting interesting optical properties. A major focus of this review has been to ignite a critical discussion around the 
influence of different physico-chemical properties of AuNPs on their biological activity. The ability to finely tune these properties of AuNPs by controlling the synthesis process puts great power in the hands of researchers by allowing them to tailor particles specifically for their intended purpose. While there seems to be some concerns about practical in vivo applicability of AuNPs due to potential metal accumulation in the body, such concerns have not been thoroughly validated through long-term in vivo studies. It is only recently that the importance of such studies has been recognised and research community has more seriously started to investigate the influence of various in vivo factors such as spontaneous protein corona formation on nanoparticles in response to in vivo exposure. In authors' opinion, among various aspects of research involving use of AuNPs for nanomedicine, an in-depth understanding of dynamic biological corona formation on AuNP surface on their exposure to biological fluid, remains the cornerstone of achieving clinically translatable therapies. New knowledge gained from nanoparticle-protein corona dynamic interactions will not only lead the way forward for tailor designed AuNP-based in vivo therapies; they will also offer equally valuable opportunities to take in vitro applications of AuNPs such as diagnostics to a commercialisation stage. The authors foresee that the impact of such studies on in vitro applications is likely to be more significant, as bioaccumulation and long-term cytotoxicity issues of gold outside the body are of least concern. Further, while the versatility of AuNP usage for biological applications remains undeniable, the scientific literature regularly shows conflicting outcomes in regards to gold-bio interactions. To overcome this inconsistency, a set of guiding principles need to be developed so that only appropriate assays are used to assess the toxicity of AuNPs; careful assessment of surface corona is performed before correlating biological action to nanoparticle surface chemistry; and the change in surface chemistry of AuNPs is carefully considered on exposure to biological fluids, whether under in vitro or under in vivo conditions. Such guiding principles will allow researchers to be able 
to predict the toxicity, uptake and action profile of AuNPs of different sizes, shapes and surface chemistry without necessarily warranting extensive testing. Overall, this Review has provided a critical analysis of different AuNPs synthesis methods, while assessing relevant biological studies to highlight emerging trends in AuNPs uptake and toxicity. The authors are hopeful that this review will ignite a critical discussion around new ways of assessing nanomaterial toxicity, while paying close attention to the influence of biological corona formed on the nanomaterial surface during their exposure to the biological world.

\section{Acknowledgements}

V.B. thanks the valuable support of Ian Potter Foundation in establishing an Ian Potter NanoBioSensing Facility at RMIT University. Research funding support by the Australian Research Council in the form of a Future Fellowship to V.B. (FT140101285) and Linkage Grants to V.B. and R.S. (LP130100437) is also acknowledged. The authors acknowledge the facilities, and the scientific and technical assistance of the Australian Microscopy \& Microanalysis Research Facility at the RMIT Microscopy \& Microanalysis Facility.

\section{References}

1. Healey, J., Natural History. 1991: Penguin Books Limited.

2. Venable, S.L., Gold : a cultural encyclopedia. 2011, ABC-CLIO: Santa Barbara, California. p. 34-35.

3. Becker, M.J., Etruscan Gold Dental Appliances: Three Newly "Discovered" Examples. American Journal of Archaeology, 1999. 103(1): p. 103-111.

4. Nagender Reddy, P., P.-M. Eladia Maria, and H. Josef, Gold and nano-gold in medicine: overview, toxicology and perspectives. Journal of Applied Biomedicine, 2009. 7(2): p. 75-91.

5. Jana, N.R. and X. Peng, Single-phase and gram-scale routes toward nearly monodisperse $\mathrm{Au}$ and other noble metal nanocrystals. Journal of the American Chemical Society, 2003. 125(47): p. 14280-14281.

6. Faraday, M., The Bakerian Lecture: Experimental Relations of Gold (and Other Metals) to Light. Philosophical Transactions of the Royal Society of London, 1857. 147: p. 145-181.

7. Millstone, J.E., et al., Colloidal Gold and Silver Triangular Nanoprisms. Small, 2009. 5(6): p. 646-664. 
8. Thomas, K. and P. Sayre, Research Strategies for Safety Evaluation of Nanomaterials, Part I: Evaluating the Human Health Implications of Exposure to Nanoscale Materials. Toxicological Sciences, 2005. 87(2): p. 316-321.

9. Edwards, P.P. and J.M. Thomas, Gold in a metallic divided state - From Faraday to present-day nanoscience. Angewandte Chemie-International Edition, 2007. 46(29): p. 5480-5486.

10. Nhung, T.T., Y. Bu, and S.W. Lee, Facile synthesis of chitosan-mediated gold nanoflowers as surface-enhanced Raman scattering (SERS) substrates. Journal of Crystal Growth, 2013. 373: p. 132-137.

11. Song, H.M., L. Deng, and N.M. Khashab, Intracellular surface-enhanced Raman scattering (SERS) with thermally stable gold nanoflowers grown from Pt and Pd seeds. Nanoscale, 2013. 5(10): p. 4321-4329.

12. Beqa, L., et al., Gold Nano-Popcorn Attached SWCNT Hybrid Nanomaterial for Targeted Diagnosis and Photothermal Therapy of Human Breast Cancer Cells. Acs Applied Materials \& Interfaces, 2011. 3(9): p. 3316-3324.

13. Roduner, E., Size matters: why nanomaterials are different. Chemical Society Reviews, 2006. 35(7): p. 583-592.

14. Kumar, D., et al., Gold nanoparticles: an era in bionanotechnology. Expert Opinion on Drug Delivery, 2013. 10(3): p. 397-409.

15. Buffat, P. and J.P. Borel, Size effect on the melting temperature of gold particles. Physical Review A, 1976. 13(6): p. 2287-2298.

16. Bansal, V., et al., Room-temperature biosynthesis of ferroelectric barium titanate nanoparticles. Journal of the American Chemical Society, 2006. 128(36): p. 1195811963.

17. Bharde, A., et al., Extracellular biosynthesis of magnetite using fungi. Small, 2006. 2(1): p. 135-141.

18. Pearson, A., et al., Comparison of nanostructures obtained from galvanic replacement in water and an ionic liquid for applications in electrocatalysis and SERS. Electrochemistry Communications, 2012. 25(1): p. 87-90.

19. Pearson, A., et al., Synthesis of CuTCNQ/Au Microrods by Galvanic Replacement of Semiconducting Phase I CuTCNQ with KAuBr4 in Aqueous Medium. Inorganic Chemistry, 2012. 51(16): p. 8791-8801.

20. Pearson, A., et al., Galvanic replacement of semiconductor phase i CuTCNQ microrods with $\mathrm{KAuBr} 4$ to fabricate CuTCNQ/Au nanocomposites with photocatalytic properties. Inorganic Chemistry, 2011. 50(5): p. 1705-1712.

21. Pearson, A., et al., Galvanic replacement mediated transformation of Ag nanospheres into dendritic Au-Ag nanostructures in the ionic liquid [BMIM][BF4]. Chemical Communications, 2010. 46(5): p. 731-733.

22. Bansal, V., A.P. O'Mullane, and S.K. Bhargava, Galvanic replacement mediated synthesis of hollow Pt nanocatalysts: Significance of residual Ag for the H2 evolution reaction. Electrochemistry Communications, 2009. 11(8): p. 1639-1642.

23. Bansal, V., et al., Galvanic replacement reaction on metal films: A one-step approach to create nanoporous surfaces for catalysis. Advanced Materials, 2008. 20(4): p. 717723.

24. Plowman, B.J., et al., Electrocatalytic and SERS activity of $P t$ rich $P t-P b$ nanostructures formed via the utilisation of in-situ underpotential deposition of lead. Journal of Solid State Electrochemistry, 2014. 18(12): p. 3345-3357.

25. Pearson, A., et al., Combining the UV-switchability of Keggin ions with a galvanic replacement process to fabricate TiO2-polyoxometalate-bimetal nanocomposites for 
improved surface enhanced raman scattering and solar light photocatalysis. ACS Applied Materials and Interfaces, 2013. 5(15): p. 7007-7013.

26. Pearson, A., et al., Gold nanoparticle-decorated keggin ions/TiO2 photococatalyst for improved solar light photocatalysis. Langmuir, 2011. 27(11): p. 6661-6667.

27. Pearson, A., S.K. Bhargava, and V. Bansal, UV-switchable polyoxometalate sandwiched between TiO2 and metal nanoparticles for enhanced visible and solar light photococatalysis. Langmuir, 2011. 27(15): p. 9245-9252.

28. Campbell, J.L., et al., Quasi-cubic magnetite/silica core-shell nanoparticles as enhanced mri contrast agents for cancer imaging. PLoS ONE, 2011. 6(7).

29. Sawant, P.D., et al., In-depth nano-scale analysis of complex interactions of $\mathrm{Hg}$ with gold nanostructures using AFM-based power spectrum density method. Physical Chemistry Chemical Physics, 2009. 11(14): p. 2374-2378.

30. O'Mullane, A.P., et al., Premonolayer oxidation of nanostructured gold: An important factor influencing electrocatalytic activity. Langmuir, 2009. 25(6): p. 3845-3852.

31. Ramanathan, R. and V. Bansal, Ionic liquid mediated synthesis of nitrogen, carbon and fluorine-codoped rutile TiO2 nanorods for improved $U V$ and visible light photocatalysis. RSC Advances, 2015. 5(2): p. 1424-1429.

32. Kelly, K.L., et al., The Optical Properties of Metal Nanoparticles: The Influence of Size, Shape, and Dielectric Environment. The Journal of Physical Chemistry B, 2002. 107(3): p. 668-677.

33. Kandjani, A.E., et al., Zinc oxide/silver nanoarrays as reusable SERS substrates with controllable 'hot-spots' for highly reproducible molecular sensing. Journal of Colloid and Interface Science, 2014. 436: p. 251-257.

34. Pearson, A., et al., Decoration of TiO 2 nanotubes with metal nanoparticles using polyoxometalate as a UV-switchable reducing agent for enhanced visible and solar light photocatalysis. Langmuir, 2012. 28(40): p. 14470-14475.

35. Ramanathan, R., et al., Aqueous phase synthesis of copper nanoparticles: A link between heavy metal resistance and nanoparticle synthesis ability in bacterial systems. Nanoscale, 2013. 5(6): p. 2300-2306.

36. Link, S. and M.A. El-Sayed, Optical properties and ultrafast dynamics of metallic nanocrystals. Annual Review of Physical Chemistry, 2003. 54: p. 331-366.

37. Eustis, S. and M.A. El-Sayed, Why gold nanoparticles are more precious than pretty gold: Noble metal surface plasmon resonance and its enhancement of the radiative and nonradiative properties of nanocrystals of different shapes. Chemical Society Reviews, 2006. 35(3): p. 209-217.

38. Joshi, H., et al., Isothermal titration calorimetry studies on the binding of amino acids to gold nanoparticles. Journal of Physical Chemistry B, 2004. 108(31): p. 1153511540.

39. Selvakannan, P., et al., Probing the effect of charge transfer enhancement in off resonance mode SERS via conjugation of the probe dye between silver nanoparticles and metal substrates. Physical Chemistry Chemical Physics, 2013. 15(31): p. 1292012929.

40. Sadek, A.Z., et al., Facile, size-controlled deposition of highly dispersed gold nanoparticles on nitrogen carbon nanotubes for hydrogen sensing. Sensors and Actuators, B: Chemical, 2011. 160(1): p. 1034-1042.

41. Sharma, V., K. Park, and M. Srinivasarao, Colloidal dispersion of gold nanorods: Historical background, optical properties, seed-mediated synthesis, shape separation and self-assembly. Materials Science \& Engineering R-Reports, 2009. 65(1-3): p. 1-38.

42. El-Sayed, M.A., Some interesting properties of metals confined in time and nanometer space of different shapes. Accounts of Chemical Research, 2001. 34(4): p. 257-264. 
43. Harris, N., et al., Tunable infrared absorption by metal nanoparticles: the case for gold rods and shells. Gold Bull, 2008. 41(1): p. 5-14.

44. Xia, Y. and N.J. Halas, Shape-controlled synthesis and surface plasmonic properties of metallic nanostructures. MRS bulletin, 2005. 30(05): p. 338-348.

45. Ringe, E., et al., Plasmon Length: A Universal Parameter to Describe Size Effects in Gold Nanoparticles. The Journal of Physical Chemistry Letters, 2012. 3(11): p. 14791483.

46. Demeritte, T., et al., Highly efficient SERS substrate for direct detection of explosive TNT using popcorn-shaped gold nanoparticle-functionalized SWCNT hybrid. Analyst, 2012. 137(21): p. 5041-5045.

47. Durr, N.J., et al., Two-Photon Luminescence Imaging of Cancer Cells Using Molecularly Targeted Gold Nanorods. Nano Letters, 2007. 7(4): p. 941-945.

48. $\mathrm{Hu}$, J.Q., Z.P. Wang, and J.H. Li, Gold nanoparticles with special shapes: Controlled synthesis, surface-enhanced Raman scattering, and the application in biodetection. Sensors, 2007. 7(12): p. 3299-3311.

49. Wani, I.A. and T. Ahmad, Size and shape dependant antifungal activity of gold nanoparticles: A case study of Candida. Colloids and Surfaces B: Biointerfaces. 101(0): p. 162-170.

50. Sabri, Y.M., et al., Mercury vapor sensor enhancement by nanostructured gold deposited on nickel surfaces using galvanic replacement reactions. Journal of Materials Chemistry, 2012. 22(40): p. 21395-21404.

51. Sabri, Y.M., et al., Creating gold nanoprisms directly on quartz crystal microbalance electrodes for mercury vapor sensing. Nanotechnology, 2011. 22(30).

52. Chrimes, A.F., et al., Active control of silver nanoparticles spacing using dielectrophoresis for surface-enhanced Raman scattering. Analytical Chemistry, 2012. 84(9): p. 4029-4035.

53. Shukla, R., et al., Laminin receptor specific therapeutic gold nanoparticles (198AuNP$E G C g)$ show efficacy in treating prostate cancer. Proceedings of the National Academy of Sciences U S A, 2012. 109(31): p. 12426-31.

54. Viator, J.A., et al., Gold nanoparticle mediated detection of prostate cancer cells using photoacoustic flowmetry with optical reflectance. Journal of Biomedical Nanotechnology, 2010. 6(2): p. 187-191.

55. El-Sayed, I.H., X.H. Huang, and M.A. El-Sayed, Surface plasmon resonance scattering and absorption of anti-EGFR antibody conjugated gold nanoparticles in cancer diagnostics: Applications in oral cancer. Nano Letters, 2005. 5(5): p. 829-834.

56. Shukla, R., et al., Biocompatibility of Gold Nanoparticles and Their Endocytotic Fate Inside the Cellular Compartment: A Microscopic Overview. Langmuir, 2005. 21(23): p. 10644-10654.

57. Lewinski, N., V. Colvin, and R. Drezek, Cytotoxicity of Nanoparticles. Small, 2008. 4(1): p. 26-49.

58. Mahl, D., et al., Gold nanoparticles: dispersibility in biological media and cellbiological effect. Journal of Materials Chemistry, 2010. 20(29): p. 6176-6181.

59. Chithrani, B.D., A.A. Ghazani, and W.C.W. Chan, Determining the size and shape dependence of gold nanoparticle uptake into mammalian cells. Nano Letters, 2006. 6(4): p. 662-668.

60. Schaeublin, N.M., et al., Does Shape Matter? Bioeffects of Gold Nanomaterials in a Human Skin Cell Model. Langmuir, 2012. 28(6): p. 3248-3258.

61. Tarantola, M., et al., Toxicity of gold-nanoparticles: Synergistic effects of shape and surface functionalization on micromotility of epithelial cells. Nanotoxicology, 2011. 5(2): p. 254-268. 
62. Wang, S., et al., Challenge in understanding size and shape dependent toxicity of gold nanomaterials in human skin keratinocytes. Chemical Physics Letters, 2008. 463(1-3): p. 145-149.

63. Hillyer, J.F. and R.M. Albrecht, Gastrointestinal persorption and tissue distribution of differently sized colloidal gold nanoparticles. Journal of pharmaceutical sciences, 2001. 90(12): p. 1927-1936.

64. Alkilany, A.M. and C.J. Murphy, Toxicity and cellular uptake of gold nanoparticles: what we have learned so far? Journal of Nanoparticle Research, 2010. 12(7): p. 23132333.

65. Khlebtsov, N. and L. Dykman, Biodistribution and toxicity of engineered gold nanoparticles: a review of in vitro and in vivo studies. Chemical Society Reviews, 2011. 40(3): p. 1647-1671.

66. Lasagna-Reeves, C., et al., Bioaccumulation and toxicity of gold nanoparticles after repeated administration in mice. Biochemical and Biophysical Research Communications, 2010. 393(4): p. 649-655.

67. Fischer, H.C. and W.C.W. Chan, Nanotoxicity: the growing need for in vivo study. Current Opinion in Biotechnology, 2007. 18(6): p. 565-571.

68. Casals, E., et al., Time Evolution of the Nanoparticle Protein Corona. Acs Nano, 2010. 4(7): p. 3623-3632.

69. Turkevich, J., P.C. Stevenson, and J. Hillier, The formation of colloidal gold. Journal of Physical Chemistry, 1953. 57(7): p. 670-673.

70. Zhao, P.X., N. Li, and D. Astruc, State of the art in gold nanoparticle synthesis. Coordination Chemistry Reviews, 2013. 257(3-4): p. 638-665.

71. Kumar, S., K.S. Gandhi, and R. Kumar, Modeling of formation of gold nanoparticles by citrate method. Industrial \& Engineering Chemistry Research, 2007. 46(10): p. 3128-3136.

72. Frens, G., Controlled nucleation for regulation of particle-size in monodisperse gold suspensions. Nature-Physical Science, 1973. 241(105): p. 20-22.

73. Giersig, M. and P. Mulvaney, Preparation of ordered colloid monolayers by electrophoretic deposition. Langmuir, 1993. 9(12): p. 3408-3413.

74. Brust, M., et al., Synthesis of thiol-derivatised gold nanoparticles in a two-phase liquid-liquid system. J. Chem. Soc., Chem. Commun., 1994(7): p. 801-802.

75. Brust, M., et al., Synthesis and reactions of functionalised gold nanoparticles. J. Chem. Soc., Chem. Commun., 1995(16): p. 1655-1656.

76. Slot, J.W. and H.J. Geuze, A new method of preparing gold probes for multiplelabeling cytochemistry. European journal of cell biology, 1985. 38(1): p. 87-93.

77. Johnson, C.J., et al., Growth and form of gold nanorods prepared by seed-mediated, surfactant-directed synthesis. Journal of Materials Chemistry, 2002. 12(6): p. 17651770.

78. Liu, M. and P. Guyot-Sionnest, Mechanism of silver(I)-assisted growth of gold nanorods and bipyramids. J Phys Chem B, 2005. 109(47): p. 22192-200.

79. Nikoobakht, B. and M.A. El-Sayed, Preparation and growth mechanism of gold nanorods (NRs) using seed-mediated growth method. Chemistry of Materials, 2003. 15(10): p. 1957-1962.

80. Dong, S., et al., Photochemical synthesis of gold nanoparticles by the sunlight radiation using a seeding approach. Gold Bulletin, 2004. 37(3-4): p. 187-195.

81. Yang, G.W., Laser Ablation in Liquids: Principles and Applications in the Preparation of Nanomaterials. 2012: p. Xxi-Xxiii.

82. Shankar, S.S., et al., Biological synthesis of triangular gold nanoprisms. Nat Mater, 2004. 3(7): p. 482-488. 
83. Bansal, V., et al., Fungus-mediated biosynthesis of silica and titania particles. Journal of Materials Chemistry, 2005. 15(26): p. 2583-2589.

84. Ramanathan, R., et al., Bacterial Kinetics-Controlled Shape-Directed Biosynthesis of Silver Nanoplates Using Morganella psychrotolerans. Langmuir, 2011. 27(2): p. 714719.

85. Wang, Z., et al., DNA-Mediated Control of Metal Nanoparticle Shape: One-Pot Synthesis and Cellular Uptake of Highly Stable and Functional Gold Nanoflowers. Nano Letters, 2010. 10(5): p. 1886-1891.

86. Bansal, V., et al., Biosynthesis of zirconia nanoparticles using the fungus Fusarium oxysporum. Journal of Materials Chemistry, 2004. 14(22): p. 3303-3305.

87. Bansal, V., et al., Bioleaching of sand by the fungus fusarium oxysporum as a means of producing extracellular silica nanoparticles. Advanced Materials, 2005. 17(7): p. 889892.

88. Sanyal, A., et al., Heavy-metal remediation by a fungus as a means of production of lead and cadmium carbonate crystals. Langmuir, 2005. 21(16): p. 7220-7224.

89. Bansal, V., A. Ahmad, and M. Sastry, Fungus-mediated biotransformation of amorphous silica in rice husk to nanocrystalline silica. Journal of the American Chemical Society, 2006. 128(43): p. 14059-14066.

90. Bansal, V., et al., Zirconia enrichment in zircon sand by selective fungus-mediated bioleaching of silica. Langmuir, 2007. 23(9): p. 4993-4998.

91. Soni, S.K., et al., Self-assembled enzyme capsules in ionic liquid [BMIM][BF4] as templating nanoreactors for hollow silica nanocontainers. Langmuir, 2010. 26(20): p. 16020-16024.

92. Parikh, R.Y., et al., Genus-wide physicochemical evidence of extracellular crystalline silver nanoparticles biosynthesis by morganella spp. PLoS ONE, 2011. 6(6).

93. Ramanathan, R., et al., Cationic amino acids specific biomimetic silicification in ionic liquid: A quest to understand the formation of 3-D structures in diatoms. PLoS ONE, 2011. 6(3).

94. Soni, S.K., et al., Self-assembled histidine acid phosphatase nanocapsules in ionic liquid [BMIM][BF4] as functional templates for hollow metal nanoparticles. Langmuir, 2012. 28(28): p. 10389-10397.

95. Shukla, R., et al., Soybeans as a phytochemical reservoir for the production and stabilization of biocompatible gold nanoparticles. Small, 2008. 4(9): p. 1425-1436.

96. Katti, K., et al., Green Nanotechnology from Cumin Phytochemicals: Generation of Biocompatible Gold Nanoparticles. International Journal of Green Nanotechnology Biomedicine, 2009. 1(1): p. B39-B52.

97. Nune, S.K., et al., Green Nanotechnology from Tea: Phytochemicals in Tea as Building Blocks for Production of Biocompatible Gold Nanoparticles. Journal of Materials Chemistry, 2009. 19(19): p. 2912-2920.

98. Chanda, N., et al., Radioactive gold nanoparticles in cancer therapy: therapeutic efficacy studies of GA- 198AuNP nanoconstruct in prostate tumor-bearing mice. Nanomedicine: Nanotechnology, Biology, and Medicine, 2010. 6(2): p. 201-209.

99. Du, L., et al., Biosynthesis of gold nanoparticles assisted by Escherichia coli DH5 $\alpha$ and its application on direct electrochemistry of hemoglobin. Electrochemistry Communications, 2007. 9(5): p. 1165-1170.

100. Ahmad, A., et al., Intracellular synthesis of gold nanoparticles by a novel alkalotolerant actinomycete, Rhodococcus species. Nanotechnology, 2003. 14(7): p. 824. 
101. Ahmad, A., et al., Extracellular Biosynthesis of Monodisperse Gold Nanoparticles by a Novel Extremophilic Actinomycete, Thermomonospora sp. Langmuir, 2003. 19(8): p. 3550-3553.

102. Thakkar, K.N., S.S. Mhatre, and R.Y. Parikh, Biological synthesis of metallic nanoparticles. Nanomedicine: Nanotechnology, Biology and Medicine, 2010. 6(2): p. 257-262.

103. Kumar, V. and S.K. Yadav, Plant-mediated synthesis of silver and gold nanoparticles and their applications. Journal of Chemical Technology \& Biotechnology, 2009. 84(2): p. 151-157.

104. Durán, N., et al., Mechanistic aspects in the biogenic synthesis of extracellular metal nanoparticles by peptides, bacteria, fungi, and plants. Applied Microbiology and Biotechnology, 2011. 90(5): p. 1609-1624.

105. Mittal, A.K., Y. Chisti, and U.C. Banerjee, Synthesis of metallic nanoparticles using plant extracts. Biotechnology Advances, 2013. 31(2): p. 346-356.

106. Bansal, V., et al., Inorganic materials using 'unusual' microorganisms. Advances in Colloid and Interface Science, 2012. 179-182(0): p. 150-168.

107. Bansal, V., R. Ramanathan, and S.K. Bhargava, Fungus-mediated biological approaches towards 'green' synthesis of oxide nanomaterials. Australian Journal of Chemistry, 2011. 64(3): p. 279-293.

108. Schmid, G., Large clusters and colloids. Metals in the embryonic state. Chemical Reviews, 1992. 92(8): p. 1709-1727.

109. Esumi, K., K. Matsuhisa, and K. Torigoe, Preparation of Rodlike Gold Particles by UV Irradiation Using Cationic Micelles as a Template. Langmuir, 1995. 11(9): p. 32853287.

110. Itakura, T., K. Torigoe, and K. Esumi, Preparation and characterization of ultrafine metal particles in ethanol by UV irradiation using a photoinitiator. Langmuir, 1995. 11(10): p. 4129-4134.

111. Zhou, Y., et al., A novel ultraviolet irradiation technique for shape-controlled synthesis of gold nanoparticles at room temperature. Chemistry of materials, 1999. 11(9): p. 2310-2312.

112. Sau, T.K., et al., Size Controlled Synthesis of Gold Nanoparticles using Photochemically Prepared Seed Particles. Journal of Nanoparticle Research, 2001. 3(4): p. 257-261.

113. Jana, N.R., L. Gearheart, and C.J. Murphy, Seeding Growth for Size Control of 5-40 $n m$ Diameter Gold Nanoparticles. Langmuir, 2001. 17(22): p. 6782-6786.

114. Rodríguez-Fernández, J., et al., Seeded growth of submicron Au colloids with quadrupole plasmon resonance modes. Langmuir, 2006. 22(16): p. 7007-7010.

115. Bastús, N.G., J. Comenge, and V. Puntes, Kinetically controlled seeded growth synthesis of citrate-stabilized gold nanoparticles of up to $200 \mathrm{~nm}$ : size focusing versus Ostwald ripening. Langmuir, 2011. 27(17): p. 11098-11105.

116. Kojima, C., et al., X-ray computed tomography contrast agents prepared by seeded growth of gold nanoparticles in PEGylated dendrimer. Nanotechnology, 2010. 21(24): p. 245104.

117. Ziegler, C. and A. Eychmuller, Seeded growth synthesis of uniform gold nanoparticles with diameters of 15- $300 \mathrm{~nm}$. The Journal of Physical Chemistry C, 2011. 115(11): p. 4502-4506.

118. Song, J.Y., H.-K. Jang, and B.S. Kim, Biological synthesis of gold nanoparticles using Magnolia kobus and Diopyros kaki leaf extracts. Process Biochemistry, 2009. 44(10): p. 1133-1138. 
119. Hiramatsu, H. and F.E. Osterloh, A Simple Large-Scale Synthesis of Nearly Monodisperse Gold and Silver Nanoparticles with Adjustable Sizes and with Exchangeable Surfactants. Chemistry of Materials, 2004. 16(13): p. 2509-2511.

120. Yu, et al., Gold Nanorods: Electrochemical Synthesis and Optical Properties. The Journal of Physical Chemistry B, 1997. 101(34): p. 6661-6664.

121. Wang, Z.L., et al., Crystallographic facets and shapes of gold nanorods of different aspect ratios. Surface Science, 1999. 440(1-2): p. L809-L814.

122. Mohamed, M.B., et al., Thermal reshaping of gold nanorods in micelles. The Journal of Physical Chemistry B, 1998. 102(47): p. 9370-9374.

123. Jana, N.R., L. Gearheart, and C.J. Murphy, Wet Chemical Synthesis of High Aspect Ratio Cylindrical Gold Nanorods. The Journal of Physical Chemistry B, 2001. 105(19): p. 4065-4067.

124. Jana, N.R., L. Gearheart, and C.J. Murphy, Seed-Mediated Growth Approach for Shape-Controlled Synthesis of Spheroidal and Rod-like Gold Nanoparticles Using a Surfactant Template. Advanced Materials, 2001. 13(18): p. 1389-1393.

125. Jana, N.R., L. Gearheart, and C.J. Murphy, Wet chemical synthesis of silver nanorods and nanowires of controllable aspect ratio. Chemical Communications, 2001(7): p. 617-618.

126. Gao, J., C.M. Bender, and C.J. Murphy, Dependence of the Gold Nanorod Aspect Ratio on the Nature of the Directing Surfactant in Aqueous Solution. Langmuir, 2003. 19(21): p. 9065-9070.

127. Gole, A. and C.J. Murphy, Seed-Mediated Synthesis of Gold Nanorods: Role of the Size and Nature of the Seed. Chemistry of Materials, 2004. 16(19): p. 3633-3640.

128. Murphy, C.J., et al., Anisotropic Metal Nanoparticles: Synthesis, Assembly, and Optical Applications. The Journal of Physical Chemistry B, 2005. 109(29): p. 1385713870.

129. Jin, R., et al., Controlling anisotropic nanoparticle growth through plasmon excitation. Nature, 2003. 425(6957): p. 487-490.

130. Xue, C., et al., Mechanistic Study of Photomediated Triangular Silver Nanoprism Growth. Journal of the American Chemical Society, 2008. 130(26): p. 8337-8344.

131. Métraux, G.S. and C.A. Mirkin, Rapid thermal synthesis of silver nanoprisms with chemically tailorable thickness. Advanced Materials, 2005. 17(4): p. 412-415.

132. Ha, T.H., H.-J. Koo, and B.H. Chung, Shape-Controlled Syntheses of Gold Nanoprisms and Nanorods Influenced by Specific Adsorption of Halide Ions. The Journal of Physical Chemistry C, 2006. 111(3): p. 1123-1130.

133. Chandran, S.P., et al., Synthesis of Gold Nanotriangles and Silver Nanoparticles Using Aloevera Plant Extract. Biotechnology Progress, 2006. 22(2): p. 577-583.

134. Shankar, S.S., et al., Controlling the optical properties of lemongrass extract synthesized gold nanotriangles and potential application in infrared-absorbing optical coatings. Chemistry of Materials, 2005. 17(3): p. 566-572.

135. Rai, A., et al., Role of halide ions and temperature on the morphology of biologically synthesized gold nanotriangles. Langmuir, 2006. 22(2): p. 736-41.

136. Millstone, J.E., G.S. Métraux, and C.A. Mirkin, Controlling the Edge Length of Gold Nanoprisms via a Seed-Mediated Approach. Advanced Functional Materials, 2006. 16(9): p. 1209-1214.

137. Millstone, J.E., et al., Observation of a Quadrupole Plasmon Mode for a Colloidal Solution of Gold Nanoprisms. Journal of the American Chemical Society, 2005. 127(15): p. 5312-5313.

138. Millstone, J.E., et al., Iodide Ions Control Seed-Mediated Growth of Anisotropic Gold Nanoparticles. Nano Letters, 2008. 8(8): p. 2526-2529. 
139. Zhu, J., et al., Synthesis of PEGylated gold nanorods (Au NRs) as absorption nanoprobes for near-infrared optical imaging. RSC Advances, 2013. 3(30): p. 1228012286.

140. Jain, P.K., et al., Calculated Absorption and Scattering Properties of Gold Nanoparticles of Different Size, Shape, and Composition: Applications in Biological Imaging and Biomedicine. The Journal of Physical Chemistry B, 2006. 110(14): p. 7238-7248.

141. Weissleder, R., A clearer vision for in vivo imaging. Nat Biotechnol, 2001. 19(4): p. 316-7.

142. Alkilany, A.M., et al., Gold nanorods: Their potential for photothermal therapeutics and drug delivery, tempered by the complexity of their biological interactions. Advanced Drug Delivery Reviews, 2012. 64(2): p. 190-199.

143. Plowman, B., et al., Gold nanospikes formed through a simple electrochemical route with high electrocatalytic and surface enhanced Raman scattering activity. Chemical Communications, 2009(33): p. 5039-5041.

144. Tao, A.R., S. Habas, and P. Yang, Shape Control of Colloidal Metal Nanocrystals. Small, 2008. 4(3): p. 310-325.

145. Khan, Z., et al., Au(III)-CTAB reduction by ascorbic acid: Preparation and characterization of gold nanoparticles. Colloids and Surfaces B: Biointerfaces, 2013. 104(0): p. 11-17.

146. Simoes, M., M.O. Pereira, and M.J. Vieira, Action of a cationic surfactant on the activity and removal of bacterial biofilms formed under different flow regimes. Water Research, 2005. 39(2-3): p. 478-486.

147. Amaral, M.H., et al., Foamability of Detergent Solutions Prepared with Different Types of Surfactants and Waters. Journal of Surfactants and Detergents, 2008. 11(4): p. 275278.

148. Lush. Lush Fresh Handmade Cosmetics. 2014 [cited 2014 17/04/2014]; Ingredient: Cetrimonium Bromide]. Available from: https://www.lush.co.uk/cetrimonium-bromide.

149. Grzelczak, M., et al., Shape control in gold nanoparticle synthesis. Chemical Society Reviews, 2008. 37(9): p. 1783-1791.

150. Nikoobakht, B. and M.A. El-Sayed, Evidence for Bilayer Assembly of Cationic Surfactants on the Surface of Gold Nanorods. Langmuir, 2001. 17(20): p. 6368-6374.

151. Alkilany, A.M. and C.J. Murphy, Gold Nanoparticles with a Polymerizable Surfactant Bilayer: Synthesis, Polymerization, and Stability Evaluation $\%$ Langmuir, 2009. 25(24): p. 13874-13879.

152. Bullen, C., et al., Chemical Kinetics of Gold Nanorod Growth in Aqueous CTAB Solutions. Crystal Growth \& Design, 2011. 11(8): p. 3375-3380.

153. Smith, D.K. and B.A. Korgel, The Importance of the CTAB Surfactant on the Colloidal Seed-Mediated Synthesis of Gold Nanorods. Langmuir, 2008. 24(3): p. 644-649.

154. Busbee, B.D., S.O. Obare, and C.J. Murphy, An Improved Synthesis of High-AspectRatio Gold Nanorods. Advanced Materials, 2003. 15(5): p. 414-416.

155. Wei, Q., J. Ji, and J. Shen, pH controlled synthesis of high aspect-ratio gold nanorods. J Nanosci Nanotechnol, 2008. 8(11): p. 5708-14.

156. Orendorff, C.J. and C.J. Murphy, Quantitation of Metal Content in the Silver-Assisted Growth of Gold Nanorods. The Journal of Physical Chemistry B, 2006. 110(9): p. 3990-3994.

157. Sau, T.K. and C.J. Murphy, Room Temperature, High-Yield Synthesis of Multiple Shapes of Gold Nanoparticles in Aqueous Solution. Journal of the American Chemical Society, 2004. 126(28): p. 8648-8649. 
158. Bansal, V., et al., Shape dependent electrocatalytic behaviour of silver nanoparticles. CrystEngComm, 2010. 12(12): p. 4280-4286.

159. Sanchez, C.G., M.G. del Popolo, and E.P.M. Leiva, An embedded atom approach to underpotential deposition phenomena. Surface Science, 1999. 421(1): p. 59-72.

160. Sun, Y. and Y. Xia, Shape-Controlled Synthesis of Gold and Silver Nanoparticles. Science, 2002. 298(5601): p. 2176-2179.

161. Kim, M., et al., Shape Transformation of Gold Nanoparticles from Octahedron to Cube Depending on in situ Seed-Growth Time. Bulletin of the Korean Chemical Society, 2013. 34(8): p. 2243-2244.

162. Narayanan, R., R.J. Lipert, and M.D. Porter, Cetyltrimethylammonium bromidemodified spherical and cube-like gold nanoparticles as extrinsic Raman labels in surface-enhanced Raman spectroscopy based heterogeneous immunoassays. Analytical Chemistry, 2008. 80(6): p. 2265-2271.

163. Petroski, J.M., et al., Kinetically Controlled Growth and Shape Formation Mechanism of Platinum Nanoparticles. The Journal of Physical Chemistry B, 1998. 102(18): p. 3316-3320.

164. Rayavarapu, R.G., et al., Iodide Impurities in Hexadecyltrimethylammonium Bromide (CTAB) Products: Lot-Lot Variations and Influence on Gold Nanorod Synthesis. Langmuir, 2010. 26(7): p. 5050-5055.

165. Magnussen, O.M., Ordered anion adlayers on metal electrode surfaces. Chem Rev, 2002. 102(3): p. 679-725.

166. Kwon, H., et al., The Effects of Ambient Ions on the Growth of Gold Nanoparticles by Laser Ablation in Liquid. Bulletin of the Korean Chemical Society, 2014. 35(3): p. 865870.

167. Zhang, X., M.R. Servos, and J. Liu, Surface Science of DNA Adsorption onto CitrateCapped Gold Nanoparticles. Langmuir, 2012. 28(8): p. 3896-3902.

168. Brewer, S.H., et al., Probing BSA Binding to Citrate-Coated Gold Nanoparticles and Surfaces. Langmuir, 2005. 21(20): p. 9303-9307.

169. Daniel, M.-C. and D. Astruc, Gold nanoparticles: assembly, supramolecular chemistry, quantum-size-related properties, and applications toward biology, catalysis, and nanotechnology. Chemical reviews, 2004. 104(1): p. 293-346.

170. Giljohann, D.A., et al., Gold Nanoparticles for Biology and Medicine. Angewandte Chemie International Edition, 2010. 49(19): p. 3280-3294.

171. Alexandridis, P., Gold Nanoparticle Synthesis, Morphology Control, and Stabilization Facilitated by Functional Polymers. Chemical Engineering \& Technology, 2011. 34(1): p. 15-28.

172. Daima, H.K., et al., Fine-tuning the antimicrobial profile of biocompatible gold nanoparticles by sequential surface functionalization using polyoxometalates and lysine. PloS one, 2013. 8(10): p. e79676.

173. Philip, D., Green synthesis of gold and silver nanoparticles using Hibiscus rosa sinensis. Physica E: Low-dimensional Systems and Nanostructures, 2010. 42(5): p. 1417-1424.

174. Pandey, S., et al., Green synthesis of highly stable gold nanoparticles using Momordica charantia as nano fabricator. Archives of Applied Science Research, 2012. 4(2): p. 1135-1141.

175. Lu, Z., et al., Self-assembly and tunable plasmonic property of gold nanoparticles on mercapto-silica microspheres. Journal of Materials Chemistry, 2009. 19(26): p. 45974602.

176. Sajanlal, P.R., et al., Anisotropic nanomaterials: structure, growth, assembly, and functions. Nano Reviews, 2011. 2: p. 10.3402/nano.v2i0.5883. 
177. Wang, L., et al., Synthesis of Gold Nano- and Microplates in Hexagonal Liquid Crystals. The Journal of Physical Chemistry B, 2005. 109(8): p. 3189-3194.

178. Chanda, N., et al., Gastrin Releasing Protein Receptor Specific Gold Nanorods: Breast and Prostate Tumor Avid Nanovectors for Molecular Imaging. Nano Letters, 2009. 9(5): p. 1798-1805.

179. Huang, X.H., et al., Cancer cell imaging and photothermal therapy in the near-infrared region by using gold nanorods. Journal of the American Chemical Society, 2006. 128(6): p. 2115-2120.

180. Huang, X.H., et al., Cancer cells assemble and align gold nanorods conjugated to antibodies to produce highly enhanced, sharp, and polarized surface Raman spectra: A potential cancer diagnostic marker. Nano Letters, 2007. 7(6): p. 1591-1597.

181. Jokerst, J.V., et al., Gold Nanorods for Ovarian Cancer Detection with Photoacoustic Imaging and Resection Guidance via Raman Imaging in Living Mice. ACS Nano, 2012. 6(11): p. 10366-10377.

182. Jokerst, J.V., et al., Nanoparticle PEGylation for imaging and therapy. Nanomedicine, 2011. 6(4): p. 715-728.

183. Murphy, C.J., et al., Gold Nanoparticles in Biology: Beyond Toxicity to Cellular Imaging. Accounts of Chemical Research, 2008. 41(12): p. 1721-1730.

184. Zhang, Y., et al., Multifunctional Gold Nanorods with Ultrahigh Stability and Tunability for In Vivo Fluorescence Imaging, SERS Detection, and Photodynamic Therapy. Angewandte Chemie-International Edition, 2013. 52(4): p. 1148-1151.

185. Arnida, A. Malugin, and H. Ghandehari, Cellular uptake and toxicity of gold nanoparticles in prostate cancer cells: a comparative study of rods and spheres. Journal of Applied Toxicology, 2010. 30(3): p. 212-217.

186. Cheng, Y., et al., Highly efficient drug delivery with gold nanoparticle vectors for in vivo photodynamic therapy of cancer. Journal of the American Chemical Society, 2008. 130(32): p. 10643-10647.

187. Das, S., et al., Comparative analysis of stability and toxicity profile of three differently capped gold nanoparticles for biomedical usage. Biometals, 2012. 25(5): p. 1009-1022.

188. Ghosh, P.S., et al., Efficient Gene Delivery Vectors by Tuning the Surface Charge Density of Amino Acid-Functionalized Gold Nanoparticles. Acs Nano, 2008. 2(11): p. 2213-2218.

189. Han, G., P. Ghosh, and V.M. Rotello, Functionalized gold nanoparticles for drug delivery. Nanomedicine (Lond), 2007. 2(1): p. 113-23.

190. Huang, X., et al., Gold nanoparticles: interesting optical properties and recent applications in cancer diagnostics and therapy. Nanomedicine (Lond), 2007. 2(5): p. 681-93.

191. Paciotti, G.F., et al., Colloidal gold: A novel nanoparticle vector for tumor directed drug delivery. Drug Delivery, 2004. 11(3): p. 169-183.

192. Pissuwan, D., T. Niidome, and M.B. Cortie, The forthcoming applications of gold nanoparticles in drug and gene delivery systems. Journal of Controlled Release, 2011. 149(1): p. 65-71.

193. Rosi, N.L., et al., Oligonucleotide-modified gold nanoparticles for intracellular gene regulation. Science, 2006. 312(5776): p. 1027-1030.

194. Sharma, T.K., et al., Aptamer-mediated 'turn-off/turn-on' nanozyme activity of gold nanoparticles for kanamycin detection. Chemical Communications, 2014. 50(100): p. 15856-15859.

195. Weerathunge, P., et al., Aptamer-Controlled Reversible Inhibition of Gold Nanozyme Activity for Pesticide Sensing. Analytical Chemistry, 2014. 
196. Zhao, W., M.A. Brook, and Y. Li, Design of Gold Nanoparticle-Based Colorimetric Biosensing Assays. ChemBioChem, 2008. 9(15): p. 2363-2371.

197. Sabri, Y.M., et al., Gold nanospikes based microsensor as a highly accurate mercury emission monitoring system. Scientific Reports, 2014. 4.

198. Webster, T.J., Nanomedicine: Real commercial potential or just hype? International Journal of Nanomedicine, 2006. 1(4): p. 373-374.

199. Podila, R. and J.M. Brown, Toxicity of Engineered Nanomaterials: A Physicochemical Perspective. Journal of Biochemical and Molecular Toxicology. 27(1): p. 50-55.

200. Sadek, A., et al., High-temperature anodized WO3 nanoplatelet films for photosensitive devices. Langmuir, 2009. 25(16): p. 9545-9551.

201. Kalantar-zadeh, K., et al., Nanostructured WO3 films using high temperature anodization. Sensors and Actuators, B: Chemical, 2009. 142(1): p. 230-235.

202. Mukherjee, S., et al., Influence of $\mathrm{Zr}$ doping on the structure and ferroelectric properties of BiFeO3 thin films. Journal of Applied Physics, 2010. 107(12).

203. Ramanathan, R., et al., 3-D nanorod arrays of metal-organic KTCNQ semiconductor on textiles for flexible organic electronics. RSC Advances, 2013. 3(39): p. 1765417658.

204. Rezk, A.R., et al., Acoustic-Excitonic Coupling for Dynamic Photoluminescence Manipulation of Quasi-2D MoS2 Nanoflakes. Advanced Optical Materials, 2015.

205. Nili, H., et al., Donor-Induced Performance Tuning of Amorphous SrTiO<inf $>3</$ inf $>$ Memristive Nanodevices: Multistate Resistive Switching and Mechanical Tunability. Advanced Functional Materials, 2015.

206. Kroll, A., et al., Current in vitro methods in nanoparticle risk assessment: Limitations and challenges. European Journal of Pharmaceutics and Biopharmaceutics, 2009. 72(2): p. 370-377.

207. Buzea, C., I.I. Pacheco, and K. Robbie, Nanomaterials and nanoparticles: Sources and toxicity. Biointerphases, 2007. 2(4): p. Mr17-Mr71.

208. Hinton, T.M., et al., Bicontinuous cubic phase nanoparticle lipid chemistry affects toxicity in cultured cells. Toxicology Research, 2014. 3(1): p. 11-22.

209. Ning, Z., et al., Experimental study of environmental tobacco smoke particles under actual indoor environment. Sci Total Environ, 2006. 367(2-3): p. 822-30.

210. Donaldson, K., et al., Combustion-derived nanoparticles: a review of their toxicology following inhalation exposure. Part Fibre Toxicol, 2005. 2: p. 10.

211. Elsaesser, A. and C.V. Howard, Toxicology of nanoparticles. Adv Drug Deliv Rev, 2012. 64(2): p. 129-37.

212. Nel, A.E., et al., Understanding biophysicochemical interactions at the nano-bio interface. Nat Mater, 2009. 8(7): p. 543-557.

213. Doak, S.H., et al., Confounding experimental considerations in nanogenotoxicology. Mutagenesis, 2009. 24(4): p. 285-293.

214. Cook, J.A. and J.B. Mitchell, Viability measurements in mammalian cell systems. Analytical Biochemistry, 1989. 179(1): p. 1-7.

215. Han, X.L., et al., Validation of an LDH assay for assessing nanoparticle toxicity. Toxicology, 2011. 287(1-3): p. 99-104.

216. Kong, B., et al., Experimental considerations on the cytotoxicity of nanoparticles. Nanomedicine, 2011. 6(5): p. 929-941.

217. Oostingh, G.J., et al., Problems and challenges in the development and validation of human cell-based assays to determine nanoparticle-induced immunomodulatory effects. Particle and Fibre Toxicology, 2011. 8.

218. Tournebize, J., et al., Pitfalls of assays devoted to evaluation of oxidative stress induced by inorganic nanoparticles. Talanta, 2013. 116: p. 753-763. 
219. Monteiro-Riviere, N.A., A.O. Inman, and L.W. Zhang, Limitations and relative utility of screening assays to assess engineered nanoparticle toxicity in a human cell line. Toxicology and Applied Pharmacology, 2009. 234(2): p. 222-235.

220. Male, K.B., et al., Assessment of Cytotoxicity of Quantum Dots and Gold Nanoparticles Using Cell-Based Impedance Spectroscopy. Analytical Chemistry, 2008. 80(14): p. 5487-5493.

221. Sayes, C.M., K.L. Reed, and D.B. Warheit, Assessing toxicity of fine and nanoparticles: Comparing in vitro measurements to in vivo pulmonary toxicity profiles. Toxicological Sciences, 2007. 97(1): p. 163-180.

222. Haruta, M., et al., Novel gold catalysts for the oxidation of carbon monoxide at a temperature far below 0 C. Chemistry Letters, 1987. 16(2): p. 405-408.

223. Davis, R.R., et al., In vitro biological effects of sodium titanate materials. J Biomed Mater Res B Appl Biomater, 2007. 83(2): p. 505-11.

224. Monteiro-Riviere, N.A. and A.O. Inman, Challenges for assessing carbon nanomaterial toxicity to the skin. Carbon, 2006. 44(6): p. 1070-1078.

225. Veranth, J., et al., Cytokine responses of human lung cells (BEAS-2B) treated with micron-sized and nanoparticles of metal oxides compared to soil dusts. Particle and Fibre Toxicology, 2007. 4(1): p. 2.

226. Johnston, H.J., et al., A review of the in vivo and in vitro toxicity of silver and gold particulates: particle attributes and biological mechanisms responsible for the observed toxicity. Crit Rev Toxicol, 2010. 40(4): p. 328-46.

227. Timko, B.P., T. Dvir, and D.S. Kohane, Remotely triggerable drug delivery systems. Advanced materials, 2010. 22(44): p. 4925-4943.

228. Chanda, N., et al., An effective strategy for the synthesis of biocompatible gold nanoparticles using cinnamon phytochemicals for phantom CT imaging and photoacoustic detection of cancerous cells. Pharm Res, 2011. 28(2): p. 279-91.

229. Bhattacharya, R., et al., Attaching folic acid on gold nanoparticles using noncovalent interaction via different polyethylene glycol backbones and targeting of cancer cells. Nanomedicine: Nanotechnology, Biology and Medicine, 2007. 3(3): p. 224-238.

230. de la Rica, R., D. Aili, and M.M. Stevens, Enzyme-responsive nanoparticles for drug release and diagnostics. Advanced drug delivery reviews, 2012. 64(11): p. 967-978.

231. Goethals, E.C., et al., Role of the templating approach in influencing the suitability of polymeric nanocapsules for drug delivery: LbL vs SC/MS. Langmuir, 2013. 29(39): p. $12212-12219$.

232. Sivakumar, S., et al., Degradable, surfactant-free, monodisperse polymer-encapsulated emulsions as anticancer drug carriers. Advanced Materials, 2009. 21(18): p. 18201824.

233. Wang, Y., et al., Templated synthesis of single-component polymer capsules and their application in drug delivery. Nano Letters, 2008. 8(6): p. 1741-1745.

234. Goethals, E.C., et al., Decoupling the effects of the size, wall thickness, and porosity of curcumin-loaded chitosan nanocapsules on their anticancer efficacy: Size is the winner. Langmuir, 2013. 29(2): p. 658-666.

235. Stern, J.M., et al., Efficacy of laser-activated gold nanoshells in ablating prostate cancer cells in vitro. J Endourol, 2007. 21(8): p. 939-43.

236. Khan, J.A., et al., Molecular Effects of Uptake of Gold Nanoparticles in HeLa Cells. ChemBioChem, 2007. 8(11): p. 1237-1240.

237. The Search for Antiviral Drugs: Case Histories from Concept to Clinic. 2013: Birkhäuser Boston.

238. Kroll, A., et al., Interference of engineered nanoparticles with in vitro toxicity assays. Archives of Toxicology, 2012. 86(7): p. 1123-1136. 
239. Carlsson, H., V. Prachayasittikul, and L. Bulow, Zinc ions bound to chimeric His4/lactate dehydrogenase facilitate decarboxylation of oxaloacetate. Protein Eng, 1993. 6(8): p. 907-11.

240. Oh, S.-J., et al., Incompatibility of silver nanoparticles with lactate dehydrogenase leakage assay for cellular viability test is attributed to protein binding and reactive oxygen species generation. Toxicology Letters, 2014. 225(3): p. 422-432.

241. Casey, A., et al., Spectroscopic analysis confirms the interactions between single walled carbon nanotubes and various dyes commonly used to assess cytotoxicity. Carbon, 2007. 45(7): p. 1425-1432.

242. Guadagnini, R., et al., Toxicity screenings of nanomaterials: challenges due to interference with assay processes and components of classic in vitro tests. Nanotoxicology, 2015. 9(sup1): p. 13-24.

243. Wörle-Knirsch, J.M., K. Pulskamp, and H.F. Krug, Oops They Did It Again! Carbon Nanotubes Hoax Scientists in Viability Assays. Nano Letters, 2006. 6(6): p. 1261-1268.

244. Belyanskaya, L., et al., The reliability and limits of the MTT reduction assay for carbon nanotubes-cell interaction. Carbon, 2007. 45(13): p. 2643-2648.

245. Wang, S., H. Yu, and J.K. Wickliffe, Limitation of the MTT and XTT assays for measuring cell viability due to superoxide formation induced by nano-scale TiO2. Toxicology in Vitro, 2011. 25(8): p. 2147-2151.

246. Laaksonen, T., et al., Failure of MTT as a Toxicity Testing Agent for Mesoporous Silicon Microparticles. Chemical Research in Toxicology, 2007. 20(12): p. 1913-1918.

247. Sadik, O., et al., Sensors as tools for quantitation, nanotoxicity and nanomonitoring assessment of engineered nanomaterials. Journal of Environmental Monitoring, 2009. 11(10): p. 1782-1800.

248. Oostingh, G.J., et al., Problems and challenges in the development and validation of human cell-based assays to determine nanoparticle-induced immunomodulatory effects. Particle and Fibre Toxicology, 2011. 8(1): p. 1-21.

249. Brown, D.M., et al., Interaction between nanoparticles and cytokine proteins: impact on protein and particle functionality. Nanotechnology, 2010. 21(21): p. 215104.

250. Kocbach, A., et al., Differential binding of cytokines to environmentally relevant particles: a possible source for misinterpretation of in vitro results? Toxicol Lett, 2008. 176(2): p. 131-7.

251. Kain, J., H.L. Karlsson, and L. Möller, DNA damage induced by micro- and nanoparticles-interaction with FPG influences the detection of DNA oxidation in the comet assay. Mutagenesis, 2012.

252. Karlsson, H.L., et al., Can the comet assay be used reliably to detect nanoparticleinduced genotoxicity? Environ Mol Mutagen, 2015. 56(2): p. 82-96.

253. Ferraro, D., et al., Overestimation of nanoparticles-induced DNA damage determined by the comet assay. Nanotoxicology, 2016: p. 1-10.

254. Magdolenova, Z., et al., Can standard genotoxicity tests be applied to nanoparticles? J Toxicol Environ Health A, 2012. 75(13-15): p. 800-6.

255. Tkachenko, A.G., et al., Cellular Trajectories of Peptide-Modified Gold Particle Complexes: Comparison of Nuclear Localization Signals and Peptide Transduction Domains. Bioconjugate Chemistry, 2004. 15(3): p. 482-490.

256. Yu, C., L. Varghese, and J. Irudayaraj, Surface Modification of Cetyltrimethylammonium Bromide-Capped Gold Nanorods to Make Molecular Probes. Langmuir, 2007. 23(17): p. 9114-9119.

257. Connor, E.E., et al., Gold Nanoparticles Are Taken Up by Human Cells but Do Not Cause Acute Cytotoxicity. Small, 2005. 1(3): p. 325-327. 
258. Goodman, C.M., et al., Toxicity of Gold Nanoparticles Functionalized with Cationic and Anionic Side Chains. Bioconjugate Chemistry, 2004. 15(4): p. 897-900.

259. Takahashi, H., et al., Modification of gold nanorods using phosphatidylcholine to reduce cytotoxicity. Langmuir, 2006. 22(1): p. 2-5.

260. Alkilany, A.M., et al., Cellular Uptake and Cytotoxicity of Gold Nanorods: Molecular Origin of Cytotoxicity and Surface Effects. Small, 2009. 5(6): p. 701-708.

261. Gabas, I.M., et al., In vitro cell cytotoxicity profile and morphological response to polyoxometalate-stabilised gold nanoparticles. New Journal of Chemistry, 2016.

262. Gu, Y.J., et al., Nuclear penetration of surface functionalized gold nanoparticles. Toxicol Appl Pharmacol, 2009. 237(2): p. 196-204.

263. Uboldi, C., et al., Gold nanoparticles induce cytotoxicity in the alveolar type-II cell lines A549 and NCIH44I. Part Fibre Toxicol, 2009. 6.

264. Beddoes, C.M., C.P. Case, and W.H. Briscoe, Understanding nanoparticle cellular entry: A physicochemical perspective. Advances in colloid and interface science, 2015. 218: p. 48-68.

265. Mahmoudi, M., et al., Protein-Nanoparticle Interactions: Opportunities and Challenges. Chemical Reviews, 2011. 111(9): p. 5610-5637.

266. Villiers, C.L., et al., Analysis of the toxicity of gold nano particles on the immune system: effect on dendritic cell functions. Journal of Nanoparticle Research, 2010. 12(1): p. 55-60.

267. Patra, H.K., et al., Cell selective response to gold nanoparticles. NanomedicineNanotechnology Biology and Medicine, 2007. 3(2): p. 111-119.

268. Osaki, F., et al., A quantum dot conjugated sugar ball and its cellular uptake. On the size effects of endocytosis in the subviral region. J Am Chem Soc, 2004. 126(21): p. 6520-1.

269. Huo, S., et al., Superior penetration and retention behavior of $50 \mathrm{~nm}$ gold nanoparticles in tumors. Cancer Res, 2013. 73(1): p. 319-30.

270. Wang, S.-H., et al., Size-dependent endocytosis of gold nanoparticles studied by threedimensional mapping of plasmonic scattering images. Journal of Nanobiotechnology, 2010. 8(1): p. 33.

271. Boyoglu, C., et al., Microscopic Studies of Various Sizes of Gold Nanoparticles and Their Cellular Localizations. ISRN Nanotechnology, 2013. 2013: p. 13.

272. Pan, Y., et al., Gold nanoparticles of diameter $1.4 \mathrm{~nm}$ trigger necrosis by oxidative stress and mitochondrial damage. Small, 2009. 5(18): p. 2067-76.

273. Pan, Y., et al., Size-dependent cytotoxicity of gold nanoparticles. Small, 2007. 3(11): p. 1941-9.

274. Chen, Y.S., et al., Assessment of the In Vivo Toxicity of Gold Nanoparticles. Nanoscale Research Letters, 2009. 4(8): p. 858-864.

275. Mironava, T., et al., Gold nanoparticles cellular toxicity and recovery: effect of size, concentration and exposure time. Nanotoxicology, 2010. 4(1): p. 120-37.

276. Tsai, S.-W., et al., Internalized Gold Nanoparticles Do Not Affect the Osteogenesis and Apoptosis of MG63 Osteoblast-Like Cells: A Quantitative, In Vitro Study. PLoS ONE, 2013. 8(10): p. e76545.

277. Majid Kazemian Abyaneh and, D.P.a.S.V.a.S.W.G.a.S.K.K., Formation of gold nanoparticles in polymethylmethacrylate by UV irradiation. Journal of Physics D: Applied Physics, 2007. 40(12): p. 3771.

278. Kasture, M., M. Sastry, and B.L.V. Prasad, Halide ion controlled shape dependent gold nanoparticle synthesis with tryptophan as reducing agent: Enhanced fluorescent properties and white light emission. Chemical Physics Letters, 2010. 484(4-6): p. 271275. 
279. Alkilany, A.M., et al., Cation Exchange on the Surface of Gold Nanorods with a Polymerizable Surfactant: Polymerization, Stability, and Toxicity Evaluation. Langmuir, 2010. 26(12): p. 9328-9333.

280. Chithrani, B.D. and W.C.W. Chan, Elucidating the mechanism of cellular uptake and removal of protein-coated gold nanoparticles of different sizes and shapes. Nano Letters, 2007. 7(6): p. 1542-1550.

281. Malugin, A. and H. Ghandehari, Cellular uptake and toxicity of gold nanoparticles in prostate cancer cells: a comparative study of rods and spheres. J Appl Toxicol, 2010. 30(3): p. 212-7.

282. Niidome, T., et al., PEG-modified gold nanorods with a stealth character for in vivo applications. Journal of Controlled Release, 2006. 114(3): p. 343-347.

283. Mosqueira, V.C., et al., Interactions between a macrophage cell line (J774A1) and surface-modified poly (D,L-lactide) nanocapsules bearing poly(ethylene glycol). J Drug Target, 1999. 7(1): p. 65-78.

284. Singh, A., et al., Cytotoxicity and Cellular Internalization Studies of Biogenic Gold Nanotriangles in Animal Cell Lines. International Journal of Green Nanotechnology, 2011. 3(4): p. 251-263.

285. Basu, N., R. Bhattacharya, and P. Mukherjee, Protein-mediated autoreduction of gold salts to gold nanoparticles. Biomedical Materials, 2008. 3(3): p. 034105.

286. Elavazhagan, T. and K.D. Arunachalam, Memecylon edule leaf extract mediated green synthesis of silver and gold nanoparticles. International Journal of Nanomedicine, 2011. 6: p. 1265-1278.

287. Schaeublin, N.M., et al., Surface charge of gold nanoparticles mediates mechanism of toxicity. Nanoscale, 2011. 3(2): p. 410-420.

288. Daima, H.K., et al., Synergistic influence of polyoxometalate surface corona towards enhancing the antibacterial performance of tyrosine-capped Ag nanoparticles. Nanoscale, 2014. 6(2): p. 758-765.

289. Davoudi, Z.M., et al., Hybrid antibacterial fabrics with extremely high aspect ratio Ag/AgTCNQ nanowires. Advanced Functional Materials, 2014. 24(8): p. 1047-1053.

290. Cedervall, T., et al., Detailed identification of plasma proteins adsorbed on copolymer nanoparticles. Angewandte Chemie-International Edition, 2007. 46(30): p. 5754-5756.

291. Lynch, I., et al., The nanoparticle - protein complex as a biological entity; a complex fluids and surface science challenge for the 21st century. Advances in Colloid and Interface Science, 2007. 134-35: p. 167-174.

292. Peters, T., All about Albumin: Biochemistry, Genetics, and Medical Applications. 1996: Academic Press.

293. Hauck, T.S., A.A. Ghazani, and W.C.W. Chan, Assessing the Effect of Surface Chemistry on Gold Nanorod Uptake, Toxicity, and Gene Expression in Mammalian Cells. Small, 2008. 4(1): p. 153-159.

294. Marisca, O.T., et al., Comparison of the in Vitro Uptake and Toxicity of Collagen-and Synthetic Polymer-Coated Gold Nanoparticles. Nanomaterials, 2015. 5(3): p. 14181430.

295. Jiang, Y., et al., The Interplay of Size and Surface Functionality on the Cellular Uptake of Sub-10 nm Gold Nanoparticles. ACS Nano, 2015. 9(10): p. 9986-9993.

296. Yao, M., et al., Uptake of Gold Nanoparticles by Intestinal Epithelial Cells: Impact of Particle Size on Their Absorption, Accumulation, and Toxicity. Journal of Agricultural and Food Chemistry, 2015. 63(36): p. 8044-8049.

297. Favi, P.M., et al., Shape and surface effects on the cytotoxicity of nanoparticles: Gold nanospheres versus gold nanostars. Journal of Biomedical Materials Research Part A, 2015. 103(11): p. 3449-3462. 
298. Benetti, F., et al., Gold nanoparticles: role of size and surface chemistry on blood protein adsorption. Journal of Nanoparticle Research, 2013. 15(6): p. 1-9.

299. Lynch, I. and K.A. Dawson, Protein-nanoparticle interactions. Nano Today, 2008. 3(12): p. 40-47.

300. Ehrenberg, M.S., et al., The influence of protein adsorption on nanoparticle association with cultured endothelial cells. Biomaterials, 2009. 30(4): p. 603-610.

301. Casals, E., et al., Hardening of the Nanoparticle-Protein Corona in Metal (Au, Ag) and Oxide (Fe3O4, CoO, and CeO2) Nanoparticles. Small, 2011. 7(24): p. 3479-3486.

302. Rahman, M., et al., Nanoparticle and Protein Corona, in Protein-Nanoparticle Interactions. 2013, Springer Berlin Heidelberg. p. 21-44.

303. Zolghadri, S., et al., Interaction between silver nanoparticle and bovine hemoglobin at different temperatures. Journal of Nanoparticle Research, 2009. 11(7): p. 1751-1758.

304. Conner, S.D. and S.L. Schmid, Regulated portals of entry into the cell. Nature, 2003. 422(6927): p. 37-44.

305. Lundqvist, M., I. Sethson, and B.-H. Jonsson, Protein adsorption onto silica nanoparticles: conformational changes depend on the particles' curvature and the protein stability. Langmuir, 2004. 20(24): p. 10639-10647.

306. Klein, J., Probing the interactions of proteins and nanoparticles. Proceedings of the National Academy of Sciences, 2007. 104(7): p. 2029-2030.

307. Monopoli, M.P., et al., Physical-Chemical Aspects of Protein Corona: Relevance to in Vitro and in Vivo Biological Impacts of Nanoparticles. Journal of the American Chemical Society, 2011. 133(8): p. 2525-2534.

308. Roach, P., D. Farrar, and C.C. Perry, Surface Tailoring for Controlled Protein Adsorption: Effect of Topography at the Nanometer Scale and Chemistry. Journal of the American Chemical Society, 2006. 128(12): p. 3939-3945.

309. Walkey, C.D., et al., Nanoparticle size and surface chemistry determine serum protein adsorption and macrophage uptake. Journal of the American Chemical Society, 2012. 134(4): p. 2139-2147.

310. Asuri, P., et al., Enhanced stability of enzymes adsorbed onto nanoparticles. Journal of nanoscience and nanotechnology, 2007. 7(4-5): p. 1675-1678.

311. Karajanagi, S.S., et al., Structure and function of enzymes adsorbed onto single-walled carbon nanotubes. Langmuir, 2004. 20(26): p. 11594-11599.

312. Shang, W., et al., Cytochrome c on silica nanoparticles: influence of nanoparticle size on protein structure, stability, and activity. Small, 2009. 5(4): p. 470-476.

313. Dobrovolskaia, M.A., et al., Interaction of colloidal gold nanoparticles with human blood: effects on particle size and analysis of plasma protein binding profiles. Nanomedicine : nanotechnology, biology, and medicine, 2009. 5(2): p. 106-117.

314. Pastorino, F., et al., Ligand-targeted liposomal therapies of neuroblastoma. Curr Med Chem, 2007. 14(29): p. 3070-8.

315. Jones, S.W., et al., Nanoparticle clearance is governed by Th1/Th2 immunity and strain background. The Journal of clinical investigation, 2013. 123(7): p. 3061-3073.

316. Soppimath, K.S., et al., Biodegradable polymeric nanoparticles as drug delivery devices. Journal of controlled release, 2001. 70(1): p. 1-20.

317. Gref, R., et al., 'Stealth'corona-core nanoparticles surface modified by polyethylene glycol (PEG): influences of the corona (PEG chain length and surface density) and of the core composition on phagocytic uptake and plasma protein adsorption. Colloids and Surfaces B: Biointerfaces, 2000. 18(3): p. 301-313.

318. Moghimi, S.M., A.C. Hunter, and J.C. Murray, Long-circulating and target-specific nanoparticles: theory to practice. Pharmacological reviews, 2001. 53(2): p. 283-318. 
319. Romberg, B., W.E. Hennink, and G. Storm, Sheddable coatings for long-circulating nanoparticles. Pharmaceutical research, 2008. 25(1): p. 55-71.

320. Otsuka, H., Y. Nagasaki, and K. Kataoka, PEGylated nanoparticles for biological and pharmaceutical applications. Advanced Drug Delivery Reviews, 2003. 55(3): p. 403419.

321. Verma, A. and F. Stellacci, Effect of surface properties on nanoparticle-cell interactions. Small, 2010. 6(1): p. 12-21.

322. Perry, J.L., et al., PEGylated PRINT nanoparticles: the impact of PEG density on protein binding, macrophage association, biodistribution, and pharmacokinetics. Nano letters, 2012. 12(10): p. 5304-5310.

323. Davis, M.E. and D.M. Shin, Nanoparticle therapeutics: an emerging treatment modality for cancer. Nature reviews Drug discovery, 2008. 7(9): p. 771-782.

324. Lacerda, S.H.D.P., et al., Interaction of gold nanoparticles with common human blood proteins. ACS nano, 2009. 4(1): p. 365-379.

325. Lacerda, S.H., et al., Interaction of gold nanoparticles with common human blood proteins. ACS Nano, 2010. 4(1): p. 365-79.

326. Dobrovolskaia, M.A., et al., Protein corona composition does not accurately predict hematocompatibility of colloidal gold nanoparticles. Nanomedicine: Nanotechnology, Biology and Medicine, 2014.

327. Mirsadeghi, S., et al., Protein corona composition of gold nanoparticles/nanorods affects amyloid beta fibrillation process. Nanoscale, 2015. 7(11): p. 5004-5013.

328. Ramezani, F., M. Amanlou, and H. Rafii-Tabar, Gold nanoparticle shape effects on human serum albumin corona interface: a molecular dynamic study. Journal of Nanoparticle Research, 2014. 16(7): p. 1-9.

329. Gagner, J.E., et al., Effect of gold nanoparticle morphology on adsorbed protein structure and function. Biomaterials, 2011. 32(29): p. 7241-7252.

330. Caswell, K., et al., Preferential end-to-end assembly of gold nanorods by biotinstreptavidin connectors. Journal of the American Chemical Society, 2003. 125(46): p. 13914-13915.

331. Chang, J.-Y., et al., Oriented assembly of Au nanorods using biorecognition system. Chem. Commun., 2005(8): p. 1092-1094.

332. Deng, Z.J., et al., Differential plasma protein binding to metal oxide nanoparticles. Nanotechnology, 2009. 20(45): p. 455101.

333. Boulos, S.P., et al., Nanoparticle-Protein Interactions: A Thermodynamic and Kinetic Study of the Adsorption of Bovine Serum Albumin to Gold Nanoparticle Surfaces. Langmuir, 2013. 29(48): p. 14984-14996.

334. Chinen, A.B., C.M. Guan, and C.A. Mirkin, Spherical Nucleic Acid Nanoparticle Conjugates Enhance G-Quadruplex Formation and Increase Serum Protein Interactions. Angewandte Chemie International Edition, 2015. 54(2): p. 527-531.

335. Hamblin, M., et al., Pegylation of charged polymer-photosensitiser conjugates: effects on photodynamic efficacy. British journal of cancer, 2003. 89(5): p. 937-943.

336. Cui, M., et al., Quantitative study of protein coronas on gold nanoparticles with different surface modifications. Nano Research, 2014. 7(3): p. 345-352.

337. Cruje, C. and B.D. Chithrani, Polyethylene Glycol Density and Length Affects Nanoparticle Uptake by Cancer Cells. J Nanomed Res, 2014. 1(1): p. 00006.

338. Sasidharan, A., J.E. Riviere, and N.A. Monteiro-Riviere, Gold and silver nanoparticle interactions with human proteins: impact and implications in biocorona formation. Journal of Materials Chemistry B, 2015. 3(10): p. 2075-2082.

339. Higby, G., Gold in medicine. Gold Bulletin, 1982. 15(4): p. 130-140. 
340. Paul, W. and C.P. Sharma, Blood compatibility studies of Swarna bhasma (gold bhasma), an Ayurvedic drug. International Journal of Ayurveda Research, 2011. 2(1): p. 14-22.

341. Mitra, A., et al., Evaluation of chemical constituents and free-radical scavenging activity of Swarnabhasma (gold ash), an ayurvedic drug. Journal of Ethnopharmacology, 2002. 80(2-3): p. 147-153.

342. Jans, H. and Q. Huo, Gold nanoparticle-enabled biological and chemical detection and analysis. Chemical Society Reviews, 2012. 41(7): p. 2849-2866.

343. Park, C.H., et al., Evaluation of the Duopath Verotoxin Test for Detection of Shiga Toxins in Cultures of Human Stools. Journal of Clinical Microbiology, 2003. 41(6): p. 2650-2653.

344. Sharma, T.K., et al., Moving forward in plant food safety and security through NanoBioSensors: Adopt or adapt biomedical technologies? Proteomics, 2015.

345. Agrawal, G.K., et al., Biomarker discovery and applications for foods and beverages: Proteomics to nanoproteomics. Journal of Proteomics, 2013. 93: p. 74-92.

346. Zhu, Q., et al., Development of a biosensor for the detection of carcinoembryonic antigen using faradic impedance spectroscopy. Chemistry Letters, 2005. 34(12): p. 1682-1683.

347. Nath, N. and A. Chilkoti, A colorimetric gold nanoparticle sensor to interrogate biomolecular interactions in real time on a surface. Analytical Chemistry, 2002. 74(3): p. 504-509.

348. Bangs, L.B., New developments in particle-based immunoassays: introduction. Pure and applied chemistry, 1996. 68(10): p. 1873-1879.

349. Ewan, P. and D. Coote, Evaluation of a capsulated hydrophilic carrier polymer (the ImmunoCAP) for measurement of specific IgE antibodies. Allergy, 1990. 45(1): p. 2229.

350. Elghanian, R., et al., Selective colorimetric detection of polynucleotides based on the distance-dependent optical properties of gold nanoparticles. Science, 1997. 277(5329): p. 1078-1081.

351. Otsuka, H., et al., Quantitative and reversible lectin-induced association of gold nanoparticles modified with $\alpha$-lactosyl- $\omega$-mercapto-poly (ethylene glycol). Journal of the American Chemical Society, 2001. 123(34): p. 8226-8230.

352. Thanh, N.T.K. and Z. Rosenzweig, Development of an Aggregation-Based Immunoassay for Anti-Protein A Using Gold Nanoparticles. Analytical Chemistry, 2002. 74(7): p. 1624-1628.

353. Kim, Y., R.C. Johnson, and J.T. Hupp, Gold Nanoparticle-Based Sensing of "Spectroscopically Silent" Heavy Metal Ions. Nano Letters, 2001. 1(4): p. 165-167.

354. Dell, E., M. Roskamp, and J. Meuvis, Label-Free Protein-Protein Binding Kinetics Using SoPRano (TM) Gold Nano Rods (GNRs) and a Spectrometer Microplate Reader. SCIENTIST, 2012. 26(10): p. 76-77.

355. You, C.-C., et al., Detection and identification of proteins using nanoparticlefluorescent polymer 'chemical nose'sensors. Nature Nanotechnology, 2007. 2(5): p. 318-323.

356. Hakim, M., et al., Diagnosis of head-and-neck cancer from exhaled breath. British journal of cancer, 2011. 104(10): p. 1649-1655.

357. Peng, G., et al., Diagnosing lung cancer in exhaled breath using gold nanoparticles. Nature nanotechnology, 2009. 4(10): p. 669-673.

358. Peng, G., et al., Detection of lung, breast, colorectal, and prostate cancers from exhaled breath using a single array of nanosensors. British journal of cancer, 2010. 103(4): p. 542-551. 
359. Phillips, R.L., et al., Rapid and Efficient Identification of Bacteria Using GoldNanoparticle-Poly(para-phenyleneethynylene) Constructs. Angewandte Chemie International Edition, 2008. 47(14): p. 2590-2594.

360. Miranda, O.R., et al., Enzyme Amplified Array Sensing of Proteins in Solution and in Biofluids. Journal of the American Chemical Society, 2010. 132(14): p. 5285-5289.

361. De, M., et al., Sensing of proteins in human serum using conjugates of nanoparticles and green fluorescent protein. Nature chemistry, 2009. 1(6): p. 461-465.

362. Moyano, D.F. and V.M. Rotello, Nanoparticle-GFP "chemical nose" sensor for cancer cell identification. Methods Mol Biol, 2013. 991: p. 1-8.

363. Bajaj, A., et al., Array Based Sensing of Normal, Cancerous and Metastatic Cells using Conjugated Fluorescent Polymers. Journal of the American Chemical Society, 2010. 132(3): p. 1018-1022.

364. Halo, T.L., et al., NanoFlares for the detection, isolation, and culture of live tumor cells from human blood. Proceedings of the National Academy of Sciences, 2014. 111(48): p. 17104-17109.

365. Fonteh, P.N., F.K. Keter, and D. Meyer, HIV therapeutic possibilities of gold compounds. Biometals, 2010. 23(2): p. 185-196.

366. Zharov, V.P., et al., Photothermal Nanotherapeutics and Nanodiagnostics for Selective Killing of Bacteria Targeted with Gold Nanoparticles. Biophysical Journal, 2006. 90(2): p. 619-627.

367. Tsai, C.Y., et al., Amelioration of collagen-induced arthritis in rats by nanogold. Arthritis \& Rheumatism, 2007. 56(2): p. 544-554.

368. Kharlamov, A.N. and J.L. Gabinsky, Plasmonic photothermic and stem cell therapy of atherosclerotic plaque as a novel nanotool for angioplasty and artery remodeling. Rejuvenation Res, 2012. 15(2): p. 222-30.

369. Chen, J.Y., et al., Immuno gold nanocages with tailored optical properties for targeted photothermal destruction of cancer cells. Nano Letters, 2007. 7(5): p. 1318-1322.

370. Comenge, J., et al., Detoxifying Antitumoral Drugs via Nanoconjugation: The Case of Gold Nanoparticles and Cisplatin. PLoS ONE, 2012. 7(10): p. e47562.

371. El-Sayed, I.H., X. Huang, and M.A. El-Sayed, Selective laser photo-thermal therapy of epithelial carcinoma using anti-EGFR antibody conjugated gold nanoparticles. Cancer letters, 2006. 239(1): p. 129-135.

372. Everts, M., et al., Covalently Linked Au Nanoparticles to a Viral Vector: Potential for Combined Photothermal and Gene Cancer Therapy. Nano Letters, 2006. 6(4): p. 587591.

373. Fabio, P., et al., Nanocarrier-Mediated Targeting of Tumor and Tumor Vascular Cells Improves Uptake and Penetration of Drugs into Neuroblastoma. Frontiers in Oncology, 2013. 3.

374. Huang, X., et al., Cancer cell imaging and photothermal therapy in the near-infrared region by using gold nanorods. Journal of the American Chemical Society, 2006. 128(6): p. 2115-2120.

375. Kennedy, L.C., et al., A New Era for Cancer Treatment: Gold-Nanoparticle-Mediated Thermal Therapies. Small, 2011. 7(2): p. 169-183.

376. Li, J.-L., et al., In vitro cancer cell imaging and therapy using transferrin-conjugated gold nanoparticles. Cancer Letters, 2009. 274(2): p. 319-326.

377. Libutti, S.K., et al., Phase I and pharmacokinetic studies of CYT-6091, a novel PEGylated colloidal gold-rhTNF nanomedicine. Clinical Cancer Research, 2010. 16(24): p. 6139-6149.

378. Loo, C., et al., Immunotargeted nanoshells for integrated cancer imaging and therapy. Nano letters, 2005. 5(4): p. 709-711. 
379. Visaria, R., et al., Nanotherapeutics for enhancing thermal therapy of cancer. International Journal of Hyperthermia, 2007. 23(6): p. 501-511.

380. Milacic, V. and Q.P. Dou, The tumor proteasome as a novel target for gold (III) complexes: implications for breast cancer therapy. Coordination chemistry reviews, 2009. 253(11): p. 1649-1660.

381. Shaw, C.F., Gold-based therapeutic agents. Chemical reviews, 1999. 99(9): p. 25892600.

382. Best, S. and P. Sadler, Gold drugs: Mechanism of action and toxicity. Gold Bulletin, 1996. 29(3): p. 87-93.

383. Nozue, T., et al., Treatment with statin on atheroma regression evaluated by intravascular ultrasound with virtual histology (TRUTH Study) rationale and design. Circulation Journal, 2009. 73(2): p. 352-355.

384. Kharlamov, A.N. Plasmonic Nanophotothermic Therapy of Atherosclerosis (NANOM FIM). 2010 August 302012 [cited 201528 April]; Available from: http://clinicaltrials.gov/.

385. Kharlamov, A.N. Plasmonic Photothermal and Stem Cell Therapy of Atherosclerosis Versus Stenting (NANOM PCI). 2011 Last updated: April 28, 2015 [cited 201528 April].

386. Averitt, R.D., D. Sarkar, and N.J. Halas, Plasmon Resonance Shifts of Au-Coated Au2S Nanoshells: Insight into Multicomponent Nanoparticle Growth. Physical Review Letters, 1997. 78(22): p. 4217-4220.

387. Nanospectra Biosciences, I. Pilot study of aurolase (tm) therapy in refractory and/or recurrent tumors of the head and neck. 2009.

388. Nanospectra Biosciences, I. Efficacy Study of AuroLase Therapy in Subjects With Primary and/or Metastatic Lung Tumors. 2012 September 232014 [cited 201528 April 2015].

389. Cutler, C.S., et al., Nanoparticles and phage display selected peptides for imaging and therapy of cancer. 2013. p. 133-147.

390. Khan, M.K., et al., Fabrication of $\{198 A u 0\}$ radioactive composite nanodevices and their use for nanobrachytherapy. Nanomedicine, 2008. 4(1): p. 57-69.

391. Rengan, A.K., et al., In vivo analysis of biodegradable liposome gold nanoparticles as efficient agents for photothermal therapy of cancer. Nano letters, 2015. 15(2): p. 842848.

392. Faulk, W.P. and G.M. Taylor, Communication to the editors: an immunocolloid method for the electron microscope. Immunochemistry, 1971. 8(11): p. 1081-1083.

393. Geuze, H.J., et al., Use of colloidal gold particles in double-labeling immunoelectron microscopy of ultrathin frozen tissue sections. The Journal of Cell Biology, 1981. 89(3): p. 653-665.

394. Thiberge, S., et al., Scanning electron microscopy of cells and tissues under fully hydrated conditions. Proceedings of the National Academy of Sciences of the United States of America, 2004. 101(10): p. 3346-3351.

395. Siegesmund, K.A., D.E. Yorde, and R. Dragen, A quantitative immunoperoxidase procedure employing energy dispersive $x$-ray analysis. Journal of Histochemistry \& Cytochemistry, 1979. 27(9): p. 1226-30.

396. Röntgen, W.C., On a New Kind of Rays. Science, 1896. 3(59): p. 227-231.

397. Rahman, W.N., et al., Influence of Gold Nanoparticles on Radiation Dose Enhancement and Cellular Migration in Microbeam-Irradiated Cells. BioNanoScience, 2011. 1(1-2): p. 4-13. 
398. Jackson, P., et al., Evaluation of the effects of gold nanoparticle shape and size on contrast enhancement in radiological imaging. Australasian Physical and Engineering Sciences in Medicine, 2011. 34(2): p. 243-249.

399. Xi, D., et al., Gold nanoparticles as computerized tomography (CT) contrast agents. RSC Adv., 2012. 2(33): p. 12515-12524.

400. Morcos, S. and H. Thomsen, Adverse reactions to iodinated contrast media. European radiology, 2001. 11(7): p. 1267-1275.

401. Kim, D., et al., Antibiofouling Polymer-Coated Gold Nanoparticles as a Contrast Agent for in Vivo X-ray Computed Tomography Imaging. Journal of the American Chemical Society, 2007. 129(24): p. 7661-7665.

402. Cai, Q.-Y., et al., Colloidal gold nanoparticles as a blood-pool contrast agent for X-ray computed tomography in mice. Investigative radiology, 2007. 42(12): p. 797-806.

403. Chen, J., et al., Gold nanocages: bioconjugation and their potential use as optical imaging contrast agents. Nano letters, 2005. 5(3): p. 473-477.

404. Chamberland, D.L., et al., Photoacoustic tomography of joints aided by an Etanerceptconjugated gold nanoparticle contrast agent-an ex vivo preliminary rat study. Nanotechnology, 2008. 19(9): p. 095101.

405. Jackson, P.A., et al., Potential dependent superiority of gold nanoparticles in comparison to iodinated contrast agents. European Journal of Radiology, 2010. 75(1): p. 104-109.

406. Sun, I.-C., et al., Heparin-Coated Gold Nanoparticles for Liver-Specific CT Imaging. Chemistry - A European Journal, 2009. 15(48): p. 13341-13347.

407. Nurunnabi, M., et al., Heparin based nanoparticles for cancer targeting and noninvasive imaging. Quantitative Imaging in Medicine and Surgery, 2012. 2(3): p. 219-226.

408. Au, J.T., et al., Gold nanoparticles provide bright long-lasting vascular contrast for CT imaging. American Journal of Roentgenology, 2013. 200(6): p. 1347-1351.

409. Sokolov, K., et al., Real-time vital optical imaging of precancer using anti-epidermal growth factor receptor antibodies conjugated to gold nanoparticles. Cancer research, 2003. 63(9): p. 1999-2004.

410. Kang, J.W., et al., High resolution live cell raman imaging using subcellular organelletargeting SERS-sensitive gold nanoparticles with highly narrow intra-nanogap. Nano letters, 2015. 15(3): p. 1766-1772.

411. Wilson, R., The use of gold nanoparticles in diagnostics and detection. Chemical Society Reviews, 2008. 37(9): p. 2028-2045.

412. Gupta, S., H. Andresen, and M.M. Stevens, Single-step kinase inhibitor screening using a peptide-modified gold nanoparticle platform. Chem. Commun., 2011. 47(8): p. 22492251.

413. Pingarrón, J.M., P. Yanez-Sedeno, and A. González-Cortés, Gold nanoparticle-based electrochemical biosensors. Electrochimica Acta, 2008. 53(19): p. 5848-5866.

414. Rosi, N.L., et al., Oligonucleotide-modified gold nanoparticles for intracellular gene regulation. Science, 2006. 312(5776): p. 1027-1030.

415. Salem, A.K., P.C. Searson, and K.W. Leong, Multifunctional nanorods for gene delivery. Nature Materials, 2003. 2(10): p. 668-671.

416. Sandhu, K.K., et al., Gold Nanoparticle-Mediated Transfection of Mammalian Cells. Bioconjugate Chemistry, 2002. 13(1): p. 3-6. 